\title{
Selling 'Fracking': Legitimation of High Speed Oil and Gas Extraction in the Marcellus Shale Region
}

Jacob R. Matz

West Virginia University

Follow this and additional works at: https://researchrepository.wvu.edu/etd

\section{Recommended Citation}

Matz, Jacob R., "Selling 'Fracking': Legitimation of High Speed Oil and Gas Extraction in the Marcellus Shale Region" (2013). Graduate Theses, Dissertations, and Problem Reports. 4980.

https://researchrepository.wvu.edu/etd/4980

This Thesis is protected by copyright and/or related rights. It has been brought to you by the The Research Repository @ WVU with permission from the rights-holder(s). You are free to use this Thesis in any way that is permitted by the copyright and related rights legislation that applies to your use. For other uses you must obtain permission from the rights-holder(s) directly, unless additional rights are indicated by a Creative Commons license in the record and/ or on the work itself. This Thesis has been accepted for inclusion in WVU Graduate Theses, Dissertations, and Problem Reports collection by an authorized administrator of The Research Repository @ WVU. For more information, please contact researchrepository@mail.wvu.edu. 


\author{
Selling 'Fracking': \\ Legitimation of High Speed Oil and Gas Extraction \\ in the Marcellus Shale Region
}

Jacob R. Matz

Thesis submitted to the Eberly College of Arts and Sciences at West Virginia University

in partial fulfillment of the requirements

for the degree of

Master of Arts

in

Sociology

Daniel Renfrew, PhD, Chair

Jennifer Steele, PhD

Joshua Woods, PhD
Department of Sociology and Anthropology
Morgantown, West Virginia
2013

Keywords: Natural Gas, Framing, Public Relations, Environmental Sociology Copyright 2013 Jacob R. Matz 


\section{ABSTRACT \\ Selling 'Fracking': Legitimation of High Speed Oil and Gas Extraction in the Marcellus Shale Region}

Jacob R. Matz

The advent of horizontal hydraulic fracture drilling, or 'fracking,' a technology used to access oil and natural gas deposits, has allowed for the extraction of deep, unconventional shale gas and oil deposits in various shale seams throughout the United States and world. One such shale seam, the Marcellus shale, extends from New York State, across Pennsylvania, and throughout West Virginia, where shale gas development has significantly increased within the last decade. This boom has created a massive amount of economic activity surrounding the energy industry, creating jobs for workers, income from leases and royalties for landowners, and profits for energy conglomerates. However, this bounty comes with risks to environmental and public health, and has led to divisive community polarization over the issue in the Marcellus shale region. In the face of potential environmental and social disruption, and a great deal of controversy surrounding 'fracking,' the oil and gas industry has had to undertake a myriad of public relations campaigns and initiatives to legitimize their extraction efforts in the Marcellus shale region, and to project the oil and gas industry in a positive light to residents, policy makers, and landowners. This thesis describes one such public relations initiative, the Energy in Depth Northeast Marcellus Initiative. Through qualitative content analysis of Energy in Depth's online web material, this thesis examines the ways in which the oil and gas industry narrates the shale gas boom in the Marcellus shale region, and the ways in which the industry frames the discourse surrounding natural gas development. Through the use of environmental imagery, appeals to scientific reason, and appeals to patriotism, the oil and gas industry uses Energy in Depth to frame the shale gas extraction process in a positive way, all the while framing those who question or oppose the processes of shale gas extraction as irrational obstructionists. 


\section{Table of Contents}

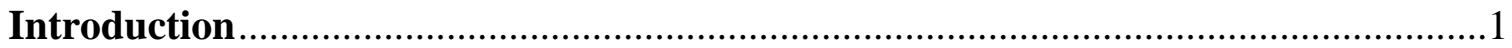

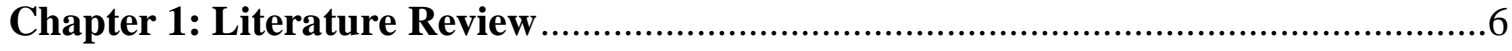

The Physical Processes of Shale Gas Development .........................................6

Human Health and Environmental Impacts ...................................................8

Social Disruption in the Marcellus Shale...........................................................12

Neoliberalism and the 'Polluter Industrial Complex' ........................................16

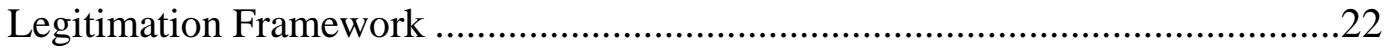

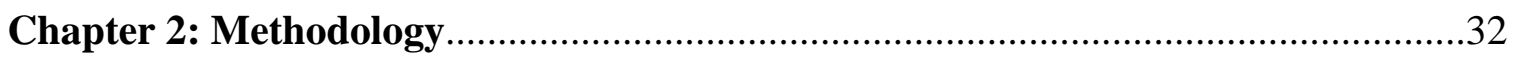

Chapter 3: Framing Natural Gas Extraction in the Marcellus Shale........................35

National Pride, Community, and Natural Gas ..................................................37

Environmental Imagery and Greenwash.......................................................68

Scientific Imagery, Expertise, and the Facts..................................................95

Discrediting the Opposition .......................................................................118

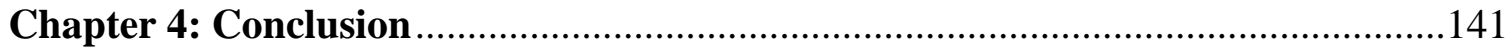

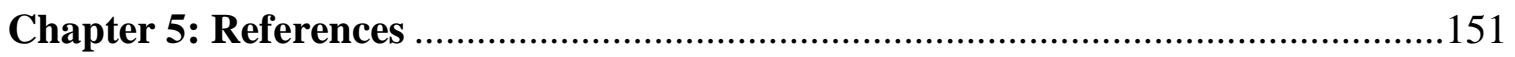

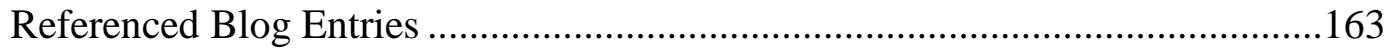




\section{Introduction}

'The Marcellus Shale' is the name given to a geological shale formation that extends from New York to Tennessee and could contain over 500 trillion cubic feet of natural gas (Bertola 2011). This mass of shale rock, buried several thousand feet beneath the surface of the earth, has created a rush in states like West Virginia and Pennsylvania to extract the plentiful and valuable fossil fuel. Dreams of riches and domestic energy has led to a booming natural gas extraction effort as it is purported that the gas could last the United States up to a century and could be worth over \$1 Trillion (Center for Energy 2011; Bertola 2011). However, the new technology and processes that have allowed access to the deep shale gas have created a great deal of local and national controversy surrounding potential environmental and health impacts, leading to intense criticism and scrutiny of the industry. Still, in the midst of divisive community polarization, the Marcellus shale accounts for $90 \%$ of all natural gas produced in the Unites States (Saiers 2012; Weigle 2011).

Critics of the current natural gas extraction processes have cited environmental threats to water and air quality, as well as social threats to infrastructure, local economies, and rural ways of life in the Marcellus shale area. Residents, landowners, environmental organizations, state policy makers, and industry personnel have become social actors in one of the most controversial issues states in the Marcellus shale region have experienced. The controversy surrounds a now-common term in the area, 'fracking', or horizontal hydraulic fracture drilling. In short, this is the process of pumping millions of gallons of chemical brine water into a shale seam several thousand feet below the surface to release hydrocarbons naturally occurring in shale rock. This issue has drawn attention 
from academia, the media, local and state governments, and has led to a string of public relations campaigns, town hall debates, conferences, opinion editorials, prominent documentary films, and intense discourse among the lives of residents of the Marcellus shale area (Weigle 2011).

How does the multibillion-dollar fossil fuel industry frame the debate surrounding natural gas? How do they respond to criticism and claims of environmental and social disruption? This thesis will describe the industry framing and legitimation activities surrounding "one of the most polarizing events" states in the Marcellus region have experienced (Weigle 2011, 3). A strategy many powerful social/economic actors use to make their case in the public forum is the use of public relations initiatives, advertising campaigns, think tanks, lobbying groups, and non-profit entities framed as research, education and public outreach campaigns (EID 2012, Faber 2008). Faber (2008) refers to the interconnected network of such campaigns operating in support of extractive, chemical, and other polluting industries as the 'polluter industrial complex' (Faber 2008). One such public relations organization within this network, Energy-In-Depth (EID), operates as the public "voice" of the trade organization Independent Petroleum Association of America, which represents up to 95\% of oil and natural gas producers operating within the United States (IPAA 2012). Through qualitative content analysis of publically-available materials on EID’s website, including blog posts, images, and other web material, as well as public appearances and statements from representatives of EID, this thesis will describe and examine the framing strategies used to legitimize high-speed shale gas extraction to a divide public of multiple stakeholder groups in the Marcellus shale in the face of potential environmental and social disruption. 
Energy in Depth's blog posts are appropriate content to analyze as they depict one major way in which the oil and gas industry transmit information about the natural gas debate in the Marcellus shale region. The Internet is relied upon as the number one source of information for residents of the Marcellus shale region (Weigle 2011). While the Internet provides an accessible forum for alternative viewpoints like those of environmental groups, it also provides a strong and expansive forum for big business and public relations activities. Polluting chemical and extractive industries routinely employ a vast network of think tanks and PR organizations that have been previously documented and shown to deliberately us e the Internet to "disseminate misleading and confusing information that contradicts the scientific consensus, so as to raise doubt and present more complicated arguments. This, in turn, prevents public awareness and action” (Holcomb 2008, 205). Furthermore, unbiased explanations of social and environmental impacts are difficult to find elsewhere as information is often circulated by industry public relations campaigns that filter through both news media and political actors, and are ultimately picked up by residents (Perry 2012). Conflicting information from radically different viewpoints tends to discourage an unsure public from seeking objective information, and has lead to a climate of confusion and distrust (Weigle 2011). This reinforces the need to qualitatively describe strategies used by public relations initiatives to disseminate information and frame the debate surrounding horizontal hydraulic fracture drilling by the energy industry's public relations campaigns on the Internet (Holcomb 2008).

Environmental, health, and human safety problems have increased within the high-speed capitalism of the neoliberal world that has seen government oversight 
decreased as industrial activities increase (Faber 2008). An increase in public awareness of such environmental problems such as global warming, oil spills, and gas pipeline explosions has created a need for an in depth public relations sector to grow alongside neoliberal reform. As the state and its democratic electorate are losing political power to corporations operating under a neoliberal political framework, sophisticated communications campaigns must be employed to convince the democratic public of the benefits of small government, privatization, and a growing corporate control (Faber 2008). These campaigns are transmitted via what social scientists refer to as frames, and through the act of framing discourse (Gamson and Ryan 2006, Lakoff 2004, Powell 2003, Benford and Snow 2000). Framing involves the use of language, words and imagery, to evoke a particular conceptual framework or worldview. In discourse, frames are a way of organizing facts and ideas into a particular outlook, making sense of them. In short, frames give phenomena and events a particular meaning, reflecting the perspective of the actor using the frame (Gamson and Ryan 2006, Lakoff 2004, Powell 2003, Benford and Snow 2000).

It is through the treatment of the Energy-in-Depth public relations campaign as a framing agent of hurried natural gas extraction within the neoliberal world order that this thesis attempts to describe the various framing techniques used to narrate the oil and natural gas industry's activities in the Marcellus shale region. Through a qualitative content analysis of a random sample of the "Energy in Depth -Marcellus Initiative” blog posts from October 2011 to April 2012, this thesis will describe the frames through which EID discusses the natural gas debate and narrates the energy boom in the Marcellus shale region. Predominately, these frames include environmental imagery, appeals to 
patriotism, scientific imagery, and the framing of those who question or oppose the processes of natural gas extraction as irrational obstructionists. 


\section{The Physical Processes of 'Fracking' and Natural Gas Extraction}

The process of hydraulic fracture drilling 'fracking' has been used since the late 1940's when it was first utilized by Halliburton oil and gas extractors in Texas (Mooney 80). In the past vertical wells were drilled into formations such as shale, hundreds to thousands of feet below the surface of the earth. Once the wells reach their target, a mixture of water, chemicals, and sand are propelled at high pressure into the well to break up the rock and release the gas it contains. This gas flows up the well and is harvested. New technology has allowed for something much more economically beneficial to drillers, and the source of the current public debate surrounding 'fracking'horizontal fracture drilling. In horizontal fracture drilling, the well is drilled thousands of feet below the surface where the drill now has the ability to make sharp turns and drill parallel to the surface of the Earth (Mooney 2011, 80). The drill bore travels for several thousand feet to a mile horizontally allowing for much larger areas of shale to be accessed and broken apart releasing much more natural gas with each procedure (Center for Energy 2011).

A special blend of 'frack' fluid is needed to access and open shale deposits. As previously stated, most of this fluid is sandy water with a small percentage containing a chemical cocktail used to stimulated the fracture process. 3-8 million gallons of fluid is used in each fracture job and even the miniscule percentage of chemicals still amounts to hundreds of tons of chemicals (Subra 2012, Center for Energy 2011). Furthermore, wells can be injected with frack fluid several times over the span of their existence (Subra 2012). These fluid concoctions are not fully disclosed by the industry (they are said to be trade secrets which could risk hurting a company's competitive advantage) (Center for 
Energy 2011). The purpose of each chemical however, revealed by industry sources such as fracfocus.org, which shows that of the $.49 \%$ of the fluid that is not sand and water, materials like gelling agents, friction reducers, acid, corrosion inhibitors, biocides, and surfactants are used in the frack fluid (Fracfocus 2012). If one million gallons of fluid are used in a process, 4,900 gallons (20 tons) of this would be this chemical concoction (Center for Energy 2011). Two thirds of this chemical water stays underground inside of the well, som returning in the following weeks and months, the rest hopefully never to be seen again (Ameri 2011).

Drilling is not the only process involved with a fracture job. "Well Pads" are the square upon which wells are drilled and fracked, and all operations are centered. Wastewater from operations is stored in Olympic swimming pool- sized waste pits as it awaits shipment away from the site. When taking into account the size of the well pad, roads needed to be constructed to access the site, and room needed to place pipelines, storage tanks and pits, compressor stations, trucks, and all other machinery needed for the entire extraction process. In total, each well pad in a fracking operation disturbs around nine acres (seven football fields) of land total. Thus far Pennsylvania has a total of 20 square miles of ‘disturbed’ land (Saiers 2012). The Pennsylvania Energy Impacts Assessment conducted by the Nature Conservancy and the Audubon Society estimates that by 2030 a range of 38,000 to 90,000 acres of forest could be cleared by Marcellus development in the state (Johnson 2010). Gas is shipped to compressor stations and lastly to a gas processing plant for the final product. Waste water is shipped from sites to nearby municipalities, landfills, and injection sites where the contaminated liquid is pumped into old oil wells and coal mines (Larson 2011, 6). 


\section{Human Health and Environmental Impacts Associated with Shale Gas Development}

The natural gas exploration and extraction process has raised environmental concerns throughout the Marcellus area, even leading to a moratorium in New York and in the Delaware River Basin. Residents', landowners’, and activists' concerns vary. Whether it is chemical spills, declining health of humans and animals, private water well contamination, environmental decay surrounding the natural gas boom has been cited by residents and scientists (Beard 2012; Federman 2011; Finkel and Law 2011; Gas Safety 2012; Global Community 2011; Horwitt 2011; Horwitt 2011; Howarth 2011; Howarth 2011; Jackson et al 2011; Jacquet 2009; Johnson 2010; Kusnetz 2011; Levitt 2011; Lustgarten 2011; Montz et al 2010; Mooney 2011; Osborn et al 2011; Perry 2012; Rubiinkam 2011; Rutherford 2012; Romm 2012; Schmidt 2011; Schwartzel 2012; Skirboll 2012; Stover 2012; Subra 2012; Ward 2012; Weigle 2011; Wilber 2012; Willitis et al 2012). Current reports indicate over 1,000 complaints of contaminated water due to natural gas activities have been reported by residents in Pennsylvania alone (Browning 2011). Numerous activist groups have formed in the wake of the shale gas boom, leading to civil disobedience and symbolic protests nationwide (Artel 2012, Bauers 2011, Petition 2011). Reports of environmental harm are seemingly widespread, for example, the Pennsylvania Department of Environmental Protection reports that between January 2010 and December 2010, there were 532 inspections conducted at well sites in Bradford County, PA. Over 25\% of these inspections resulted in the violation of environmental or administrative laws (Perry 2012).

The amount and sources of water are of primary concern, as millions of gallons are needed at each frack site. Other concerns include the destruction of rural areas to 
create gas sites, contamination of ground water, well water and aquifers, and air pollution from multiple sources throughout the process.

The United States House of Representatives Committee on Energy and Commerce detailed information about the oil and gas industries in a an April 2011 report entitled “Chemicals Used in Hydraulic Fracturing” after studying the processes of fourteen oil and gas companies from 2005-2009. In terms of the chemical composition of water used for fracturing, the report showed that over 4 years time, 780 million gallons of non-water fracturing products were used in the process, indicating a large volume of chemical ingredients in frack fluid (OVEC 2012). 29 chemicals used in the process are either known or possible carcinogens; regulated under the Safe Drinking Water Act for risks to human health; or listed as hazardous air pollutants under the Clean Air Act, indicating a level of hazard in regard to the chemical composition of frack fluid. A chemical product used in fracturing fluid that is particularly cited as risky and hazardous by concerned groups is known as BTEX (benzene, toluene, xylene, ethylbenzene). Exposure to BTEX can cause damage to the central nervous system, liver, and kidneys. BTEX was found in 60 products and was injected at a volume of 11.4 million gallons over a four-year period by the natural gas industry. Other chemical compounds like 2 butoxy ethanol (2-BE) are particularly dangerous, as 2-BE is easily absorbed and rapidly distributed in humans by inhalation, ingestion, and skin exposure, causing destruction of red blood cells, liver damage, bone marrow damage, and damage to the spleen (OVEC 2012). This compound was found in 126 frack products and 21.9 million gallons were injected into the ground from 2005-2009. Other unsavory chemicals used in the natural gas and oil exploitation processes include diesel fuel (carcinogen); heavy metals like 
arsenic, barium, cadmium, chromium, led, mercury, selenium, and zinc (skin problems, hair loss, kidney damage, rise in blood pressure, carcinogenic, neurological damage); and PAHs (polycyclic aromatic hydrocarbons - possible carcinogens with reproductive effects). This list of carcinogens, chemicals, and possible health effects are more than enough to raise concern among residents in the Marcellus region but when coupled with the trend in industry to downplay the particular chemical recipes for frack fluid, hesitation and skepticism is imminent.

Both residents and industry member cite accidents and human-error as potential sources of water and air contamination. In Bradford County, Pennsylvania a blow-out of a gas well sent thousands of gallons of chemical laced frack fluid into a nearby stream, forcing seven families to be evacuated from their homes (Rubinkam 2011). Cheseapeake Energy blamed a failed piece of equipment for the blowout that led to the flow of contaminated fluid that lasted throughout a night and a day. Local farmers were advised to keep their cows from drinking from nearby tributaries by DEP officials. Human-error and accidents are often said to be the only cause of contamination by the natural gas industry. The industry openly admits that the failure of cement around the well casing has contaminated ground water, surface water, soil and air. Though this is admitted, the industry generally maintains that the contamination of groundwater is not a 'result of fracturing' (Subra 2011).

Subra (2011) cites several chronic and acute health impacts reported by individuals living in close proximity to shale gas drilling, fracturing, and processing wells. These long-term impacts experienced by some individuals include damage to lungs, liver, and kidneys; damage to nervous system; leukemia, aplastic anemia, changes 
in blood cells, and impacts to blood clotting ability. The list of acute (short term) impacts is long and disheartening: irritated skin, eyes, nose throat, and lungs; headaches, dizziness, nausea and vomiting; fatigue, tension and nervousness, personality changes, depression, anxiety, irritability; confusion, drowsiness, muscle cramps, and heart arrhythmia (Subra 2011). With evidence of environmental contamination and impacts to human health, how does the oil and industry use public relations campaigns to frame processes that potentially lead to such outcomes? 


\section{Social Disruption in the Marcellus Shale}

The 'boom-bust' cycle is a frequently cited economic concern when it comes to natural resource extraction debates. This concept refers to a cycle of rapid growth centered around one finite resource or another, be it coal, gold, or natural gas, followed by a period of rapid decline as resources are depleted. Rapid, industrial, economic growth of previously small rural communities often achieve these communities the label 'boomtowns' (Brasier 2011). The cycle of the boom has a similar cyclical effect on residential perceptions and expectations, and thus informs residents’ view of further rapid economic development. First, attitudes are generally enthusiastic as imaginaries of economic growth and jobs are said to be on the horizon; second, residents feel an uncertainty amidst unexpected changes to their community and unmet expectations; third, panic, as residents realize the magnitude of impacts on their community; and lastly, adaptation, as the changes to the community are seen as permanent with long-lasting and now unavoidable impacts (Brasier 2011). This cycle of growth and decline informs ways in which residents interpret and view their communities, especially in terms of energy production (Brasier 2011). So a shared history with coal boom will in turn influence perceptions of the new natural gas booms in West Virginia and Pennsylvania. Residents of Pennsylvania cited a history with exploitative extraction industries that they were note eager to repeat in the case of natural gas boom (Brasier 2011).

Ethnographic research suggests that some residents of counties like Bradford, in Pennsylvania, welcomed the gas industry enthusiastically. It was seen as a way to not only increase a fading economy, but also as a way to bring home U.S troops as a new domestic energy source was tapped. Patriotism was employed not only by leasing agents 
(locally referred to as 'landmen'), but also by neighboring landowners, family members, and local and state politicians to justify leasing land to the industry (Perry 2012). Many residents share individual, family, or community ties to the military, and thus patriotism is highly valued. This reflects the general patterns of support described in sociological boomtown literature. Jacquet (2009) cites nationalism and perceived sense of civic duty to the country as a whole to be a primary reason for residential support of energy development regardless of the local impacts. Oil companies have routinely used patriotism and 'national security' as a selling point for operations. Energy companies in both the U.S and U.K have used nationalism since WWI to convince the military to work with them to secure the 'strategic interests' of the state and general public (Mitchell 2012). Pressures from labor and populous political movements forced the industry to frame their interests as the best interests of the state and the people (Mitchell 2012).

Road conditions and transportation issues are a reoccurring concern found in sociological literature surrounding the Marcellus shale gas boom (Perry 2012). Traffic accidents in Bradford County Pennsylvania rose 25\% between 2008 and 2009, and by 2010 local news outlets were regularly reporting traffic accidents involving trucks and smaller vehicles daily (Perry 2012). Traffic and road conditions associated with natural gas and oil extraction through horizontal hydraulic fracture drilling are the main concerns cited by many residents throughout Pennsylvania (Perry 2012). Increased traffic and road damage has resulted in people changing their daily travel routines, increased dangerous travel conditions, increased automobile fatalities, and an increase in noise and dust pollution resulting from a mass of oversized trucks traveling along winding, narrow, dirt or gravel roads (Perry 2012). This is cited among the most serious source of stress, 
aggravation, fear, and the most significant change for Pennsylvania residents surrounded by the shale gas boom (Perry 2012).

The shale gas boom has also impacted public and social services. Schools and government services are in high demand, as would be expected with a large influx of people to a rural area with low levels of infrastructure. Housing, roads, bridges, water supplies, and electric grids are simply not designed to account for a rapid influx of industry personnel. Housing assistance, health care, emergency services, administration, records, and law enforcement and other social services have been strained in the population spike. Even school busses have been reported to have lost access to students' homes due to damaged roads and heavy industrial traffic. As government becomes in even higher demand, it too deals with the reality of competition from the oil and gas industry. Employees from various sectors of government including the Conservation District, County Planning Office, court house, school bus drivers, and local law enforcement have begun to take higher paying jobs from the industry (Perry 2012). Bradford County, like many rural areas throughout Pennsylvania and West Virginia had been declining in population for years before the oil and gas boom. Therefore, infrastructure is not only relatively low, it was also in the process of being cut by the time of the Marcellus shale boom, leaving counties like Bradford very much unready for such a large influx of people (Perry 2012).

Preliminary sociological literature surrounding the shale gas boom in the Marcellus region suggests mixed findings in perceptions and impacts of the boom on the social lives of residents. Concerns range infrastructure harm, to concerns about the potential of a 'bust' after the 'boom' of gas and oil productions (Jacquet 2009). Though a 
perceived civic duty, and the potential for much-needed financial gain in leasing lands to the gas and oil industry remain very real forces driving the support for oil and gas production among residents of the Marcellus shale region (Perry 2012). The divisions in public perceptions of social impacts of the shale gas boom reinforce the call for a large scale public relations initiative to narrate and frame the discourse surrounding boom in a positive light for the industry. 


\section{Neoliberalism, Environmental Degradation, and the Polluter Industrial Complex}

Harvey (2005) characterizes neoliberalism as a sociopolitical economic movement born into world capitalism of the 1970’s. Rhetorically, neoliberalism holds that individual freedoms, strong property rights, and the 'free market' are pillars of human happiness and overall wellbeing (Harvey 2005). In practice, neoliberalism is concerned with the expansion and consolidation of capital, the mediation of the government in its dealings with private enterprise, including the placement of limits on taxation and regulation of corporations and the financial sector. In general, neoliberalism opposes any sort of regulation impinging on profitability, and involves the weakening and dismantling of unions, the rolling back of municipal governments and state socialspending, privatization of public services, and reduction of taxes for businesses (Faber 2008).

Neoliberalism embodies corporate investment in extraction 'sacrifice zones’ like Appalachia or the 'global south', where government regulation is more lax or nonexistent, therefore providing a greater return on investment, as worker safety cost, environmental stewardship, and high tax rates can be avoided or minimized (Hedges, Sacco 2012). In response to world populist, workers, civil rights, and student movements of the 1960's and 70's, the neoliberal movement has specifically and purposefully utilized a network of think tanks, public relations groups, trade organizations, lobbying firms, and a general class of free market intelligentsia to disseminate the messages of neoliberal capitalism to the public (Faber 2008). Energy-in-Depth exists alongside this network of public discourse actors and works specifically to frame the natural gas debate in directions that favor profit-driven neoliberalism. 
Neoliberalism itself can be viewed as an elite social and political response to populist gains born out of a “coal civilization” (Mitchell 2012). The neoliberal response to the crises of global oil capitalism (dwindling supplies and increasing environmental contamination) has been to increase production at the cost of deregulation and deterioration of environmental and human health standards worldwide (Mitchell 2012). Costs of dealing with harm to the environment or to hazardous production conditions of natural resources like coal, oil, and natural gas is externalized. This refers to the act of placing costs of production (environmental/human health impacts) onto society, rather than investing to avoid environmental decay or taking time to utilize strict safety standards. Standards in safety and health are routinely and systematically avoided by multinational corporations seeking maximum profitability (Faber 2008). For Americans in 2004, these externalities included: 1.8 billion pounds of toxic air and water pollutants, 70 million pounds carcinogens, 134 million pounds of toxins linked to development and reproductive problems, and 608 million pounds of carcinogens and developmental/reproductive toxins released onto land (Faber 2008).

For residents of America's historic coal, oil, and natural gas extraction zone, Appalachia, externalities include hundreds of millions of pounds of carcinogens and developmental/reproductive toxins, as 100 tons of coal is extracted every 2 seconds via "mountaintop removal", an automated method of blowing up mountaintops to quickly reach and extract from coal seams. It requires very few workers, and produces exponentially more coal than underground mines, making large industry profits. Mountaintop removal has resulted in 6,700 valley fills of overburden and industrial coal waste, 724 miles of buried Appalachian streams, 300,000 acres of scorched forests, and a 
poverty rate stagnant at $30 \%$ since the 1960s. This "cost of doing business" leaves the landscape of states like West Virginia and Kentucky flattened for coal. The sparsely employed, automated, and above ground processes of modern coal extraction, coupled with the consolidation of coal, oil, and gas corporations into multination energy conglomerates has helped energy corporations in Appalachia retake a great deal of power won by well-organized and politically-powerful coal unions (Lockard 2010). As a result, the most externalities are placed on isolated, marginalized, and impoverished residents surrounding extraction zones (Faber 2008).

Owners of multinational corporations, justices, congressmen, and lobbyists, derive and maintain their neoliberal philosophical base in what Faber (2008) calls the polluter industrial complex; a series of interlocking think-tanks, research foundations, policy institutes, research centers, public-opinion shaping organizations, public relations campaigns, non profits, and political strategy groups in both the Democratic and Republican party that attempt to discredit both the environmental and labor movements, as well as state programs, policies, and regulations concerning environmental and human health (Faber 2008, Stauber and Rampton 1995). Conservative think-tanks decrying environmental regulations have grown rapidly since the 1990's when public support for environmental values and protection began to grow exponentially. The general consensus among this network is view of environmentalism as a threat to social and economic progress and the American way of life (Jacques et al. 2008).

First, political candidates with neoliberal viewpoints are chosen and groomed for political service by the polluter industrial complex. The biggest corporate spenders on elections are electric utilities, oil, gas, automobile manufacturers, and the chemical 
industry, thriving in low regulation neoliberalism. Lobbying is a specialty of the polluter industrial complex, in fact, $\$ 92.5$ million a month was spent on lobbying by the energy industry in 2005 (Faber 2008). Second, business-friendly politicians appoint industry representatives to government agencies tasked with regulating safety, environmental protection, and health. Third, the candidates and agencies selected by the polluter industrial complex routinely create policy that is helpful for environmentally destructive industries and the neoliberal model of deregulation. Both major parties work within and provoke a political infrastructure in which policies supporting deregulation are most successful and widely supported. Last, corporate PR firms create 'independent' scientific reports that are presented to legislators to 'educate' them with information hospitable to the neoliberal agenda. Extraction industries have been proven to withhold, falsify, and alter their own internal studies (Faber 2008). Studies also serve the cause of discrediting and rejecting scientific literature revealing environmental disruptions. In all, these actions work to deny the authenticity of environmental problems, such as climate change, and to call into question the motives of scientific literature and legislative efforts dealing with environmental protection (Jacques et al. 2008). This network of think tanks, organizations, public relations firms, and industry academics foster influence not only in the realm of politics, but also in the realm of public opinion where their tactics are carried out via news media and public relations campaigns (Stauber and Rampton 1995).

The 2005 federal Energy Bill is an example of such a process as it relates to oil and natural gas extraction. It is evident that industry elites worked directly with the federal government's energy sector to secure lax federal regulations for fracture drilling, resulting in what many have referred to as the 'Halliburton Loophole' (Faber 2008). In 
2001, the George W. Bush administration appointed an "Energy Policy Task Force” headed by Vice President Dick Cheney, former CEO of energy corporation Halliburton, to devise a new federal energy plan. Halliburton is not only directly involved in the shale gas rush, but they are the company that first developed hydraulic fracturing technologies (Hines 2012). As early as May of that year, the task force agreed and recommended that the new plan should exempt hydraulic fracturing from enforcement under the Safe Water Drinking Act. The subsequent Energy Policy Act of 2005 exempted hydraulic fracturing from this federal law (Hines 2009).

Seeking out minimal regulation and safety standards has had an effect on the oil and natural gas industry. According to the trade journal, Oil Daily, massive profit accumulation in the oil and gas industry is attributed to: large layoffs; cuts in pollution prevention; cuts in worker health and safety standards; cuts in oil recovery programs; and cuts in maintenance and repair of oil and gas operations. Events such as the massive oil spill in Purdhoe Bay, Alaska, or the 2010 Gulf oil spill both on the part of BP, who consistently cut safety standards during hundreds of billions of dollars in profits from 1999-2010. More generally, the oil and gas industry account for 240,000 chemical accidents/year and 658 accidents per day (Faber 2008). The oil industry has consistently replaced highly trained and well-paid union workers with less-costly contingent workers. Currently up to $30 \%$ of industry hours are worked by contracted workers. Every 4.3 days there is a death in the oil and gas industry, 8.5 times higher than the average fatality rate for all US industries (Faber 2008).

The reliance of the western world on finite resources such as oil, natural gas, and coal has produced a situation of modern global capitalism in which extractive industry 
corporate elites dominate public discourse and government legislation through an interconnected series of think tanks, nonprofit political strategy groups, and public relations organizations. Current reliance has centered on oil, allowing capital and political power taken by steel/coal/rail workers to fall largely back into the hands of corporate managers (Mitchell 2012). The neoliberal model of business-government relations heralded by the oil industry has allowed for worldwide destruction of ecology in the name of securing resources to fuel the modern world. Worker, health, and environmental safety are routinely bypassed and looked over in search of maximum profitability (Harvey 2005). Through complex and expensive public relations, lobbying strategies, and plain old corruption, the owners of capital has sufficiently inundated both the political arena, as well as the public mind, with neoliberal thought. 


\section{$\underline{\text { Legitimation Framework }}$}

Snow and Benford (2000) suggest that social actors are actively engaged in the process of production and maintenance of meaning when seeking to influence an audience of proponents, opponents, and neutral observers (Benford and Snow 2000, 613). 'Framing' is the act of creating meaning attached to an event, phenomena, persons, or movements. It is an active process whereby actors attempt, through language, to organize events, occurrences, meanings, and create a narrative of a situation that best represents their interests (Lakoff 2004, Benford and Snow 2000). It is the use of language to evoke and carry specific ideas about a given situation (Lakoff 2004).

The best metaphor to represent a frame is just that, a frame. A 'frame' as it is used by social actors, politicians, and public relations organizations is much like a picture frame. It denotes what parts of a story fit within the rectangle, and which parts of the scene lay untold, outside of the frame. A frame makes sense of the picture within it. The symbols, images, arguments, actors, and landscape are linked through an underlying theme, principle, or organizing idea that creates meaning out of what is held within the frame (Gamson and Ryan 2006). Allowing for certain facts, events, and occurrences to be within the frame, while others are not, allows the actor to define the terms of a conversation. It allows the actor the ability to house the debate within a particular narrative dictated by that actor, thus controlling the boundaries of discussion and debate.

Mills (1959), Gramsci (1971), Gaventa (1982), Chomsky (1999, 2002) contend that power can be maintained in three ways: the threat of force, the threat of sanction, and the invocation of ideology to manage and manipulate consent (Mills 1959, Achbar and 
Wintonick 1992). When force and sanction are socially unacceptable ways of maintaining the legitimation of power, the symbols of ideology will be invoked. This is often in the form of propaganda, used to frame a given social issue or cultural product (Chomsky 2002, Achbar and Wintonick 1992, Bernays 1959). Social myths, language, symbols, cues, and routines can be utilized to frame and manipulate the debate surrounding any issue threatening power. According to Mills (1959), social actors in positions of authority consistently link their authority to widely held moral symbols, sacred themes, and other ‘symbols of justification’ (Mills 1959). Further, the control of available information, domination of mass media outlets, and other institutions of socialization can shape the parameters of a debate, allowing certain symbols and themes to permeate any discussion. The goal is to shape wants, keep certain issues out of the discourse, and affect common conceptions of the issue through the use of certain themes, symbols, and frames (Gaventa 1982).

Framing and the Public Relations Industry

A brief review of academic public relations literature can help the social sciences explore the role of the oil and gas industry in generating public support for certain activities and ideas. Just as sociological framing research suggests, the success of gathering support for ideas, values, and behaviors is largely reliant on presented themes and symbols that correspond with widely-held social values and beliefs (Bernays 1955). According to Bernays (1955), nephew of Sigmund Freud, and often cited as a central architect of the public relations industry, the success of public relations can be attributed to the consistent presentation of themes, symbols, and 'propaganda' that speak to public motivations and the psychological satisfaction of the individual (Bernays 1928, 1955). 
The basic tools of public relations are symbols and themes. Issues must be framed in such a way to evoke certain themes and motivations in the general interest of the audience to which they are conveyed. These themes and symbols must appeal to the basic motivations of the audience, according to public relations literature (Bernays 1955). These audiences can be individuals, subgroups, specific social units, or the general public, and the themes must fit accordingly. For example, themes for individuals may include personal economics and individualism, while themes for the basic social unit of the family may include appeals to safety, comfort, or security. Certainly specific subgroups will be targeted for specific issues, such as landowners in the Marcellus shale region. In this case, themes and symbols adapt to specific motivations and urges of the landowners. Themes for the general public will mirror and amplify overall values and beliefs, often western-specific motivations (Bernays 1955). In this regard, these tenants (hard work, personal freedom, limited government) of the neoliberal world order may permeate public relations campaigns surrounding natural gas extraction.

'Propaganda' itself can be viewed as the fundamental product of the public relations industry. In his pamphlet Propaganda, Bernays (1928) defines propaganda as a neutral term that denotes the process of disseminating ideas on a mass scale, which he argues is a major source of most ideas in society. Propaganda can be utilized to promote any idea, belief, or doctrine, and by any institution in society. The ideas or institutions in and of themselves can be positive or negative, though the defining feature of propaganda that it is a systematic and organized effort to gain public support for an idea or institution (Bernays 1928). Bernays' explanation of propaganda and public relations in regard to new technologies sheds light on how processes such as horizontal hydraulic fracturing may 
benefit from intensive public relations initiatives. He writes, "propaganda assists in marketing new inventions. Propaganda, by repeatedly interpreting new scientific ideas and inventions to the public, has made the public more receptive. Propaganda is accustoming the public to change and progress" (Bernays 1928, 59).

This view of the public as malleable in their opinions is a dominant perspective of the political and economic elite (Mills 1958, Chomsky 1999; 2002), and thus appropriate to explore in relation to major economic players such as the oil and gas industry. Bernays (1928), as a major thinker in the 'art' or 'science' of opinion manipulation concurs with this viewpoint on elitism. He characterizes this group as an 'invisible government' which exists in a concentrated small group of professional propagandists who, "can and do, make the rest of us think what they please about a given subject” (Bernays 1928, 57). Bernays contends that the increasing complexity of social life calls for this segment of society to explain one aspect of reality to people consumed on a daily basis with other aspects of reality (Bernays 1928). Society certainly does put its trust in the experts in situations and issues that are complex, foreign, technical, or not easily comprehendible to people outside of the issue. For example, the general public places its trust in the expertise of those few producing oil and natural gas, as the vast majority is not employed by the industry nor has the time or ability to research and understand the complex process of energy production in a meaningful way. And thus, they will look towards industry expertise in the face of uncertainty.

Though the economic elite have power and money to invest in the 'manufacture of consent', they are still dependent on the success of that manufacture and on favorable public opinion (Bernays 1955). Authors Wilson and Ogden (2006), in academic public 
relations textbook "Strategic Communications Planning”, contend that public trust is key to an organization's survival. The text reveals three main concerns that underscore the need for a well-maintained and consistent public relations operation for industry.

First, modern society has seen a dramatic increase in social problems that are affecting more and more of the population. These problems leave the general public searching for answers and for culprits. A steady stream of public relations materials helps to ensure that industry can be seen in a positive light in the face of relevant social problems. Second, the public is more knowledgeable about the origins of social problems and more business-savvy than ever before. There has been an increase in demand for social accountability and transparency of corporations. According to the text, "the public understands just enough about the operation of business to be dangerous" (Wilson and Ogden 2006, 8). Last, sources of information are becoming more and more democratically controlled and multi-faceted. Channels of information are growing, as are the avenues for easy access to information concerning corporate deviance and white collar crime (Wilson and Ogden 2006) In summary, social problems, such as environmental disruption, are becoming more and more exacerbated and allencompassing, and it is becoming easier and easier to find out about these problems. For these reasons, corporations much launch well-funded and consistent public relations initiatives to save face in the midst of disruption and public skepticism.

\section{Extraction Framework}

Sociological literature provides some level of insight into the major frames used by public relations sectors of extractive industries in the past in order to create a level of 
regional support for operations of extraction. The following provides an introduction into some of the most common frames found in the literature surrounding energy industries', and multinational corporations’ framing techniques.

Economic actors, such as the oil and gas industry must rely on their own public, observable qualities to create a desirable selling point for consumers and thus rely on their own set of frames from which to narrate the shale gas boom. These frames must outweigh and overcome negative observable consequences of their business venture (in this case, natural gas extraction) (Spicer 2009). Bell and York (2010) argue that these frames are exceptionally pertinent to historic extractive regions like Appalachia, and that energy corporations routinely and consistently construct narratives positively linking themselves to the local community in order to avert legitimation crises (Bell and York 2010). Fortune 500 companies and other large corporations (including energy companies) "engage in complex strategies and counter strategies that serve to shift the focus and attention away from the firm, create confusion, undermine credibility, criticize viable alternatives, and deceptively posture firm objectives, commitments, and accomplishments" (Laufer 2003, 255).

'Greenwashing' is one of the major frames associated with industries and products associated with environmental harm (Scanlan 2013, Dahl 2010). ‘Greenwash’ refers to claims of environmental safety and soundness as an attribute of an organization or process that distorts the actual consequences to the environment that a product or practice may have (Dahl 2010). This can take the form of claims of sustainability, environmental friendliness, or simply the use of environmental imagery and language like 'green' or 'natural'. Environmental claims are often made for calculated reasons and have 
little to do with practice in reality (Laufer 2003). 'Greenwash’ can take several forms, including flat-out false claims, claims made without proof, vague claims like 'all natural', claims based on attributes of a product or process that are irrelevant and ignore more salient environmental issues, or purchased third party labels like 'Earth-Friendly Certified' (Scanlan 2013, Dahl 2010). Market research shows that greenwash is on the rise, and now accounts for $10 \%$ of total advertising in print media. Furthermore, companies with the worst environmental record tend to engage in the most greenwash framing, and in a review of over 2,000 so-called 'green' products researchers found that 98\% were greenwashed (Dahl 2010). Greenwashing not only serves to assuage concern about an industry's product or practices, it also serves to expand corporate markets to consumers concerned about environmental degradation (Reynolds 2004).

Patriotism is another frame used by energy companies as a legitimizing aspect of their role in the Marcellus shale region (Jacquet 2009, Perry 2010).The oil and natural gas industry has linked itself to patriotism with the idea that drilling for natural gas will lessen our dependence on foreign oil, thus supporting our troops by reducing conflict in oil-rich regions (Perry 2010). Here, the natural gas industry aligns itself with such ideals as military support. If the public accepts this claim as truth, then opposition to natural gas could be seen as unpatriotic and unsupportive of the American military. In towns filled with enlisted troops and their families, veterans, and yellow ribbons, this is not a desirable position. Jacquet (2009) cites nationalism and perceived sense of civic duty to the country as a whole to be a primary reason for residential support of energy development regardless of the local impacts (Jacquet 2009). Miller (2010) cites the coal industry’s tendency to target residents with patriotic and nationalist imagery in 
advertisements in Appalachia (Miller 2010). Not only is nationalist imagery used, but energy production in Appalachia is touted as the only alternative to foreign warfare for oil (Bell and York 2010). Gaventa (1982) cites the use of an 'American Dream’ patriotic framing device used by the coal industry in Appalachia to create 'industrial solidarity' among residents of coal communities, guaranteeing support of industrial presence and practices (Gaventa 1982). Furthermore, oil companies have routinely used patriotism and 'national security' as a selling point for energy operations. Energy companies in both the U.S and U.K have used nationalism since WWI to convince the military to work with them to secure the 'strategic interests' of the state and general public (Mitchell 2012). Pressures from labor and populist political movements forced the industry to frame their interests as the best interests of the state and the people (Mitchell 2012).

Regional economic success is a third signal produced by the natural gas industry to garner support for hydraulic fracture drilling in Marcellus. In historically extractive regions such as Appalachia, support for industry has been maintained through elaborate public relations campaigns, coupled with the fact that industries like coal are some of the few sources of employment available. This practice of building local support for industrial activity has been called the construction of ‘economic ideology’ (Bell and York 2010). This practice targets residents living in regions known for coal extraction by evoking regional pride, pride in professions within the industry, and to call attention to community identity, characteristics of industry workers, and a common "heritage" linked to coal production (Miller 2010).

The 'Friends of Coal' exemplify this frame in their public relations activities in West Virginia. Through the use of 'cultural icons' associated with residency in West 
Virginia like WVU football, identification with underground coal miners, heroism, and hard work, pioneering patriotism, and identification with the archetypal West Virginian outdoorsman, the Friends of Coal work to maintain support and legitimation in the face of dwindling jobs. Through consistent and pervasive use of 'Friends of Coal' propaganda in an effort to posture as a 'grassroots' initiative, rather than a public relations initiative, the 'Friends of Coal' successfully influence public perceptions of the role of the coal industry in West Virginia (Bell and York 2010; Miller 2010). Gaventa cites the use of promises of regional economic success as a frame used by the coal industry throughout Appalachia (Gaventa 1982). This frame included the "boom myth" that characterized the burgeoning coal economy as classless and horizontally beneficial to all. According to Gaventa, this egalitarian "spirit of the boom" myth masked the unequal power structure associated with coal communities (Gaventa 1982 58).

Via ideological manipulation, or what Gaventa (1982) calls the 'mobilization of bias,' economic actors attempt to define individuals' goals and values through the use of public relations and marketing campaigns (Gaventa 1982, Bell and York 2010). With access to multimillion-dollar PR campaigns, industry has the ability to amplify its own agenda in ways that less powerful institutions and individuals cannot (Bell and York 2010). No matter the frame, it is clear that in modern capitalism, management of reputation is important to corporate entities. According to Laufer (2003), “corporations creatively manage their reputations with the public, financial community, and regulators, so as to hide deviance, deflect attributions of fault, obscure the nature of the problem or allegation, reattribute blame, ensure an entity's reputation and, finally, seek to appear in a leadership position” (Laufer 2009, 255). Public perception is likewise manipulated and 
maintained by energy industries. Energy in Depth, as generalizable to most major oil and gas operations in the Marcellus shale region, is a perfect case study to explore frames and practices such as greenwashing, local economic ideology, patriotism, and others that may be at work in the Marcellus shale region. This thesis will attempt to explore and describe the existence of these previously documented extraction frames, as well as others that may exist within the oil and gas industry's narrative of the Marcellus shale gas boom. 


\section{Methods: Qualitative Media Analysis}

Qualitative content analysis allows researchers to take steps toward clear description and definition of a situation, interaction, or document (Altheide 1996, 17). The study of Energy In Depth will not seek to create theory, but will rather describe the frames (textual themes, imagery, and organizing ideas that create meaning) used by an industry public relations initiative to narrate the oil and gas activity in the Marcellus shale region (Gamson and Ryan 2006, Lakoff 2004). The frames of environmental commitment; appeals to patriotism; and the framing of those opposed to 'fracking' as irrational obstructionists are expected based on previous literature and theory surrounding identity maintenance of extractive industries (Mitchell 2011, Bell and York 2010, Faber 2008, Stauber and Rampton 1995). The fourth frame of 'scientific imagery' and appeals to objective scientific truth emerged as a prominent frame following the method of "progressive theoretical sampling," that allows for other notable frames, themes, and meanings to emerge over time as the text is analyzed. This type of both inductive and deductive qualitative content analysis allows for constant discovery of frames, imagery, and ideas used to narrate the shale gas boom beyond those found in the previous literature regarding the identity maintenance of extractive industries (Altheide 1996).

A random sample of blog entries was taken from 700 publically available blog posts on Energy in Depth’s “Northeast Marcellus Initiative” website, posted online between April 2011 and October 2012. Twenty-one of the sampled blogs were not taken randomly, but rather came from an Energy in Depth blog post tagged as "Year in Review," that offered a 'best of' selection of blog posts from Energy in Depth Northeast Marcellus Initiative's first year. These 'best of' blog posts were selected as they offer a 
self-selected and representative sample of the EID narrative. Through the review of these randomly and specifically-selected blog posts, this thesis will attempt to describe the frames used by Energy in Depth to narrate the debate surrounding natural gas and oil extraction in the Marcellus shale region.

Social artifacts, like websites and blog posts, are laden with narratives that make sense of the world in a way that best represents the interests of the creator. Altheide (1996) describes this as 'reality maintenance'; interaction serves actors to rationalize their social reality in the form of a social narrative, maintained and constructed through social interaction (Altheide 1996, 8). It is in this light that EID can be viewed as the natural gas and oil industry's attempt to distribute their narrative, values, and worldview through the use of web-based public relations campaigns.

Deductively, the frames of environmental commitment, patriotism, and the framing of individuals and groups opposed to 'fracking' as irrational obstructionists were examined based on their prevalence in the literature regarding extractive public relations initiatives (Scanlan 2013, Mitchell 2011, Bell and York 2010, Faber 2008, Stauber and Rampton 1995). Scientific imagery and appeals to objective truth became a clear fourth frame upon analysis of Energy in Depth's narrative, following the methodology of progressive theoretical sampling (Altheide 1996). These four frames are described as the textual and visual 'thematic emphasis' inherent in the selection, presentation, and organization of the information presented by Energy in Depth (Goffman 1967, Altheide 1996). Language and imagery that suggests a commitment to the conservation of the environment, including landscape photos, rhetoric of 'natural,' or 'green,' and the denial of environmental harm was be treated as the frame of environmental imagery and 
'greenwash' throughout the thesis. Text and imagery surrounding personal liberties, Americanism, community commitment, progress, and national ‘energy security’ was treated as symbolic of the frame of nationalism associated with natural gas development. Appeals to objective 'truth,' the ideals of scientific methodology, commitments to modern technology, and the description of Energy in Depth as a purely educational initiative was treated as indicative of a frame of 'scientific imagery'. Lastly, text and imagery used to call into question the expertise, motives, and character of individuals and groups that question high speed oil and gas development in the Marcellus shale region was treated as the framing of individuals opposed to natural gas extraction via 'fracking' as irrational obstructionists. A random sample taken from 700 blog entries dated April 2011 to October 2012, in addition to twenty-one EID-selected 'best of' blog entries was reviewed to qualitatively describe the presentation of these four frames within the Energy in Depth narrative.

This thesis treats Energy in Depth as a singular social actor operating as the public voice of the oil and gas industry in the Marcellus shale boom debate. For this reason blog entries are cited in paper only by date of entry, not by the name of the individual author. This paper takes the position that the individual author of the blog post does not affect the fact that the IPAA hosts the blog as representative of the industry's stance in the debate. Furthermore, this thesis is not intended to discredit any particular individuals, but rather to describe the ways in which the industry frames the natural gas debate in the Marcellus shale region via Energy in Depth. For these reasons, blog entry authors’ names are left out of the text of the thesis, but can be found on an included blog citation page. 


\section{The Framing Processes and Legitimation Themes of Energy in Depth}

Energy in Depth (EID) is a public relations campaign created by the Independent Petroleum Association of America (IPAA) in 2009, specifically oriented around the issue of hydraulic fracture drilling for oil and natural gas. The IPAA newsletter that unveiled the creation of Energy in Depth in June 2009 states the overall goal of EID to be combating taxes and environmental regulation, as well as confronting criticism in regard to hydraulic fracturing (Russell 2009). Energy in Depth was created by the IPAA's government relations and communications teams, and is determined to "reach into the new communications tools that are becoming the pathway of choice in national political campaigns,” (Russell 2009, 1). Through public relations, EID seeks attention and cooperation from major news outlets, as well as state and federal policy makers (Russell 2009).

EID presents itself as a research and education organization dedicating to "getting the facts out" about the benefits and "promise" of utilizing American natural gas and oil. Energy in Depth's role in the debate is to be the industry's "eyes and ears (as well as arms, legs and heart)" in shale regions where EID vows to educate, engage, and mobilize "supporters of responsible resource development” (EID 2012, EID Northeast 2012). The organization is dedicated "straightening out the myths" about domestic oil and natural gas production and 'fracking' technology. In this sense, EID is a direct response to the criticisms of the practice of fracking, and seeks to counter these claims.

As EID is an organization created and funded by IPAA, which represents $95 \%$ of natural gas and oil operations in the country, EID is arguably representative of the oil and 
gas industry’s claims as a whole (Lomax 2012). Funders listed by IPAA as integral in the creation of Energy in Depth include BP, Marathon, Chevron, Shell, Halliburton, among many other major energy conglomerates. EID is not only associated with IPAA, but has connections to other trade organizations as well. The West Virginia Oil and Natural Gas Association, the Virginia Oil and Gas Association, the Independent Oil and Gas Association of West Virginia, Pennsylvania Independent Oil and Gas Association, and numerous other trade groups throughout the Marcellus shale region and the country fund Energy in Depth and are listed as members (EID 2012). Membership is vast, in fact the organization claims on its homepage to have over 6,000 members. The numerous industry connections, including corporations and trade groups representing the largest companies involved in 'fracking', makes EID an appropriate case study to examine how the oil and natural gas industry legitimizes its efforts to rapidly expand production through 'fracking' technology in the Marcellus Shale region.

Energy in Depth presents the narrative of natural gas and oil development via hydraulic fracture drilling the Marcellus shale in a collection of clear frames and dichotomies. It is a story of liberty versus tyranny, of science versus emotion, of fact versus fiction, and of progress versus despair. On one side of the debate is the oil and gas industry; while on the other side are those who question the legitimacy of oil and gas extraction processes. These dichotomies are revealed in discourse revolving around three key frames: patriotism, scientific truth, and environmental stewardship, commitments to which are championed by the industry but thwarted by its opponents. 


\section{National Pride, Community, and Natural Gas}

The first major frame used to legitimate and narrate the oil and gas boom in the Marcellus shale region is the ideal of patriotism. Natural gas through fracking is presented as symbolic of personal liberty and freedom while bans, moratoriums, and regulations are depicted as dichotomous with the ideals of freedom. EID positions itself as dedicated to confronting these attacks on liberty through a "grassroots" social movement in solidarity with landowners and communities in the Marcellus shale region. Through this frame EID contends that natural gas and oil production is an opportunity for all and promotes American progress, economic renewal, and energy security. This use of nationalistic framing is documented throughout history to legitimize potentially dangerous or environmentally destructive forms of energy extraction (Mitchell 2012, Gaventa 1982, Miller 2010, Bell and York 2010, Faber 2008, Bernays 1955, Mills 1959, Chomsky 2002; 1999).

\section{Liberty, Serfdom, and the Constitution}

Energy in Depth invokes the neoliberal development narrative throughout their discussion of natural gas and oil processes in the Marcellus shale region. This is the story of freedom through the free market economy, centered on personal property rights, and limited government intervention. Inherent in the narrative of natural gas and oil operations presented by Energy in Depth is the assertion that natural gas and oil operations are emblematic of personal freedom, property rights, and the freedom of individuals to choose what to do on their own land. Local bans, state moratoriums, and EPA regulations are presented as affronts to these tenets of American liberty, and 
symbolic of deprivation of personal opportunities and freedoms at the hands of tyrannical governments.

Energy in Depth contends that oil and gas production is a personal property rights issue, and thus decisions about whether or not to allow natural gas and oil operations to take place in the Marcellus shale region are best left up to individual landowners rather than town councils or governments (October 13, 2012, October 18, 2012, October 16, 2012, June 15, 2011, March 13, 2012, April 8, 2012, March 9, 2012, October 3, 2011). The ability of landowners to make decisions about the use of their land is presented as undeniably linked to Americanism, as land ownership "serves as the founding principle of our nation and society" (October 3, 2011). This position is exemplified in a March 2012 blog entry entitled, "Serfdom, Coming to a Town Near You" where EID explores the disparities in individual freedoms found in areas in moratorium compared to those without bans or moratoriums on fracking. EID writes,

"The United States was founded on the doctrine of freedom. America is where liberty has always supported a healthy economy. This is evident in Pennsylvania, as landowners all across the state were able to choose to develop their Marcellus Shale natural gas resources. The Commonwealth, as a result, now enjoys a new age of prosperity.

Meanwhile, in New York [under a fracking moratorium], fundamental liberties are in question every day... Landowners in places such as Dryden and Middlefield; (sic) have become victims of irresponsible exercise of local control, as these communities have banned all natural gas development. These bans not only limit 
residents' property rights, but they also heavily restrict self-determination to buy natural gas products for heating and cooking. Choice and freedom have been seemingly stripped away in these two towns" (March 19, 2012).

This blog entry goes on to portray town bans and state moratoriums as affronts to economic freedom and as a form of socialism. Another blog post reiterates the claim that property rights and liberty, associated with the ideals of Americanism, are under attack in New York State, EID writes,

"The founders [of the U.S.A] viewed the protection of property rights as integral to protecting against tyranny - John Adams wrote, 'Property must be secured or liberty cannot exist.' But, as time has passed and people have forgotten or just never learned about why we fought a war of independence and composed the Constitution, and as the politics of envy has come to dominate the politics in the U.S., property rights have been under attack.

We can look at the Town of Dryden as one such example of how these rights have been violated, but it is by far not the only community in New York with so much at stake from misinformation and fear mongering in the form of bans. Dryden is just the rest of the country writ small. There's a story to tell here, a cautionary tale" (May 26, 2012).

EID frames New York state as “Travelling the Road of Serfdom Again,” as local governments are limiting residents' "liberty of choice," by, "blocking the ability of private landowners to develop their mineral rights” (March 19, 2012). Due to these seizures of freedom, EID argues that "all of upstate New York is in the doldrums," but 
can recover by lifting bans and moratoriums. The decision to allow or ban natural gas development through horizontal hydraulic fracture drilling is presented in a clear dichotomy of outcomes. EID asks,

"Will [NY] seize the opportunity to allow natural gas development or will it seize the liberty of its landowners? Will those landowners have the freedom to pursue happiness or will they be serfs? It's an old question before us every single day. History tells us, unequivocally, the price of surrendering liberty is serfdom" (March 19, 2012).

As is evident in the above quote, EID argues that bans on natural gas development are oppressive and tyrannical as they disallow landowners the choice of whether or not to allow oil and natural gas production on their property. In an April 2012 blog post, EID reiterates these points, stating that bans and moratoria symbolize, “deprivation of property rights," are “offensive to constitutional rights," and are, "simply a new form of an old dangerous idea - tyranny” (April 8, 2012). Next to these claims is a picture of the United States Constitution - a document now associated with EID’s narrative of natural gas regulation through local bans and moratoria. But who is the tyrant in this narrative?

According to Energy in Depth, property rights are being threatened by tyrannical board members, and at times, the federal Environmental Protection Agency, who are both negatively influenced by “special interest” groups (May 16, 2012, May 26, 2012, May 26, 2011, July 17, 2011, November 10, 2011, March 9, 2012, April 8, 2012, April 30, 2012, July 23, 2012, March 13, 2012, July 4, 2011). Energy in Depth refers to moratoriums and bans as "special interest laws" adopted by towns who have been 
“besieged by the anti-gas forces” (May 16, 2012, October 2, 2011). EID maintains throughout their narrative that moratoriums are the result of outsider intervention and, "single minded political opportunists who seek election for the purpose of imposing their particular ideologies and political will upon others regardless of constitutional protections and property rights” (May 16, 2012).

Town Boards, EPA officials, “political opportunists” and outsider “special interests" who attempt to enact bans and moratoriums are seen as in dichotomy to the tenets of the constitution, the free market, and personal property rights. EID maintains that outside groups like the Park Foundation and the Clean Air Council are interfering in state and local laws and effectively meddling in the individual right to lease land for natural gas and oil operations (May 16, 2012, May 26, 2012, May 26, 2011, July 17, 2011, November 10, 2011, March 9, 2012, April 8, 2012, April 30, 2012, July 23, 2012, March 13, 2012, July 4, 2011). Communities are “targeted” by ideologically-driven environmental organizations who "drown out the voices" of local residents and “intimidate municipalities" into enacting bans, moratoriums, and anything else that delays natural gas and oil development (November 10, 2011, July 17, 2011).

These tyrannical outsiders are composed of urban voters, federal government agencies, special interests, and town boards that represent Federal government bureaucracy run amok. According to EID, there is an "unholy alliance” between "hardcore environmentalists" (special interest groups) and regulators within the federal EPA, and that the EPA attempts to "secure authority by any means" in order to push for ideologically driven environmental regulation and bans on natural gas through fracking (July 17, 2011). One such "hardcore" special interest group is the Clean Air Council, 
which EID calls a "master of manipulating" who has launched a "relentless attack on Marcellus development" by entangling itself with the EPA. Through EPA, the CAC attempts to "gin up controversy" and push their extreme positions (April 30, 2012). EID contends that one of many, "dirty little secrets of many governmental agencies, especially environmental ones like EPA" is that the EPA will fund environmental organizations, like CAC, who often oppose EPA stances and actions. This is generally done to "advances the views of the bureaucrats over those elected to represent the people" and is presented by EID as a direct affront to liberty and democracy (April 30, 2012). Rather than the EPA or local town councils, EID contends that oil and natural gas development is simply a land use issue that should be left up to the states and state regulatory bodies like the DEC in New York or the DEP in Pennsylvania (July 17, 2011, April 8, 2012). In this narrative the issue of fracking for natural gas and oil becomes a "states' rights" issue that views federal regulations as overreaching and local control as tyrannical and easily manipulated, all the while stealing constitutional rights from American landowners.

EID describes the role of federal or local agencies to interfere in property rights in no uncertain terms, “This isn't about protecting the environment. It's not about pine-trees and salamanders - it's about control [original bold]... Farmers end up being sharecroppers who have to ask permission of 'massa' in order to do perfectly reasonable things” (May 26, 2012). The power of a town board or EPA to limit natural gas and oil development through fracking is now akin to the inherently unequal system of sharecropping in America, where power and wealth are concentrated in the hands of a few plantation owners, while the poor and former slaves work the land for little compensation other than tenancy. EID reiterates this implication of glaring inequality in 
another blog entry that states that oil and gas interests are "minority interests" that are "trampled by runaway activist local governments" who are trying to "enforce conformity" and are left unprotected by states like New York who have banned fracking (March 13, 2012). In conclusion, EID sums up its tyranny scenario in a question to its readers, “...how far will local governments go to enforce conformity with a local majority's biases? When they come for whatever rights you value, who will be left to defend those rights, the laws protecting individuals being down?” (March 13, 2012). EID clearly frames issues of oil and gas as issues of individual liberty. The decision of whether or not to allow fracking on private property is framed simply as a personal choice that should be left to the individual. Thus, agencies and governments that seek to limit oil and gas through regulation, bans, and moratoriums are tyrants and stand dichotomous to the tenets of personal liberty and Americanism.

In light of this story of tyranny, oppression, and loss of constitutional rights; EID calls on its audience to fight in resistance to despotism. Appealing to patriotism, populism, and ideals of revolution, EID pleas,

"My challenge is to you Wayne County folks who have been sitting on the sidelines, who have let others fight for your property rights, for your way of life, for the preservation of your natural resources and the bounty they afford you. How much longer will you be silent while a small group gives of their time, sweat equity and limited financial assets for your benefit? How can you be content or silent while an unelected body, the DRBC, holds you and your property rights hostages? Will you continue to sit back on the sofa watching the NFL while you're being robbed blind? 
Thomas Jefferson, in 1776, wrote, 'We hold these truths to be self-evident...that they are endowed by their Creator with certain unalienable Rights.' Almost 75 years later, Frederic Bastiat wrote, 'The mission of the law is not to oppress persons and plunder them of their property, even though the law may be acting in a philanthropic spirit. Its purpose is to protect persons and property... If you exceed this proper limit - if you attempt to make the law religious, fraternal, equalizing, philanthropic, industrial, or artistic - you will then be lost in uncharted territory, in vagueness and uncertainty, in a forced utopia or, even worse, in a multitude of utopias, each striving to seize the law and impose it on уои.'

What will history write of you? (October 17, 2012)"

EID frames the activities of pro-oil and gas organizations such as themselves as part of a people's movement against the oppression of these so called, "forced utopias" that outlaw natural gas and oil production via horizontal hydraulic fracture drilling. It is a social movement that draws on the teachings of Thomas Jefferson to counter the oppressive actions of governments operating at the behest of radical environmentalists. EID maintains that the majority of Americans are in support of natural gas and thus this movement for oil and gas is populist in nature (July 18, 2012, July 23, 2012, October 17, 2012, October 18, 2012, June 15, 2011, July 16, 2012, September 14, 2011). In an ode to Nixon and Reagan, EID refers to supporters of oil and gas development through fracking as representative of the "Silent Majority" - those who do not support the counterculture anti-gas advocates, but are unable to achieve such volume and attention due to a strong work ethic and moderate (seemingly 'normal') views (July 23, 2012, October 16, 2012). 
This group of people is not radical or extreme in their political viewpoints; rather they are what EID refers to as the "Rational Middle" - normal, everyday, hardworking Americans (July 17, 2012). EID describes the type of Americans that they advocate and fight for as folks who send their kids to "community schools... man the volunteer fire departments, coach in Little League, attend the church potlucks or help with the local volunteer groups” (June 5, 2011). These are the moral majority who EID contends are having their rights stripped away at the behest of radical tyrants.

In states and towns with bans or moratoriums on natural gas development via horizontal hydraulic fracture drilling, such as New York State, rallies and protests occur on a regular basis, both for and against expanded development. Both types of rally become subject of Energy in Depth blog posts. EID documents and advocates for rallies and demonstrations in support of natural gas, painting them as polar opposites to the antifracking protests and demonstrations (October 16, 2012, July 16, 2012, July 23, 2012). Rather than radical, irrational, or based in ideology, pro-gas demonstrations and protests are symbolic of the "overwhelming support for natural gas development" and emblematic of citizens who are not afraid to "take a stand" (October 16, 2012). Rather than being juvenile, arrogant, or melodramatic, pro gas rallies are described as the defenders of landowners fighting for what they believe, taking a stand, rallying for the cause, and fighting for their rights (October 16, 2012). EID says of one 2012 pro-gas march in Albany, New York, "Even though there were over 1,000 people who attended, several people had to miss the event because of work and chores. It proves the supporters of natural gas in New York State are the silent majority. We have a feeling they won't be silent anymore" (October 16, 2012). Hardworking, traditional Americans support natural 
gas development, according to EID, and they are called on to "push back when the antigas forces launch their attacks” (May 26, 2011). In coverage of another pro-gas event, EID sums up what the 'silent majority' of oil and gas supporters must do - take a stand in the name of progress,

“...Americans must demand, in this election year, that their political leaders and those who aspire to leadership positions speak honestly about our nation's energy goals. That they lay out in clear terms the policies they support to overcome our challenges. It's time we set about to construct a new energy consensus. We have the resources to meet our energy challenges, to make this a New American Energy Century. With the right leadership and vision, we can turn these challenges into a great national campaign that will make our country stronger" (July 16, 2012).

Blazing the Trail to the New American Energy Frontier

The "New American Energy Century" introduces the next major theme in the patriotic framing structure that Energy in Depth uses to narrate the processes of horizontal hydraulic fracture drilling for oil and natural gas: progress. Natural gas and oil extraction processes themselves are written about in terms that evoke images of progress and American frontiersmanship, such as "development," "exploration," and the "trail of prosperity" (July 17, 2012, April 8, 2012). Indeed, natural gas is a "bridge fuel” to strength and prosperity (February 2, 2012). Natural gas and oil operations are chronicled by EID as the technological "opportunity" that will revamp the American economy and push America into the future (October 17, 2012, October 16, 2012, October 15, 2012, 
June 14, 2011, June 9, 2011, March 13, 2012, July 17, 2012, April 8, 2012, March 19, 2012, July 8, 2011, September 1, 2011, January 13, 2012, October 7, 2011, July 17, 2012, July 16, 2012, October 3, 2011, February 2, 2012, May 30, 2012, September 18, 2012).

However, progress does not come without challenge, and EID laments at this fact with a blog post entitled, “All Aboard: The Natural Gas Train is Moving” which compares the opposition to natural gas and oil extraction via fracking to questions about the safety of other symbols of American progress, namely the railroad. They write,

"What does modern natural gas development have in common with early railroads, electricity and indoor plumbing? Well, each of those major Victorian age innovations spurred entire industries, replaced old ways of doing things and greatly improved people's everyday lives. Today we depend on railroads, electricity, and modern plumbing and take them for granted. But when first introduced all were feared and vigorously opposed by much of the public. Sound familiar? History repeats itself...

Change is one of the defining characteristics of the Victorian age as well as our own. 'Better safe than sorry' (the layman's explanation of the precautionary principle is really code for I don't want to change) (sic). Opposition to change is certainly nothing new. It's human nature. But change will come. Nobody wants to go back to covered wagons, reading by candlelight and outhouses. Well, almost nobody. So New York, get on board. Shale gas is a locomotive about to leave the station. Next stop - prosperity” (September 18, 2012). 
Here, natural gas is touted as critical to modernity and to the future of the United States (October 16, 2012). A picture in one EID blog posts credits natural gas development with the ability to "save our future" - if it occurs immediately (June 9, 2011). Natural gas development will allow communities to "overflow with all the good things” like jobs, opportunity income, tax relief, new businesses, hope, a future, and will be an "economic game changer" for the Marcellus region - if taken "across the finish line” (October 16, 2012, March 13, 2012, July 17, 2012). It is the “Golden Goose” that will return rural America to the "golden days of prosperity," if Americans "take advantage of this once-in-a-lifetime energy story” (May 30, 2012, February 2, 2012, October 3, 2011). Energy in Depth itself and other pro-gas public relations initiatives and campaigns are touted as "national campaigns to make our country stronger," who see America as "a nation with an abundance of opportunity for growth" which can only be realized through the development of shale gas in places like Pennsylvania, New York and West Virginia (July 16, 2012).

In a January 2012 blog post, Energy in Depth lays out the "bright future” that natural gas represents for the state of New York, and pleads with residents of New York to "begin the journey to energy self- sufficiency” with natural gas. They cite the overall benefits of gas and oil production stating,

"Do nothing but allow the Marcellus Shale to be developed and this country will grow. Do nothing else but allow landowners to lease and shale gas to flow, and schools and hospitals and senior centers will stay open. Firemen and police officers will keep their jobs. Public finances will stabilize and our main streets and downtowns won't be empty anymore. 
Let this valley echo with the sounds of progress, not the drumbeat of delay and procrastination. Let our resources grow local talent, as IBM and Singer-Link grew here not so long ago.

Our community needs the Marcellus. New York State needs the Marcellus. And our country needs us, in this state, to step forward and embrace energy security, not energy scarcity. To see in gas wells and pipelines independence, not dependence, and to know in our hearts that prosperity is the friend of equality (January 13, 2012).

This quote characterizes the narrative employed by Energy in Depth that natural gas and oil development through horizontal fracking is not merely beneficial to energy companies or landowners that lease their land, natural gas and oil development is beneficial to all, as "prosperity is the friend of equality" (January 13, 2012). Gaventa (1982) refers to this theme as the "spirit of the boom" myth that contend that rapid industrialization in the name of extracting natural resources will be horizontally beneficial to all members of society, as opposed to economically beneficial to only energy companies or those that work for the industry (Gaventa 1982). The claim that natural gas communities will be "booming with opportunity for everyone" is repeated throughout EID's narrative and is emblematic of next theme of patriotic framing used by Energy in Depth: broad based economic opportunity and dedication to community (March 19, 2012, July 8, 2011, September 1, 2011, January 13, 2012). 
Community and Economy

Natural gas is purported by Energy in Depth to be an "economic game changer" that will spur economic development and create thousands of jobs wherever development occurs, effectively revamping the economy of the Marcellus shale region. Oil and gas development holds the "great promise" to reinvigorate dwindling rural economies of New York and Pennsylvania, allowing them to "flourish" once again, and is poised to solve the crises of home foreclosures, unemployment, public health, the loss of family farms, and the wave of migration out of rural areas, according to Energy in Depth. (March 13, 2012, October 18, 2012, October 17, 2012, October 16, 2012, October 16, 2012, June 15, 2011, March 13, 2012, July 17, 2012, June 29, 2011, March 19, 2012, October 13, 2011, February 13, 2012, March 12, 2012, July 8, 2011, September 1, 2011, January 13, 2012, October 12, 2011, May 29, 2011, August 13, 2011, April 16, 2011, October 7, 2011, July 17, 2012, July 16, 2012, October 3, 2011, February 2, 2012).

A major theme in the frame of economic development is the claim that natural gas and oil development will give struggling farmers of the Marcellus shale region the ability to keep their farms using the extra income from natural gas leases and royalties.

Currently, farmers in the Marcellus region "face the real choice of leasing or losing" (October 3, 2011). For this reason, EID claims an overwhelming support among farmers in the Marcellus shale region, they write,

"Every farmer from upstate New York we have talked to has said the first thing they would do with leasing money is invest in more livestock, fix broken machines and pay their farm taxes. When they are asked why natural gas is important to 
them they respond by saying they wish to pass their family farm on to the next generation. In addition, the New York Farm Bureau supports continued natural gas development, I doubt they would support something that will 'hurt farming'” (July 17, 2012).

EID proposes that natural gas and oil development in the Marcellus Shale region will reverse the trend of "farms falling down, being sold and subdivided," and thus, most farmers support natural gas and oil development (July 17, 2012). This process is already in the works in states like Pennsylvania who do not have a statewide moratorium on fracking, EID writes that those opposed to gas and oil are,

“...Seemingly oblivious to the funds Marcellus Shale development would put in farmers' pockets. They would be able to purchase new equipment and keep their farms running for future generations. New Yorkers can look just south of the border to Pennsylvania to see this happening already there. Farmers have been able to pay their taxes, improve equipment, buy more livestock, and make a profit in a time of economic struggle for many in the agricultural business" (February 2, 2012).

Instead of falling or being sold to less responsible landowners, less attached to the land, farms will "return to the golden days" with natural gas and oil development (October 3, 2011). This will allow future generations to return or stay in the region, ending the pattern of the youth moving away after college or high school. According to Energy in Depth, young people are leaving towns throughout the Marcellus Shale region, and "without industrial growth, there will be no reason for our youth to return to the 
region after college" (October 7, 2011, July 17, 2012). In places of high oil and gas development, like Washington, PA, young people are returning home to enjoy the benefits of the natural gas boom, according to EID (June 15, 2011). Natural gas promises to "keep families here and allow them to live with dignity" (September 1, 2011).

Dignity will come to the Marcellus shale region in the form of the employment that the industry will provide (September 1, 2011). Unemployment is high throughout the region, and EID contends that oil and natural gas development will reverse this problem. Tens of thousands of jobs will be created by the natural gas and oil industry, and struggling workers will be able to find jobs they can be proud of and happy with (March 13, 2012, June 15, 2011). Not only will natural gas development bring jobs, but these will be $70 \%$ local jobs, according to EID, further helping the economic situation of the Marcellus shale region (July 17, 2012). "Shell Appalachia’s" plans for investing in oil and natural gas development are heralded by EID as a "huge win” for Pennsylvania, and provide an example of EID's claims of natural gas and oil turning around the economies of towns within the Marcellus Shale region. They write,

"Tioga County, Pennsylvania is known for a lot of things. From the beautiful Grand Canyon of Pennsylvania to rail trails and scenic lakes, it is the epitome of picturesque post cards depicting this great state.

Residents here historically have relatively low per capita and median household incomes at \$26,647 and \$40,338 respectfully for January 2012... They started this year with a 5.9\% unemployment rate... This could all change fairly quickly for the county as the development of natural gas by Shell Appalachia takes off. 
What do we mean by this? Well according to statistics compiled by the Pennsylvania Department of Labor and presented by the Marcellus Shale Coalition, the average salary of a Marcellus Shale worker is just under $\$ 70,000$. That's nearly triple the current per capita income found in Tioga County and with 74 percent of the natural gas labor force in Pennsylvania hailing from the Commonwealth the likelihood of finding a sustainable living close to home is on the rise. In fact this phenomenon is already starting” (March 19, 2012).

Shell Appalachia operations in Pennsylvania are said by EID to be a "win-win" for both the workforce and the economy, which is characteristic of the narrative that natural gas and oil development will have broad-based economic benefits for all community members, and especially those employed by the industry. According to EID, a Shell processing plant would serve as the prerequisite of the resurgence of the manufacturing industry, and would mean the "economic revitalization” of Pennsylvania’s faltering economy - bringing jobs to working people throughout the region (March 19, 2012). According to a January 2012 blog post written by a guest blogger and filmmaker,

"It’s time for New York State to start creating jobs. Creating businesses. Building hope and a better future for the residents of our great Southern Tier.

My documentary - Gas Odyssey - captured on film the moment when the economy of Susquehanna County, Pennsylvania took off upwards. When high school students working for water companies started to earn health benefits and pension plans. When struggling businesses stopped struggling and started expanding. When unemployment in Susquehanna County dropped, and 
landowners started getting something better than bills and tax notices in the mail” (January 13, 2012).

Not only will natural gas development help to solve the problems of unemployment, underemployment, migration out of rural areas, and the foreclosure of land and homes, with jobs it could also help to provide health care to those who currently struggle to afford health insurance. They write, “...There are public health concerns today and they exist because people are not able to afford health care. Allowing natural gas development would put people back to work and enable them to afford proper health care” (October 16, 2012). Another blog post reads,

"Natural gas would mean jobs for local residents which would provide increased health insurance coverage making it easier for citizens to care for themselves and not have to rely on the taxpayer subsidized coverage. Much evidence exists supporting the conclusion that community health improves with economic development provided in areas experiencing shale gas development” (July 17, 2012).

This is just one of the many ways in which natural gas and oil development through fracking are touted to provide long term, broad-based, economic benefits to the people of the Marcellus shale region. Long-term permanent employment, and billions of dollars in wealth and economic activity are not just emblematic of the massive amount of value found in energy extraction, but these are also symptoms of the oil and natural gas industry's deep commitment to communities throughout the Marcellus shale region. 
The narrative presented by Energy in Depth is one that marks their association and commitment to the rural communities throughout the Marcellus shale region. Unlike organizations and individuals opposed to natural gas development via fracking, who “do not share priorities with local communities,” Energy in Depth reiterates that the industry is deeply connected to the local communities and cares about their general well-being. Energy in Depth states their commitment in an April 2012 blog post,

"Looking back, it is clear the main thing is not the numbers, but, rather, the relationships we have built with so many landowners, workers, job seekers, business people and community leaders in pursuit of our common goal to raise awareness about the importance of natural gas development in our region...

We are justifiably proud of what's been accomplished over the last year, but it is the future that is important because, after all, that's what motivates all of us. Restoring the ability to economically survive in our region, without having to sell the farm or leave the area for employment, is what it's all about for us. We are driven by that very real stake in the future economy of the region. We know natural gas development can be done safely and responsibly and we are determined to see it continue (or make it happen in the case of New York and the $D R B C$ ) for the well-being of our families and our communities” (April 8, 2012).

Community support and camaraderie is demonstrated through both financial support for community needs like roads and schools, and through symbolic community events like picnics and carnivals hosted by EID and/or other natural gas and oil public relations initiatives (October 13, 2012, July 23, 2012, July 17, 2012, July 23, 2012, April 
18, 2012, April 8, 2012, March 19, 2012, February 13, 2012, November 10, 2011, May 26, 2011, August 16, 2012, September 1, 2011, February 9, 2012, May 29, 2011, July 16, 2012, May 30, 2012). EID writes in a July 2012 blog post entitled, "Shale Gas Fixes Schools, Hospitals, and Roads; Oh My!” of the "flow of money,” that will come with natural gas and oil drilling in New York and Pennsylvania,

"Many people in shale gas development areas frequently ask how the community will benefit. In Pennsylvania, the benefits to communities as a whole come in monetary spending in towns, community outreach, and job creation. The answer to this question for New York is an easy one and one that goes further in spreading wealth, so to speak, in a region. The Ad-valorem tax will flow money right into the local community where the well is located...

With this tax New Yorkers will start to see money essentially flow right from the ground and into their local communities where it can be used for fixing schools, hospitals, roads and anything else the community needs...

With shale gas development already seen throughout northern Pennsylvania you can see how the flow of cash has already helped many communities... From the Elk Lake School to the new Endless Mountain Health Systems Hospital, natural gas development has been helping Pennsylvania since its arrival. This economic prosperity has come to the area without the help of ad-valorem tax. It has been solely from gas royalties and leasing money, direct donations from the local operators, and spending within communities” (July 23, 2012). 
The economic commitment to community takes the form of roads, schools, hospitals, and other community expenses, such as libraries and senior centers, according to Energy in Depth (July 17, 2012, April 18, 2012, July 23, 2012, November 10, 2011, August 16, 2012, September 1, 2011, January 13, 2012, October 13, 2012). These muchneeded, tax payer funded staples of American life will not only benefut from regional development of natural gas and oil, but will also see direct improvements if they directly host the industry, EID writes of one Pennsylvania school district,

"Schools are not losing funding due to natural gas development in Pennsylvania. It's actually the opposite. One clear example is the Elk Lake School district which has seen a significant increase in funding thanks to natural gas. This is due not only to the economic development of the region, but also because the school leased its land and now hosts working natural gas wells” (July 17, 2012).

Roads themselves become safer after oil and gas development as energy companies "fix them to a standard that is safe for everybody to use," directly benefitting communities that industry travels through (July 23, 2012). This issue of road use comes up throughout Energy in Depth’s narrative, as natural gas and oil operations require a myriad of truck trips to and from well sites, they write, "The hundreds of trucks seen transporting different things to and from the well sites are a great sign - a sign of desperately needed prosperity” (September 1, 2011). And in a September 2011 blog post, next to a picture of a rural road in Dimock, Pennsylvania, EID sets the record straight on the road issue, 
"As far as roads are concerned, gas companies have entered into road use agreements with every town where they are working. When the roads break or wear down, the gas companies fix them, many times leaving them better than they were before the gas companies came to the area. Millions and millions of dollars have been poured into communities for these purposes” (September 1, 2011).

Besides financial support via taxes, donations, leases, and royalties, Energy in Depth demonstrates the oil and gas industry's commitment to Marcellus shale region communities in a collection of documented picnics, fairs, and other symbolic events open to the public and hosted by the industry. Royal Dutch Shell, a multinational energy company operating in the Marcellus region, is touted by EID as committed to the communities of Pennsylvania, they write,

"Shell has been holding town hall meetings in each county where they operate. In the Northern Tier, we're following Shell's three part town hall circuit in Tioga County. If you are from the area and interested in learning more about Shell, come out to one of the following events...

At these meetings landowners will learn about the company, where development will take place over the next year, and can have any questions answered about Shell's work to develop natural gas. Shell plans to hold meetings every few months to keep the community informed on what is occurring with their operations in both Butler and Tioga Counties” (March 19, 2012).

Other events are less about information, and transparency, and more about symbolic community commitment. One such event is the "Vote4Energy Rally" in New 
York which included music, races, informational booths, free food, prizes, moon bounces, clowns, and fireworks all in support of natural gas and oil development in the Marcellus shale region. They write of "Vote4Energy,"

"Yesterday's Vote4Energy rally in New York was amazing! Shortly after we set up our booth, it started to downpour with rain... We learned quickly you should never doubt the landowners of New York because they certainly didn't let the rain stop them... There were hundreds there when the gates opened. As the rain slowed and the sun came out, so too did more people until by the end of the day we had seen and spoken with thousands. It was a truly awe inspiring day...

This event was for the landowners of New York. It was an opportunity to show the New York Department of Environmental Conservation and Governor Cuomo that the landowners of upstate have educated themselves on natural gas, weighed the risks and benefits, and are ready to decide whether or not to lease their properties...

While landowners of New York have figuratively been racing to get natural gas development within their borders for the past four years, yesterday's event took this theme to a whole new level with an actual racing theme. Check out the Friends of Natural Gas New York car! See here is driver, Kyle DeMetro, from the DeMetro racing team with Senator Libous... On hand to give autographs was Nascar driver, Blake Koch, a very nice young driver who came out because he supports natural gas as part of America and New York's energy future... 
After all of that now we say let the fun begin? That's because on top of the very serious discussions occurring throughout the day, the event was also a chance to have a good time with friends and family of all ages. There was free food, local bands, prizes, fireworks, and a lot of laughs... All in all, it was a great day and one we were very proud to be a part of" (July 16, 2012).

EID demonstrates the industry's support for both the community, as well as the region, with the story of the summer picnic hosted by industry public relations initiative "Vote4Energy". The number of fair-goers is proof for Energy in Depth that fracking holds popular support, and that New Yorkers are ready for a lift of the moratorium. The industry aligns itself with the landowners of NY, Nascar, community pride, and wholesome summer entertainment. One blog post documents an industry picnic in Pennsylvania, a similar event that was held after the Vote4Energy rally,

"While we were still enthused from the excitement of last weekend's Vote4Energy Rally where thousands of New Yorkers came out to support natural gas, we headed to Harford Fairgrounds in Susquehanna County last weekend for the $3^{\text {rd }}$ Annual Cabot Oil and Gas Picnic... this year over 7,000 people were in attendance! Seeing that many people getting their questions answered, excited for the development in their region, and holding intellectual discussions on natural gas development really puts into perspective the term 'Silent Majority!' It was an amazing day all around, as usual, and out hats go off to Cabot for the caliber of information distributed and level of commitment to the Susquehanna County community your picnic displays... 
The picnic wasn't just about educating the community on the natural gas industry. Organizations like the Center for Anti-Slavery Studies, Big Brother/Big Sister and United Way also had booths at the event and the library held a raffle, raising thousands of dollars for its efforts and for the local historic society...

And of course, there was free food, fun prizes like I-Pad's and televisions, games for the kids including a dunk tank and Taylor Rental's bouncy equipment, and great opportunities to interact with neighbors” (July 23, 2012).

Here, EID and the industry not only align themselves with community pride and support, but also with charitable organizations like the United Way and Big Brothers/Big Sisters, as well as educational programs, aligning their cause for increased natural gas and oil production via horizontal hydraulic fracture drilling with community-driven organizations and non profits. This quote also touches on the claim that community support for natural gas and oil operations is widespread, enough to identify those in attendance as the "Silent Majority". EID states that individuals held "intellectual discussions", and had their "questions answered," invoking a tone of transparency in industry/community relations that will exist during the Marcellus shale boom. With free food, family fun, and electronics giveaways, the industry demonstrates its charitable nature to the landowners in attendance, promising that there is plenty more to go around if fracking is allowed in New York State.

The community support and pride demonstrated by these previous two events is a polar opposite to the activities of those in opposition to natural gas, according to Energy in Depth. In fact, a couple of weeks after one of the picnics, an anti-fracking protest was 
occurring in Watkins Glen, New York. EID covers this in a blog post entitled, “We Asked For It, We Got It...We're Still Going to Protest,”

“...We’ll be heading up to Watkins Glen Friday afternoon for another protest... For our part, before the protest we will spend time in solidarity with our communities at two games celebrating America's pastime: the Binghamton Mets minor league baseball game, thanks to the nearly 1,000 tickets provided at the 3rd Annual Cabot Community Picnic, and the Little League World Series where the San Antonio team (from the heart of the Eagle Ford Shale) will play New Jersey” (August 16, 2012).

This quote reiterates the use of sports and giveaways to demonstrate the oil and gas industry’s commitment to the communities of Marcellus. Here, EID “celebrates America's pastime,” baseball, “in solidarity” with the Binghamton community. EID even mentions that one of the teams that played during the Little League World Series was "from the heart of the Eagle Ford Shale," furthering their association with the tradition of baseball in American communities.

In associating itself with local Marcellus Shale communities, the Energy in Depth Northeast Marcellus initiative is engaging in what sociologists have referred to as fauxgrassroots or astroturf, efforts to construct a cultural and economic community identity in alignment with extractive industries (Bell and York 2012). Indeed, Energy in Depth portrays itself and the Energy in Depth Marcellus Initiative as a community-driven, grassroots initiative (though funded and created by multinational corporations and the 
Independent Petroleum Association of America) (EID Main Page 2013). On the EID Marcellus “About Us” webpage, they write,

"Led on the ground by Wayne County, Pennsylvania, native Tom Shepstone, EID Northeast draws on the considerable expertise and technical insight of EID's coalition partners in the area (and, as needed, across the country) to bring forth the facts on the promise and potential of the Marcellus Shale. We consistently aim to create new friends along the way who are interested in joining the cause, while setting the record straight on what's really going down in their communities” (EID Marcellus About Us 2013).

“Astroturfing” is not limitied in the oil and gas industry to Energy in Depth, a myriad of “initiatives” and “coalitions” have been created that utilize imagery of community commitment and commitment to nationalism with the promise of natural gas. In fact, Energy in Depth blogs about one of these groups created by a team of public relations firms, known as the Delaware Valley Marcellus Association. They write, in a blog post that uses idioms associated with the state of Pennsylvania, “Bringing the 'Yinz' and 'Yous' Together on Marcellus Shale Business,'

“...This past month, we went forward with our efforts to educate southeast Pennsylvania businesses to the real and substantive opportunities that accompany this huge domestic energy play.

The Delaware Valley Marcellus Association launched with the intention of educating local businesses, decision makers and others to the facts and issues surrounding Marcellus Shale development. We open with four founding members, 
including Duane Morris, KPMG, ModSpace and my firm, Gregory FCA, the largest PR firm in the Commonwealth” (May 30, 2012).

Energy in Depth tells the story of an oil and gas industry dedicated to the community. Through symbolic events like picnics, fairs, and baseball ticket giveaways, and economic commitments to fix roads, build hopitals, and save schools, EID works to build what Bell and York (2010) refer to as community economic identity - the idea that the wellbeing and identity of the Marcellus Shale region's communities is synonymous with the extractive industry of oil and natural gas.

Energy Independence, Energy Security, and the End of Foreign Oil

The final commitment to American communities throughout the Marcellus shale region, comes from the promise of natural gas and oil operations to lead to American energy independence, marking the end of foreign wars for oil. As an energy source, shale gas is touted as domestic and abundant - with the ability to supply the United States with energy for many years to come, thus cutting reliance on foreign energy sources especially those from the Middle East (October 13, 2012, October 17, 2012, October 16, 2012, June 15, 2011, November 11, 2011, July 30, 2012, September 1, 2011, January 13, 2012, August 13, 2011, July 16, 2012, August 2, 2012, June 24, 2012). Energy in Depth writes, “...Natural gas offers the opportunity for ourselves as a country. We can... support ourselves if the Middle East decides they are 'cutting us off' which is a huge step in the right direction for the United States" (June 24, 2012).

The idea that "natural gas could lead us toward energy independence and reduce our dependence on foreign petroleum" is key in the patriotic frame of natural gas and oil 
drilling via hydraulic fracture drilling (August 2, 2012). They state, “we'll replace imported oil with our own resource that is cleaner and safer, and does not demand the sacrifices of foreign oil" (January 13, 2012). It is the view that natural gas and oil drilling will end wars for oil and overall "dependence" on oil producing areas outside of the United States. It is the view that natural gas and oil will allow the United States to simply rely on domestic energy resources without the need to travel abroad or engage with foreign nations to obtain oil. Energy in Depth claims that oil and gas from Marcellus shale will not be exported overseas and thus will benefit only Americans (September 1, 2011). It draws on American fear and distrust of the Middle East, Americans' need for security from war, and allows oil companies to align themselves with the solution - an American source of natural gas and oil. EID writes,

"We are an energy-rich nation. We have more oil and natural gas than anyone thought possible even twenty years ago: more potential energy than many oilexporting nations in the Mideast, and more than most countries in the world... we see a nation with an abundance of opportunity for growth...

We have the resources to meet our energy challenges, to make this a New American Energy Century” (July 16, 2012).

Military support is implicit in the call to 'drill here, drill now.' The idea, as stated, is that drilling American natural gas and oil will cease foreign oil wars and bring troops out of harm's way. Energy in Depth contends that the oil and gas industry is extremely supportive of the U.S military personnel, in a November 2011 blog post, 
“Serving Those Who Served Us All,” EID discusses Chesapeake Energy’s commitment to hiring veterans, they quote CEO Aubrey McClendon,

"'We are very pleased to be recognized for our efforts to recruit and hire America's veterans. Maturity, discipline, teamwork and work ethic are essential characteristics that any veterans share with our national work force. We hope that being able to help veterans find new and exciting careers in America's energy industry provides at least some recognition for their service to our country'”

EID continues, "Of course Chesapeake is not alone, but they are a leader. Other organizations, especially in the Marcellus Shale, are also seeking out veterans for employment in their operations... This story [of a veteran working in the Marcellus Shale] is not unique, there are hundreds, if not thousands of similar tales throughout the Marcellus and other shale plays throughout the United States.

Upon traveling through Upstate New York recently I saw a sign that read 'Drill a Gas Well Bring a Soldier Home'. While the sentiment is not always that simple given the complexities of the world. It is nice to know that safely and responsibly developing this resource is not only helping to increase energy security but is also welcoming our veterans with open arms as they return home" (November 11, 2011).

This blog posts explores the oil and gas industry's dedication to veterans, as well as their activities of increasing "energy security," aligning themselves with support for 
the troops, as well as giving their motive for fracking in the Marcellus shale region a patriotic drive. As discussed in this thesis' literature review, support for military and a civic duty to support 'energy security’ is cited as key frame used to generate support throughout Appalachia and the Marcellus shale region (Jacquet 2009, Miller 2010, Perry 2010, Bell and York 2010, Mitchell 2012).

By portraying themselves as grassroots, holding community events, and aligning themselves to the tenets of American patriotism, Energy in Depth paints the oil and gas industry as committed to local communities, the Marcellus region, and the nation. These framing techniques of local, regional, and national support and commitment from the industry work to create what sociologists have deemed ideological maintenance and cultural manipulation in efforts to create economic community identity (Bell and York 2010). It is the intertwining of culturally held values (or the 'mobilization of bias') and activities with the activities of oil and natural gas operations that allows the multinational extractive energy industry to frame itself as a staple in the community. The industry frames itself as a benevolent economic actor, one that is committed to the general wellbeing of residents throughout the extraction region, and one that shares their ideological viewpoints (Mitchell 2012, Gaventa 1982, Miller 2010, Bell and York 2010, Faber 2008, Bernays 1955, Mills 1959, Chomsky 2002; 1999, Achbar and Wintonick 1992). 


\section{Natural Gas, Environmental Imagery, and 'Greenwash'}

Energy in Depth engages in "greenwash,” the use of environmental imagery and claims of environmental stewardship as a selling point for a product or practice (Laufer 2003, Reynolds 2004, Simon 2000, Stauber and Rampton 1995, Dahl 2010, Scanlan 2013). Throughout Energy in Depth's blog activities, natural gas and oil production via hydraulic fracture drilling is portrayed as environmentally safe, with little to no incidence of environmental disruption. Environmental imagery like landscapes, farmland, and pictures of forests are used throughout the Energy in Depth blogs, and claims of the industry's commitment to environmental stewardship are common, making concern for the environment a major part of the identity of EID, and subsequently, the oil and gas industry (October 13, 2012, October 10, 2012, October 18, 2012, October 17, 2012, October 17, 2012, October 16, 2012, October 16, 2012, October 15, 2012, June 5, 2011, September 23, 2011, July 27, 2012, July 18, 2012, July 23, 2012, July 30, 2012, July 17, 2012, April 18, 2012, April 8, 2012, June 29, 2011, June 23, 2011, March 29, 2012, October 13, 2011, July 8, 2011, May 26, 2011, August 16, 2012, September 1, 2011, February 9, 2012, October 12, 2011, June 21, 2012, October 3, 2011, August 2, 2012, April 18, 2012, June 24, 2012, October 10, 2011).

The identity of the industry is one of "conservationists" rather than "environmentalists" as demonstrated in a real world commitment to the land. They write, “They are 'environmentalists.' For some, this becomes virtually a religion. 'Thou shall not harm Mother Earth.' We, however, are conservationists. We are concerned about protecting our environment, while also maintaining 'progress'” (July 18, 2012). EID demonstrates this dichotomy in a blog post comparing pro-fracking landowners' 
commitment to the natural world, to an anti-fracking landowners' commitment. They write,

“Let me also pose a question to [Anti-Fracking Resident]: 'What have you done to protect the environment besides attack us in the press, donate one of your photo images or a few dollars and produce some obscure art?'

My family and I have a non-commercial tree farm and have planted 10,000 deciduous and coniferous trees by hand on our farm and hunting lands...

We have more than 100 acres in the Conservation Reserve program; we have numerous acres in non-commercial timber stand improvement with a wildlife focus.

We have a Forest and Farm Management Plan produced with the help of the Natural Resource Conservation Service. We also maintain riparian buffer zones.

We have more than 85 bat, bird, purple martin, owl and wood duck houses built and deployed on our land to support wildlife.

We have free-range chickens that get eaten by various wildlife weekly (which is upsetting but natural).

My 95,000 bees in four hives pollinate blossoms in an 11-square-miles area, perhaps including the flowers and veggies in [anti-fracking resident's] garden, if he has one” (October 15 2012).

This blog post makes the claim that "stewardship of farmland is part of our heritage," and the actions of one pro-gas landowner in the Marcellus shale region become 
synonymous with the values of the industry as a whole. Tree planting, free-range chickens, and the creation of shelter for bats and birds, all ecologically beneficial, are aligned with the support of natural gas development. At the same time, these values and behaviors are polar-opposite to those of "environmentalists" who are merely ideologues, engaged in little real world action. A reader of this EID blog could come to the conclusion that natural gas and oil operations must be environmentally friendly if this conservationist landowner is in support of them. Oil and gas extraction becomes as environmentally friendly as bee keeping or forest conservation. This theme resonates with the traditionally conservative 'wise use movement,' that promotes land conservation via private ownership and use, rather than through government regulation or environmentalism (Kosek 2006).

EID aligns the natural gas and oil industry present in the Marcellus shale region with environmental stewardship and conservation. This is clear in the stated "core values of operation” of IPAA member Royal Dutch Shell in one EID blog. Shell's core values pertaining to the environment are as follows,

"Shell is Committed to Following Their Core Values with Safety as Priority \#1

- Shell has a Goal Zero goal for workers to prevent harm to persons or the environment.

- Shell is Committed to the Environment: Shell is committed to using 100 percent closed-loop systems and recycling of wastewater.

- Shell is committed to being aware of its consumptive water usage and reducing that amount whenever possible. 
- Shell is committed to protecting and minimizing their impact on the environment through safe, responsible techniques.

- Shell is committed to transparency with landowners and the public through meetings and disclosure of their hydraulic fracturing solutions on FracFocus.org” (March 19, 2012).

Shell paints commitment to safety in the environment and for workers as their first priority, or their "goal zero," presenting themselves as dedicated to environmental protection. Through safety, responsibility, and a commitment to the environment, major energy stakeholder Royal Dutch Shell demonstrates the environmentally friendly nature of natural gas and oil operations.

65 Years of Proven Use

The first major claim of environmental safety and stewardship used by Energy in Depth is the claim that in over 65 years of use, hydraulic fracture drilling has never resulted in environmental contamination (October 13, 2012, October 18, 2012, October 16, 2012, October 16, 2012, July 17, 2012, June 21, 2012). According to EID, “...after about 1.5 million uses in general and about 50,000 high volume horizontal hydraulic fracturing operations, [fracking] never has [polluted a water source]" (July 18, 2012). This particular blog contends that this is a vital point ignored by those opposed to natural gas operations and horizontal hydraulic fracture drilling. In another blog post entitled, “Milling Over Non-Existent Water Pollution in Milford” Energy in Depth cites a USGS study, stating, "As USGS has reported in an exhaustive 20 year study there is much contamination in private wells but non has shown any contamination from toxic materials by natural gas production. Not one instance, ever." EID cites the claim that various 
studies have nullified claims of environmental contamination with the reoccurring idea that, "study after study... shows zero ground water contamination from hydraulic fracturing” (October 13, 2012). The long-studied and time-tested use of hydraulic fracture drilling with little to no environmental damage claim is revealed again in another blog post entitled, “Natural Gas Witch Hunt”. Energy in Depth writes,

“Abraham Lincoln, who confronted a real evil once said, 'you can't fool all of the people all of time'. That's why other Marcellus states don't shun gas development. Officials there know the undisguised truth - there's nothing to fear! Even with thousands of wells now producing shale gas, there's virtually no confirmed evidence of contamination. There's nothing scary under the bed or the bedrock either. It's not supernatural gas. What you see is what you getenormous benefit with little risk” (October 16, 2012).

This quote plays on other previously discussed themes of nationalism (with an Abraham Lincoln quote) and the hysterical fear of those who oppose fracking while making the claim that there is no evidence of contamination in the natural gas industry. In this claim, natural gas production is painted in a very positive light, with the benefits far outweighing the virtually non-existent risks. In fact, the idea of environmental harm associated with natural gas development is so foolish that those concerned about environmental harm are akin to children fearful of a monster under the bed or people who believe in the supernatural. Another blog, published the same day, echoes these claims, stating that, "there were no health issues in the million wells that have been hydraulically fractured over the last sixty years" (October 16, 2012). It is important to note that the language used to deny claims of environmental degradation like groundwater 
contamination is usually in reference to the single act of "hydraulic fracture drilling" rather than the entire process of natural gas and oil extraction and production. 'Fracking' is merely one step in the long process of producing these fossil fuels, and often, different stakeholders use the term differently. The industry commonly uses the term to denote the singular act of horizontal hydraulic fracture drilling, while public opponents commonly use the word to refer to the entire process of oil and natural gas production (Dedman and Weintraub 2013, Save Colorado 2013).

\section{Minimal Harm}

The claim of 65 years of proven use may refer only to one aspect of the process of extracting and producing oil and natural gas, but the industry contends that not only is this aspect safe and clean, but the entire process is claimed to result in minimal environmental impact. According to EID, it is a tightly regulated industry that responsibly drills for oil and natural gas, resulting in a miniscule level of disturbance (Ocotber 18, 2012, October 17, 2012, July 27, 2012, July 17, 2012, September 23, 2011, July 18, 2012, July 17, 2012, April 18, 2012, April 8, 2012,June 23, 2011, March 19, 2012, October 13, 2011, July 8, 2011, May 26, 2011, September 1, 2011, February 9. 2012, October 12, 2011, June 21, 2012).

In a blog post entitled, "Natural Gas Development is Safe and Must Occur Soon," EID writes, "Lifestyle disruption during individual well and distribution infrastructure development is temporary and localized. Permanent impacts on developed properties and the environment are minimal” (April 18, 2012). A picture provided in a October 2012 blog post shows a photo of a Chesapeake well site, showing a picture of the site during 
drilling and a picture of the well site after an apparent reclamation. In this photo, a busy industrial pad is juxtaposed with an empty field amidst a wooded countryside. What is left out of this picture is a photo of the well site before natural gas operations took place, so it is unclear as to what the actual impact of this site was on the local geography.

The impact of oil and gas operations is characterized as negligible. Energy in Depth contends that this minimal impact is evident in travel throughout the Marcellus shale region. One blog describes an area of heavy natural gas and oil activity as, "an area of Lycoming County that is heavily populated with natural gas wells, although they tend to blend in with the beautiful farm landscapes. You'd probably, in fact, miss a bunch of them if you weren't looking” (April 8, 2012). One would miss these wells presumably because of the oil and gas industry's reach from a single well pad. Another blog writes, “...we are withdrawing natural from as much as a two-square mile area using a handful of wells constructed on one tiny pad that accounts for less than one-half of one percent of the landscape” (June 23, 2011). The figure of "less than one-half of one percent of the landscape,” certainly paints the picture of very little landscape impact on the part of oil and gas operations. In another blog, this frame is echoed. Above a picture of Dimock, Pennsylvania, captioned, “Can you find the Industrial Zone?” EID states,

“It's like an industrial park? Take a look at this picture below. It was taken near Carter Rd. right inside the 9-square mile moratorium zone. It is the essence of what natural gas development actually looks like. One would have to drive around for a while before finding another rig like the one pictured here. The producing wells are even harder to find as they disappear into the landscape” (February 9, 2012). 
In a blog entitled, “Don’t Believe the Anti-Hype: Natural Gas Development Is Safe," EID makes the claim that the beautiful landscapes of the Marcellus shale region and the prosperity associated with natural gas development are not mutually exclusive. They write, next to a picture of a group of cows grazing by a gas pipeline,

"It is important to note these sites can and do co-exist with nature. I have personally observed cows grazing by producing gas wells with no problems or health issues. In fact, the natural gas industry in many cases has allowed family farms to continue, and thrive...” (October 12, 2011).

According to EID, extensive federal and state government regulations preclude any sort of environmental or human health impact that could arise from oil and gas operations. Regulation, according to EID, allows the process to be carried out safely and responsibly. They write of proposed regulations in New York State,

"These regulations would go well beyond what's required by most states and the federal government in developing natural gas resources. They would implement a degree of safety that exceeds the parameters that have led three presidential administrations - Clinton, Bush and Obama - and regulators in over 16 U.S. states to declare the process as safe" (October 18, 2012).

Though exempt from the federal Safe Drinking Water Act and Clean Water Act, EID contends that state regulations are extensive. Were the moratorium on horizontal fracking overturned in New York State, EID claims that extraction would be carried out safely under far-reaching state regulation. EID quotes the New York Department of Environmental Conservation, 
“'We've deliberated, we've considered the comments, we have looked at what's gone on in other states... And at the end of this stage of the deliberations, we've concluded that high-volume hydrofracking can be undertaken safely, along with strong and aggressive regulations.' - New York DEC Commissioner, Joe Martens.

The New York Department of Environmental Conservation (NYDEC) recently released a preliminary Draft Supplemental Generic Environmental Impact Statement (dSGEIS) regarding the future development of the vast shale gas resources in the state, which includes the massive Marcellus Shale formation. NYDEC confirms that shale gas production, including the use of hydraulic fracturing, can strengthen the economy while protecting drinking water supplies and local habitats.

But you already knew all of that” (July 8, 2011).

With the agreement and the expertise of the state, Energy in Depth argues that through state regulation, fracking is safe and environmentally responsible. Not only does the state agree with EID, the federal government also agrees, as EID cites “ $\ldots$ the completion of an EPA study which found no threat to water resources from fracturing... Also, hydraulic fracturing is tightly regulated, a full understanding of these regulations can be found here and here" (September 1, 2011). These tight regulations manifest themselves in a myriad of state experts that oversee the entire process as the industry is “...checked, rechecked and triple checked for safety records, training and integrity” (July 17, 2012). According to EID, 
"The Anti's want everyone to believe that gas companies are drilling wells wherever they want with complete disregard for the environment. Indeed the idea is weaved throughout much of their narrative. I tell you from experience this is pure fantasy. The fact is, this is an extremely regulated industry and many proposed well-sites are abandoned due to environmental concerns before development even occurs. There is a very concerted process in place that governs any well site. First, a geologist reviews the data and determines the best location to drill a well. Then a team does field reconnaissance for environmental factors such as wetlands, wildlife, streams, and additional considerations. Nowadays, natural gas companies even employ archaeologists to ensure the proposed site is not historically significant and is not likely to contain historical artifacts. Finally, if a site passes the initial environmental assessment and these tests, then the surveyors come in and a complete survey of the well pad area and needed access roads (sic)" (October 12, 2011).

According to Energy in Depth all aspects of the industry are legitimized by the legal authority of state regulators, and thus the extraction and production of natural gas is legitimized as safe, with a minimal environmental impact. A tightly regulated industry is one that needs no further government intervention. In fact, the stated goal of Energy in Depth, as stated by its creator, the Independent Petroleum Association of America, is to be " $a$ state of the art online resource center to combat new environmental regulations, especially with regard to hydraulic fracturing” (Russell 2009). Claims of extreme, extensive, and tight regulations negate the need for further regulations, moratoriums or health impact studies, as proposed by some stakeholders. Here EID, reveals that the 
industry believes in the power of extensive regulation to quell environmental harm, though they do not believe there is any need for further regulation or review of potential health and environmental impacts associated with natural gas extraction.

Commonly cited areas of environmental concern include the harmful chemicals used in fracking fluids, the threat of methane migrating into water supplies, truck traffic to and from well pads, the amount of water used throughout the process, and the high noise level associated with natural gas and oil operations. Energy in Depth maintains that these aspects of the process result in minimal harm. The 'chemical cocktail' of additives in fracturing fluids as discussed previously in the literature review of this thesis, are said to be common, non harmful in small amounts, propose little health or environmental risk, and to be inconsequential by Energy in Depth (September 1, 2011, June 23, 2011, July 8 , 2011, July 17, 2012, July 27, 2012). The chemicals added to the fracture water are said to "present low to very low risks to human health and the environment," and only make up about $1 \%$ of the several millions of gallons of frack fluid (June 23, 2011). These chemicals are normalized as a part of everyday life by Energy in Depth. They write,

"The author then espouses his great understanding of carcinogenic chemicals, focusing on those involved with gas exploration. Of course, he didn't mention any of the ways people come in contact with carcinogens each day, for example, by applying scented body lotion to one's skin. The scent is pure perfume and the only way these perfumes will stick to a human body is through the use of parabens, which are carcinogens. Additionally, such varied items as shampoos, shaving cream, spray on tan, makeup and some foods also contain parabens as they act as preservatives and are used in common every day products because they are cheap 
and the exposure levels are unharmul. We consume many things that in larger quantities could be harmful. It is the amount and the level of exposure that is important and determines toxicity, not the fact that an item is carcinogenic in some quantity” (September 1, 2011).

By associating the chemicals used in the horizontal hydraulic fracturing process with seemingly neutral and common products like soap, shampoo, makeup and food, EID is able to normalize the toxicity of the carcinogenic substance. The fact that many substances that Americans come into contact with on a daily basis could also be dangerous shifts focus from the industry itself. This theme is repeated throughout EID blogs. Speaking about an individual who presented during a natural gas education workshop, who EID considered an "anti-natural gas development speaker," EID writes, “[He] then talked about chemistry, beginning with brine. He said an area doesn't need chemicals to damage streams or rivers, noting silt itself could do that. [He] said about $3 / 4$ of the chemicals used in hydraulic fracturing are dangerous but, if so, that's also true of many things. It's all a matter of concentrations, isn't it? Chlorine, for example, is extremely dangerous, but we use it everyday to bleach our clothes and clean our swimming pools.

There was no mention, for example, of the risks associated with brushing our teeth each day with fluoride or the dangers to the water supply from flushing cleaning solutions and medicines down the drain. There certainly wasn't any mention of how dish soap is used to clean our plates, but he did mention how a 
soap-like substance is used in hydraulic fracturing. Does this mean we should protest Ajax?” (July 17, 2012).

Here again, any criticism of the chemical additives used in the horizontal fracturing process are akin to the seemingly irrational and non-normal protest of such common everyday products like medicines, cleaning products, or soap. The idea is that if we already use harmful chemicals in our everyday lives, cleaning, washing dishes, or brushing our teeth, it would be hypocritical to question similar chemical additives used in frack fluids. Furthermore, frack fluid chemicals are claimed to be used in "other industrial and domestic processes without any widespread consequences” (July 27, 2012). Surely, if these chemicals are already used in the home and in other industries they must meet some level of safety.

Another major claim of environmental threat concerning natural gas operations is the migration of methane from a fracked well into a water source (October 16, 2012, September 23, 2011, February 9, 2012, September 1, 2011). Methane in a drinking water well can result in the infamous videos and pictures of flaming tap water commonly cited by stakeholders who question or oppose oil and gas industry operations in the Marcellus shale region. However, Energy in Depth characterizes flaming tap water as a simple "parlor trick" used to gin up fear about fracking (October 16, 2012). They write, "Alarmists hysterically claim gas companies are responsible for almost any strange or undesirable phenomenon. In one infamous parlor trick they set tap water on firesomething possible naturally in many methane rich areas with no gas development” (October 16, 2012). Energy in Depth contends that because methane is a naturally occurring substance in some water wells throughout the Marcellus shale region, that gas 
extraction activities should not be blamed for methane migration and flaming faucets. In another blog they write,

"Natural gas is naturally occurring and, the flaming faucet in Josh Fox's infamous Gasland scene had previously been known to have natural gas in it. There are, throughout our region, many people who can turn on their faucets and light them on fire because of naturally occurring methane in their well water, where there is no hydraulic fracturing. This is a problem that is rampant in Northern Pennsylvania and Southern New York... Lot's of claims, none found to be related to natural gas production" (September 1, 2011).

EID contends that though natural, methane in water wells is a rampant problem in Northern Pennsylvania and New York. However, this problem has nothing to do with natural gas operations, as there are other sources of methane. Again, they cite this "parlor trick" of lighting a faucet aflame as a tactic of misinformation used to spread fear of oil and gas development. However, one blog does imply that methane migration has occurred because of drilling, but contends it is not a widespread problem. They write, "Methane migration has occurred in limited qualities but this has been confined to a very limited geographic area in northeast Pennsylvania and methane is non-toxic” (September 23 2011). Here Energy in Depth downplays the extent of methane migration throughout the Marcellus shale area, and dismisses the danger of having methane coming out of water in the home, citing it as "non-toxic." Methane migration problems are normalized and the risks associated with methane are normalized as being a simple fact of life in the parts of the Marcellus region, a fact of life that the industry contends is not their responsibility. The normalization of methane is summed up in a picture of a t-shirt 
for sale at one Cabot Oil and Gas Picnic that has a picture of a flame on it and reads, “Susquehanna County, Lighting Our Water On Fire Since 1795!” (July 23, 2012).

Other problems associated with natural gas tend to revolve around water usage, noise, and air pollution generated by the process of extraction and production. Energy in Depth employs legitimation strategies to downplay these concerns. First, EID argues that water withdrawals and usage for natural gas development are insignificant, and that contaminated water is disposed of in an environmentally sound manner (July 8, 2011, May 26, 2011, September 1, 2011, February 9, 2012) One blog post concerns a controversial water withdrawal permit for natural gas industry operations in New York, that had been criticized by opponents of fracking. EID provided a list of reasons why the withdrawal permit should go through, stating,

"1. The application is for a water withdrawal. Treating it differently because the water will be used for natural gas development unfairly discriminates against economic development within the upper part of the Delaware River basin.

2. This water withdrawal permit is very small when put in perspective, requiring but a little over one-half of one percent (0.6\%) of the average daily flow.

3. Moreover, many safeguards exist to protect the creek and other water users, such as minimum flow rate thresholds before water withdrawal can occur, and a maximum withdrawal rate of 500 gallons per minute.

4. This application, if approved, is still subject to further DRBC, New York State Department of Conservation, Army Corps of Engineers and U.S. Fish and 
Wildlife Service approvals as well as a water conservation program to minimize water withdrawals” (May 26, 2011).

Again, the industry argues that the environmental harm posed by an industry operation, this time a water withdrawal, would be both minimal and properly regulated. They align themselves with a concern for conservation of water and normalize their processes as simply another form of 'economic development' that is being unfairly targeted. The disposal of wastewater is another aspect of natural gas an oil production that EID defends, stating in one blog,

"The author also claims flow back water is being dumped into the Susquehanna River. Flow back water is not being dumped in the Susquehanna River. Rather, it goes into closed loop systems and is recycled. Where it is not recycled it is properly disposed of in underground injection wells (mostly in Ohio)" (September 1, 2011).

EID cites the New York SGEIS (Supplemental Generic Environmental Impact Statement) to reinforce the claim that contaminated flowback water is managed safely, stating, “"No significant adverse impacts are identified with regard to the disposal of liquid wastes"' (September 8, 2011). According to Horton (2012), the disposal of this wastewater, or the "proper" injection of contaminated wastewater into wells has been associated with earthquakes in states like Arkansas and Colorado (Horton 2012). Energy in Depth argues that this seismic activity is insignificant. In a blog post with the subtitle “The Truth about Earthquakes and Seismic Activity,” EID cites the New York DEC, stating, “'Information reviewed indicates that there is essentially no increased risk to the public, infrastructure, or natural resources from induced seismicity related to hydraulic 
fracturing'”' (July 8, 2011). Again, it is unclear as to whether the DEC is speaking about the processes of the industry as a whole (including waste disposal), or simply the processes of hydraulic fracturing. Nevertheless, the quote is used to downplay concern about seismic activity as a result of oil and gas operations. The other concern about wastewater is that it has some level of radioactivity as it returns from the fractured well. EID characterizes this radiation as presenting little to no danger, and as being found in levels that are “insignificant” (July 18, 2012, July 8, 2011).

Noise levels resulting from compressor stations are another aspect of the natural gas development process that EID downplays. A speaker at a meeting about proposed development in New York, cited that the sound of a compressor station is akin to the decibel level of a food processor if one were standing directly next to it. EID remarked on this claim, stating,

"He said it would sound like a dishwasher and wants to know where the compensation for the noise would come from. Oh my gosh! A dishwasher! Call me cynical but I would love to ask how many people in the audience have a dishwasher in their homes. Does that interrupt them when the watch TV? Do the dishwasher companies compensate their consumers because of the noise?” (October 16, 2012).

Here EID normalized natural gas processes as nothing out of the ordinary with compressor stations merely being as loud as a household appliance. This follows the general greenwash pattern of claims that oil and gas operations produce minimal 
environmental harm and need not be further scrutinized for their environmental impact, as it is nil.

The final point about the minimal impact of environmental harm is the argument that EID makes about incidents of environmental harm or contamination. Implying that they are simply, “incidents” that are not characteristic of the industry as a whole. These problems are attributed to individual contractors or workers, individual well casings, or human error, and are described as isolated incidents that are nothing but anomalies. It is simply the case of a few bad apples. This theme is clear in an October 2012 blog post,

"As a consultant I have seen firsthand that most companies are acting in a responsible manner and are doing their best in the engineering and planning stages to prevent environmental problems. Of course, there are problems that arise despite these efforts and they must be addressed and dealt with. Larger problems, often caused by the occasional unscrupulous contractor, or gas company, can make for sensational headlines and cause people to cough up more money for the "greenies" wishing to stop natural gas development. Of course, one needs to keep in mind that these stories create headlines because they are the exceptions rather than the rule" (October 12, 2011).

Environmental problems are attributed to “unscrupulous” individuals, and are “exceptions rather than the rule" according to Energy in Depth. This anomalous frame of freak incidents rather than systemic issues with oil and gas development extends not only to individuals, but also to certain aspects of the extraction process. For example, individual faulty well casings are to blame for methane migration in water wells, rather 
than migration being a general symptom of the oil and gas production process. They write,

"Nonetheless, purported pollution evidence was reviewed by the University of Texas Energy Institute, which determined there is no water pollution caused by fracturing fluids in drinking water that could lead to widespread health problems. It found pollution problems that existed were related to faulty well casings that had caused methane migration or involved mechanical failure. Both of these problems are limited and solvable” (July 27, 2012).

These problems are simply the fault of poor construction or mechanical failure, and do not represent the process as a whole, according to Energy in Depth. EID contends that the problems are limited, solvable, and do not represent any serious health concerns. They go on to cite the New York DEC again, stating, "“Well construction associated with HVHF presents no new significant adverse impacts with regard to potential gas migration. Gas migration is a result of poor well construction (i.e., casing and cement problems).'” (July 8, 2011). Again, problems are limited to individual failures and are not telling of the industry's operations in the Marcellus shale region as a whole. This way of narrating methane migration neutralizes the threat as a rarity that most residents need not worry about.

Throughout this aspect of the greenwash frame, Energy in Depth narrates the story of natural resource extraction in the Marcellus shale region as one of minimal environmental harm. Gas and oil production sites are purported to blend into the landscape, existing harmoniously with nature; problems with methane are negligible as 
they are rare and methane is non toxic; fracture fluids are normal and safe because they contain chemicals common in everyday items like chlorine and anti-freeze; water is protected, and contaminated waste is disposed of properly; environmental problems, though anomalous, are solved by extensive state regulation; and all-in-all environmental disruption is minimal. The story EID tells of natural gas and oil production in the Marcellus shale region is one of cleanliness and safety, and just like the general public, the energy industry is concerned for the environment.

'Fracking' is Good for the Environment

The final way that Energy in Depth engages in greenwash to promote an environmentally friendly picture of oil and gas production in the Marcellus shale region is by suggesting that the increased extraction and use of natural gas is actually beneficial for the environment (October 13, 2012, July 18, 2012, July 30, 2012, July 16, 2012, August 2, 2012, June 24, 2012). Air, water, and land quality can all be improved throughout the region, according to Energy in Depth.

Energy in Depth demonstrates the oil and gas industry’s commitment to the land in a blog post entitled,

“...the land we own is something that becomes a part of us. We buy a house picturing our children growing up in it; our grandchildren playing in the yard. We buy land as an investment for the future of our families, something that becomes a part of the family and its history. Indeed it serves as the founding principle of our nation and society. On a more personal level, for those who have had a parcel of land in their family for generations, it is a treasure that is 
unfathomable to imagine losing... whoever owns that land... has finally been offered an opportunity to revitalize the land... For many, the Marcellus represents the only real possibility to conserve their land" (October 3, 2011).

Energy in Depth contends that the land is "a part of us," and that Marcellus shale gas extraction offers the opportunity to "conserve" this land for future generations, implying that natural gas extraction can help to preserve pastoral regions of the Marcellus shale. EID contends that the use of rural lands for natural gas and oil extraction is wise use; it saves the land from being developed or exploited in some other way, conserving it for natural gas development. Surely something that harms the environment cannot be the same thing that conserves the land and allows children to play in the fields, unconcerned about the threat of environmental toxins. Energy in Depth goes on to assure readers that water usage is negligible, and that natural gas extraction actually produces water, they write,

"One gas well may take 5,000,000 gal of water to hydraulic fracture but the gas produces 20,000,000 gallons of water when consumed. The net gain is 15,000,000 gallons of water! The same principle applies to gasoline and 1 gallon of it, when combusted, produces approximately 1.1 gallon of water (Did you ever wonder what that liquid dripping from your tailpipe was?)" (August 2, 2012).

This statement that natural gas exploration actually produces more water than it requires to hydraulically fracture shale rock is repeated throughout Energy in Depth’s blog posts (October 13, 2012, August 2, 2012). This statement completely negates the concern for water quality or quantity utilized in the natural gas exploration process, and 
plays into claims of environmental virtues associated with the industry. Water is not the only environmental aspect that EID claims natural gas extraction saves, they write, "We seem to live in a country where we objectively know our air and water are steadily getting cleaner, but, yet, some choose to believe they're getting dirtier.” (July 18, 2012). EID asserts that natural gas operations have made air and water cleaner throughout both the Marcellus shale region, as well as the nation. They claim, linking natural gas to a nationwide decline in greenhouse gas emissions, "thanks to natural gas, the United States is now leading the world - yes, leading it - in the annual percentage decrease in carbon dioxide” (July 30, 2012).

Presumably, this claim is referring to the growing use of natural gas in power plants, as opposed to coal (Saiers 2012). They cite not only the use of natural gas in power plants, but also the potential for natural gas vehicles to reduce greenhouse gas emissions throughout the Marcellus shale region (July 23, 2012, July 16, 2012). They write of New York State, “With New York already being one of the largest consumers of natural gas in the United States, it seems fitting the focus within should be on converting the heavy traffic in the state to cleaner burning compressed natural gas” (July 16, 2012). Natural gas is argued to be the driving force to solve climate change at the hands of greenhouse gas emissions, by EID, marking it as not only limited in environmental harm, but actually beneficial for the environment.

Energy in Depth compares the environmental footprint of natural gas operations with other energy industries and other economic operations to continue their argument that natural gas is environmentally beneficial. They point out both problems with other energy industries, as well as problems with other sectors of private industry like 
sanitation and tourism, to argue that natural gas extraction is not as environmentally detrimental as other socially accepted activities. Of other energy industries they write, "Natural gas is a cleaner energy source than anything else of comparable capacity and burning more natural gas in place of some of the other energy sources now being used would make New York a much healthier place to live. (June 24, 2102). Throughout the sampled blog posts, coal is not mentioned, however, Energy in Depth criticizes both wind and solar as alternative energy options, and criticizes supporters of such options as being in a state of denial, they write of wind and solar supporters,

"Their hypocritical use and enjoyment of fossil fuels, their inability to offer a better energy solution, and their refusal to acknowledge that 'clean', 'green', and 'sustainable' wind and solar options are more destructive to the planet and carry heavier health impacts to boot is mind boggling. Forget about the economic impracticality of these options. It is so funny how they remain close mouthed and refuse to address this issue. I think it would result in a complete collapse in their utopian dream life if they ever stepped out of their state of denial.

... Natural gas is the cleanest option. Natural gas is the most available option. Natural gas is the most water-friendly option (know what you are talking about before refuting because wind and solar do not produce water - they only contaminate it). Natural gas is the healthiest option for people and animals! Natural gas carries the least land impact” (October 13, 2012).

This quote is supplemented with a picture of a solar field in New York with the caption, “200 Acres of Land Disturbance on Long Island for a Solar Project” (October 
13, 2012). Here the dichotomy between the ways EID frames natural gas operations and the way they frame alternative energy operations becomes clear. While gas operations offer residents of the Marcellus shale region the opportunity to "revitalize the land" and "conserve" rural farms (all the while keeping water plentiful and safe), solar and wind “disturb land" and “contaminate” water (October 13, 2012, October 3, 2011). Natural gas is offered as the only choice, as it carries the "least land impact" (October 13, 2012). In summary they say of natural gas operations via horizontal hydraulic fracture drilling, “modern drilling techniques [have] dramatically reduced [gas operation's] environmental footprint to the point it is now far less than any other form of economic development we can imagine" (June 23, 2011). EID contends that natural gas operations are the pinnacle of environmental friendliness, with less of an impact than "any other form of economic development we can imagine," framing natural gas development as far ahead of everything else in terms of sustainability.

Besides energy sectors like wind and solar that present environmental concerns larger than those of natural gas operations, according to EID, there are also other sectors of the economy that are cited as environmentally destructive throughout the blog posts (September 23, 2011, May 26, 2011, August 16, 2012, February 9, 2012). This frame is used to refute the claims of fracking opponents in one 2011 blog post,

"Another woman travelled to Milford from out of state. She came to tell people that 'eventually all the fluid used will end up in the rivers.' You can listen to this nonsensical argument below. My editor won't give me the space to tell you all the ways this is completely untrue. You know what does end up in the river though, 
hundreds, no millions if not billions, of raw untreated sewage each year" (September 23, 2011).

Here Energy in Depth places the blame for contamination of water not on the extractive energy sector but rather on the sanitation sector that allows for untreated sewage to be discharged into rivers. Whether there is truth to this claim (it is unclear where the blog author is referring to, or what the measure of sewage is) or not, it serves to take the attention off of natural gas and oil operations and focus it onto an unrelated aspect of modern life. EID cites urban municipalities and tourism sectors as having a larger impact on water than natural gas operations in one blog post that discusses a proposed water withdrawal permit. They offer three reasons why the withdrawal is minimally detrimental in comparison to other withdrawals,

- "This decision cannot be a popularity contest with voters from unaffected areas who have already claimed far more of the water for themselves. Water permanently exported from the basin to New York City and New Jersey is 2,944 times the withdrawal proposed.

- The same day the DRBC decided it needed another hearing on this application it approved a new withdrawal of a similar amount for a Montgomery County golf course. Downstream recreation cannot trump job opportunities for upstream residents.

- XTO will be utilizing four-hundredths of one percent (0.04\%) of the total water New York City alone takes from the Delaware River Basin on a daily basis” (May 26, 2011). 
Here water usage in natural gas operations is compared to that of New York City and New Jersey residents as well as that of a golf course. Again this way of talking about water usage redirects the focus away from oil and gas operations and onto other aspects of U.S life that also impact fresh water supplies, seemingly minimizing the issue. Other issues that could affect water are also cited by Energy in Depth to move the focus away from oil and gas operations. They write a critical blog of the CNN coverage of Dimock, Pennsylvania, the site of controversial claims of methane contamination on the part of the oil and gas industry. EID accuses the reporting of being biased against the industry and asks, "Concerning the goats and nearby stream why did the director choose to leave out the mounds of goat and chicken manure along side the stream? There's a lot of methane there too!" (February 9, 2011). Whether goats, golf courses, sewage, or city centers, EID asserts that there are other more important sources of environmental harm that should be considered before oil and gas operations are scrutinized for their impacts.

Clearly, Energy in Depth responds to claims of environmental degradation on the part of the extractive oil and gas industry operating in the Marcellus shale region with claims of environmental stewardship, commitment, and minimal harm. This framing device is known as 'greenwash' - the use of environmental imagery and claims of environmental stewardship as a selling point for a product or practice (Laufer 2003, Reynolds 2004, Simon 2000, Stauber and Rampton 1995, Dahl 2010, Scanlan 2013). This framing device serves to reinforce the argument that natural gas that is just that, natural (the only resource used for producing energy that is colloquially described as natural), cleaner than the alternatives, and leading the nation over the bridge and into the clean energy future. Energy in Depth engages in impression management techniques to 
position the identity of the oil and gas industry as synonymous with environmental stewardship and concern. In the face of contamination claims, this framing device seeks to neutralize the potential for environmental and human health disruption presented by a large-scale oil and natural gas boom in the Marcellus shale region. 


\section{Scientific Imagery, Expertise, and the Facts}

"It's time to look to science - good science - to stop the fear mongering”

Energy in Depth employs the frame of scientific expertise, citing a dedication to the facts surrounding hydraulic fracture drilling operations in blog posts awash with scientific imagery and appeals to objective truth. Numerous examples of EID positioning the industry to be on the side of the facts and to employ rational scientific analysis when speaking on issues regarding hydraulic fracture drilling can be found throughout the Energy in Depth blog posts. In the face of an abundant amount of misinformation, according to the blogs, Energy in Depth frames itself as an educational group; it frames the fracking debate as a dichotomy of industry truth and oppositional myth; and it cites modern technology as the key element that negates environmental and human health concerns surrounding oil and gas development in the Marcellus shale region (October 13, 2012, October 10, 2012, October 18, 2012, October 17, 2012, October 16, 2012, October 16, 2012, June 14, 2011, June 15, 2011, September 23, 2011, March 13, 2012, July 27, 2012, July 23, 2012, July 30, 2012, July 17, 2012, July 23, 2012, April 18, 2012, April 8 , 2012, April 3, 2012, June 29, 2011, June 23, 2011, September 14, 2012, October 13, 2011, February 13, 2012, July 8, 2012, January 23, 2012, May 26, 2011, August 16, 2012, May 13, 2012, October 12, 2011, May 29, 2011, May 30, 2012, August 2, 2012, April 18, 2012, June 24, 2012, October 10, 2011, September 18, 2012).

Truth Vs. Myth

According to Energy in Depth, the debate surrounding natural gas development in the Marcellus shale region is rife with misinformation, distortions of science, and myth - 
creating trouble for the industry and for those seeking “objective” information concerning the social and environmental impacts of development. They write that, "Getting the straight, untwisted facts concerning any aspect of natural gas development is very difficult” (May 30, 2012). EID contends that this lack of information leads the public to unnecessarily question the environmental impacts of gas development, leading to stagnated development in parts of the Marcellus Shale region under moratorium - namely New York State. They write,

“Our slow progress has been due in large part to widespread misinformation about shale gas development and hydraulic fracturing, which has caused concern and confusion among the general public. Critics claim that the process can lead to groundwater contamination, negative health effects and environmental damage — allegations that are often unsubstantiated and untrue when examined thoughtfully” (March 13, 2012).

As previously discussed in the discussion of this thesis, Energy in Depth frames the oil and gas industry as in possession of the facts that those in opposition to natural gas development via horizontal hydraulic fracture drilling do not possess. They characterize this dichotomy as a situation of "truth versus politics," with the industry maintaining that the facts are on their side, while the opposition utilizes only politics to argue against natural gas development in the Marcellus shale region (October 13, 2012). Energy in Depth writes in a blog post entitled, “Truth or Politics: Which Will Set Our Natural Gas Opportunities Free?” 
"[EID Guest Blogger] reflects on truth versus politics in the playing out of the natural gas saga in New York State. He notes everything the other side says it wants is readily available from natural gas, yet they refuse to see it, preferring an alternative reality and narrative with nothing to back it up.

I started feeling a bit guilty for not addressing the latest stall tactic in NY with a push for a health impact review sooner. It's just that I've been getting so irritated with the anti-gas cult hypocrisy and ignorance that I decided its time to settle down (just a bit) and not get so worked up about them. Its about time to rest confidently in the facts, science, and warmth of my home comfortably and cleanly heated with abundant domestic natural gas. If the truth continues to perform as it has in NY, then we have the politics to fall back on...

...The culmination of facts, science, truth, comparative cost/benefit analysis, recent conversation with New York State DEC officials, and the extremist behavior of the anti-natural-gas-cult have recently given me a sense of calm over the issue" (October 13, 2012).

Here EID reveals the dichotomous "natural gas saga" as one where scientific truth and politics face off. On one side of the debate there exists the opposition, a group of people drawing a narrative from an "alternative reality," with "nothing to back it up." On the other side of the debate is the industry, represented by Energy in Depth, is the oil and gas industry, which is positioned calmly and "confidently with the facts" and with science on their side (October 13, 2012). The narrative of a calm and confident industry, with the "culmination of facts, science," and objective truth on their side is a sharp 
contrast to the hypocritical and ignorant “anti-gas-cult” (October 13, 2012). In another blog post entitled, “Being Loud is NOT the Same as Being Heard!” EID reveals this dichotomy again while comparing a rally of anti-fracking protestors in Harrisburg, Pennsylvania with an energy industry conference happening the same week. They write of the differences between the two groups of stakeholders,

"Much of the talk lately has centered around the anti-fracturing rally that occurred last Tuesday in Harrisburg and word from the antis is that all of their screaming in the capitol will lead to a moratorium on drilling in Pennsylvania... my guess is that it actually accomplished nothing in terms of effecting legislation. While all of the radicals were wasting their efforts on make believe issues, though, another meeting this week in Harrisburg brought the industry and the community together to discuss steps towards solving real issues effecting (sic) all parties in natural gas development.

I had the pleasure of attending Keystone Energy Forum's panel discussion on "Emerging Housing Needs and Opportunities in the Marcellus Shale Regions of Pennsylvania” Wednesday at Harrisburg Area Community College. At this meeting, three panels spoke and answered questions from a packed room... There was no shouting, everyone who wanted to speak was able to, and realistic solutions were suggested in a manner that is likely to see results. It was very impressive” (June 14, 2011).

While individuals at the anti-fracking rally are characterized as screaming radicals who "were wasting their efforts on make believe issues," that EID assures readers would 
accomplish nothing, individuals at the Keystone Energy forum spoke about solutions to “real issues" in an impressive manner, offering "realistic solutions" to problems "likely to see results” (June 14, 2011). This example offers a clear contrast of one side of the natural gas development debate in the Marcellus shale region that is characterized by hysterics and emotion (unlikely to offer any real solutions to environmental or social problems), and another side that realistically takes steps to work towards solving issues in a rational and scientific manner. Another blog also touches on the dichotomy in commitment to scientific rigor between those opposed and those supportive of natural gas as revealed at another public event, this time a Susquehanna River Basin Commission hearing in Milton, New York. They write,

"Anti-natural gas advocates showed up seeing the hearing as a target of opportunity to attack natural gas development in general. Though their wellworn claims and rhetoric didn't pass the scientific test put forward. For anyone interested in the facts, though, the hearing was a reassuring demonstration of the responsible manner in which the Marcellus Shale opportunity is being pursued.

Following the presentation on the monitoring network attendees had the opportunity to speak and ask questions...

Once questions concluded the floor was opened to public comment. From there things went downhill fast - very fast. This portion of the meeting was essentially turned into a circus of sorts where 20 or so people monopolized time to declare their resistance to the natural gas production. Some made highly technical arguments like gas drilling will poison the water forever and kill people 
(according to a board member of New York Residents Against Drilling or "NYRAD"). Keep in mind this is despite the fact that countless water testing by DEP and the Commonwealth's largest water utility has shown this to be false and has also debunked multiple claims. As USGS has reported in an exhaustive 20 year study there is much contamination in private wells but none has shown any contamination from toxic materials by natural gas production.

This SRBC public hearing was extremely informative and the presentations were extremely informative. The contrast of the Commission's professional approach with the quality of the testimony received from NYRAD true-believers was an eyeopener and we look forward to documenting more of this contrast" (September 23, 2011).

Energy in Depth specifically cites the contrast between those they consider "professionals," with science and facts on their side, and those they consider "truebelievers," with well-worn claims and rhetoric that "didn't pass the scientific test.” The behavior of both groups is generalized to represent the two opposing sides of the debate as a whole. "For anyone interested in the facts," the presentation of the SRBC was a "reassuring demonstration of the responsible manner in which the Marcellus shale opportunity is being pursued," and was "extremely informative." However, the comment period "monopolized" by the "NYRAD true-believers," is characterized not as educational or objective, but as a "circus of sorts," where individuals made scientifically-debunked claims and less than technical arguments (September 23, 2011). 
In sum, EID paints a dichotomy between those on the industry side who rely on facts, figures, and objective scientific assessments to make decisions about the fate of Marcellus shale development, and the anti-gas activists who "routinely distort science" (July 30, 2012). With “facts and science in short supply," anti-fracking individuals routinely "refuse all objective assessments provided on the safety of hydraulic fracturing," and are stuck in an irrational, and nonfactual fear of natural gas development via horizontal hydraulic fracture drilling (July 30, 2012). In the face of so much supposed misinformation, myth, and outright lies, EID tells its readers, "it is time to look to science-good science-to stop the fear mongering” (July 23, 2012)

\section{In Depth Energy Education}

Energy in Depth clearly frames their role as a research and educational organization dedicated to providing rational, scientific, and objective facts to stakeholders of the Marcellus shale region. This frame neutralizes their presence. They frame themselves not as a public relations initiative, in association with the largest multinational energy corporations, but as an objective research group in pursuit of scientific truth. Their website includes pages with titles like, "Fact Sheets," and "Studies.” A page entitled "Debunked!" which purports to "debunk" claims of the opposition, and reading lists of other industry blogs and web information all serving to frame the organization as a nonbiased research group (EID- Marcellus 2013). Scientific, educational, and researchrelated imagery is used throughout Energy in Depth's web content. This includes that of a page entitled "Library," which provides fact sheets, studies, and debunked oppositional studies and talking points below an image of a glass-enclosed, book-filled, library research room with a lone researcher sitting at a desk (EID Main 2013). Another section 
of the main Energy in Depth website is the blog “Archive,” which has pictures of hundreds of books throughout narrow library shelves, with links to Energy in Depth’s regional blogs, including "Energy in Depth Marcellus” (the subject of this thesis) (EID Main 2013). Lastly, the "Multimedia” page contains imagery of a computer lab of sorts with a row of shining computer screens. This page provides videos with hydraulic fracturing information from Energy in Depth, Chesapeake Energy, and a handful of news outlets (EID Main 2013). This imagery creates the "setting” of Energy in Depth, which can be imagined as one of a research institution, filled with rows upon rows of tomes of knowledge, and staffed with researchers digging for rational and objective information concerning natural gas development. The framing of Energy in Depth as a research organization is best described in their own words on the "What's EID?" page. They write of their goals in a way that clearly frames how they present their identity as a research and science-based institution,

“Energy In Depth (EID) is a research, education and public outreach campaign focused on getting the facts out about the promise and potential of responsibly developing America's onshore energy resource base...

On this site, you'll find fact sheets and videos and charts and graphs - some boiling down the steps involved in the development process, others straightening out the myths you may have heard about what we do and how we do it” (EID Main 2013). 
Energy in Depth Marcellus positions itself as a campaign created by the Independent Petroleum Association of America (IPAA) to "educate the world about natural gas, hydraulic fracturing and the extraordinarily important role these play in the future of Northeastern Pennsylvania and the Southern Tier of New York State” (April 8, 2012). EID frames education surrounding natural gas development as their main objective. They write in an April 2012 blog,

“... [Our] common goal [is] to raise awareness about the importance of natural gas development in our region (21 counties in Northeast Pennsylvania and Upstate New York). We aim to support the work of these constituencies in educating the general population about natural gas and hydraulic fracturing, while setting the record straight when the debate ventures into the absurd (as it so often does)” (April 8, 2012).

EID frames the debate surrounding natural gas and oil development in the Marcellus shale region as one that has a tendency to venture into the "absurd". Therefore, Energy in Depth must work to provide an objective education campaign to the public in order to "set the record straight" (April 8, 2012). EID frames themselves in the role of the educators - providing the facts to counter the misinformation surrounding horizontal hydraulic fracture drilling. As educators, they seek to play a role in the unfolding debate in the Marcellus shale region. They write in the same blog,

"You can expect us to be wherever the action is, confronting the anti-natural gas opposition with facts, but, most importantly, helping our friends get their message out... We hope to have constructive discussions with...members of the 
communities where we work about how to conduct natural gas development in the very best way possible. You'll see us participating in more panel discussions and more events for that purpose. We do not fear hard questions because we know the facts are on our side and we're committed to get them out” (April 8, 2012).

Again, this example of the way EID frames the debate surrounding natural gas development reveals a sharp contrast between the industry (with the facts on their side) and the "anti-natural gas opposition," who EID contends needs to be confronted with these facts. Energy in Depth reiterates that their commitment is to revealing the objective truths about natural gas development.

Though the entirety of the Energy in Depth blog posts seek to support natural gas and oil development in the Marcellus shale region, with blogs that frame the extraction of these resources in a positive light, there are a few examples within the sampled blog posts through which Energy in Depth explicitly seeks to educate various stakeholder groups whether readers of the blogs or others. The first example of this comes from a blog post that documents Energy in Depth’s presentation of the horizontal hydraulic fracturing process to a group of French and Canadian officials. The group received a tour from opponents of natural gas extraction in the Marcellus shale region previous to EID’s presentation, and EID vowed to clear up inconsistencies provided by those whom they do not consider experts. Energy in Depth representatives, in collaboration with Cabot Oil and Gas Corporation, took the visitors on a tour of a natural gas production site. First, they write of their oppositions' presentation, 
"As mentioned above, this smaller group was part of a larger tour.

Unfortunately, upon arriving in Montreal, members of the French delegation who had been informed by organizers they would be able view well site operations, learned this did not mean they would get to interact with industry on a well site. Rather, the organizers planned to drive them around in a bus and show them activity from a distance with resident explanations, rather than those of experts" (September 14, 2012).

Here EID clearly lays out the problem with the first tour: it was conducted "from a distance with resident explanations, rather than those of experts." Energy in Depth goes on to explain the difference between the oppositional presentation, and their own expert presentation. They write,

"We happily obliged and spent Sunday with this group and Cabot, in lieu of their original plans to tour the region with [a] local activist... The fact they chose to come with us was beneficial to them because... nothing clarifies the data more than seeing the process in action and speaking with the experts who perform these operations every day...

...They asked several questions pertaining to what they had heard the day before from our friends on the other side of the natural gas debate and were extremely pleased to hear our answers were supported by hard facts, numerical/quantitative data, and statistics.

... We brought them to the well site and where they asked questions pertaining to the development process from how does the drill turn for the horizontal leg to 
what kinds of additives are used in hydraulic fracturing and everything in between. The group had many questions and now they have information to report back to Canada and France directly from a source of experts.

... They greatly appreciated being able to come to Pennsylvania. More shockingly to them, they got the answers to those questions in full detail from an industry they had heard throughout the weekend from the activists they were with, was not very forthcoming with information.

...By the end of the tour the delegation felt they had learned a lot about natural gas development and they seemed pleased with the process. They all took notes and many got pictures and videos on site” (September 14, 2012).

Energy in Depth tells the story of an industry dedicated to transparency that happily took this group on a tour of a producing Marcellus shale well site. They assure readers that they, unlike the local activists, are experts whose evidence supporting fracking exists in the form of "hard facts, numerical/quantitative data, and statistics." Energy in Depth and Cabot answered all questions asked by the group, providing them with information to take back home "directly from a source of experts." The blog implies that the activist presentation did not provide any hard facts or quantitative statistics. It also accuses the activists of characterizing the industry as secretive and not transparent. Energy in Depth’s educational tour proved this implication wrong (September 14, 2012). In all, Energy in Depth presents themselves as an educational group, in possession of hard facts in support of shale gas development, and eager and willing to provide their 
expertise to those looking for the truth about oil and gas development via horizontal hydraulic fracture drilling.

A final example combines the dichotomy of irrational protestors versus rational supporters of natural gas development with the framing of Energy in Depth as an educational group, there to sort out the mess of misinformation and fear. This example comes from a Delaware River Basin Commission hearing about a proposed water withdrawal from XTO Energy, a subsidiary of Exxon Mobil. They write of the event,

"Contrary to what some folks trying to stop Marcellus development would like our leaders to believe, most sensible people do support responsible natural gas exploration. So it's only natural that the plans of anti-gas interests to use the Delaware River Basin Commission's June 1st hearings as a tool to pressure that agency into denying XTO's water withdrawal application has caused a lot of concern among landowners...Most have told us that they want to see this application approved so natural gas development can proceed, but fear it will be refused for reasons having more to do with politics than science. We certainly hope not” (May 29, 2011).

According to Energy in Depth, support for natural gas and oil development via horizontal hydraulic fracture drilling is the most "sensible" stance to take on the issue. For this reason, anti-fracking individuals can be framed as irrational individuals, who wish to see the XTO water withdrawal application "refused for reasons having more to do with politics than science" (May 29, 2011). They go on to offer their educational services, 
“The DRBC's docket (the agency's term for a decision, which also includes background data and any conditions attached to the approval) is encouraging because it is a straightforward explanation of the XTO proposal together with appropriate conditions based on the science of the matter at hand. Residents have every right to expect such a decision will be backed by sound science, of course, but legitimately wonder if this will carry the day against the emotional and irrelevant anti-gas misinformation with which the DRBC is currently being barraged. Many have turned to the Joint Landowners Coalition, Independent Oil and Gas Association of NY, America's Natural Gas Alliance, and Energy In Depth Marcellus for the basic facts that can be used in letters and testimony to clear the air and remind DRBC of just what the real scientific and rational reasons to approve the application are. EID Marcellus has already posted twice on this issue... and added the following three files as guidelines for pro-gas folks looking to encourage the DRBC to stand up for timely science-based decisionmaking” (May 29, 2011).

Energy in Depth posted multiple blogs, two "Call to Action" flyers, and a list of talking points, all linked to this blog post. This information is there to assist the, "Many [who] have turned to [a handful of public relations initiatives, including Energy in Depth] for the basic facts that can be used in testimony to clear the air and remind DRBC of just what the real scientific and rational reasons to approve the application are" (May 29, 2011). Energy in Depth reiterates that "sound science" substantiates the XTO Energy application for water withdrawal. They echo the frame that this objective evidence is in competition with the "emotional and irrelevant anti-gas misinformation" that the anti- 
fracking opponents have barraged the commission with (May 29, 2011). They provide information to residents to encourage the DRBC to "stand up for timely science-based decision-making” (May 29, 2011). In another blog post about the same water withdrawal application, EID speaks about the irrelevance of a public comment period that would be overwhelmed by oppositional individuals. They write, "The science is already plain... so the likelihood of additional substantive comments is nil and there is no need for additional time or delay, unless...this a popularity contest rather than a decision based on science" (May 26, 2011). So, in the face of a public comment period, and in a push for objectivity and "timely science based decisions," EID offers to train residents on talking points to take to the meeting, solidifying their role as industry educators. They write, "EID Marcellus has arranged for a place for everyone to meet prior to the hearing to exchange information and organize testimony. We'll have everything you need, plus some food and refreshments” (May 29, 2011).

Energy in Depth frames itself as an educational source for stakeholders in the natural gas development debate. Not only is their web-based presence framed as an educational source, but in this previous example they "exchange in formation and organize testimony," with New York residents to take and use in a water withdrawal permitting hearing. In this way, Energy in Depth uses its educational and objective institution frame to mobilize residents in support of natural gas development via horizontal hydraulic fracking. As EID frames itself in scientific, educational, and objective in their assessment of oil and gas development, they frame themselves as an objective source of information for those seeking to 'get the facts' about oil and natural gas development. EID becomes a major social actor in the public debate surrounding natural gas and oil development in the 
Marcellus shale region. Residents, landowners, city council members, and legislatures are all given the opportunity to draw references from Energy in Depth’s public relations material. A plain example of Energy in Depth utilizing their influence in the debate can

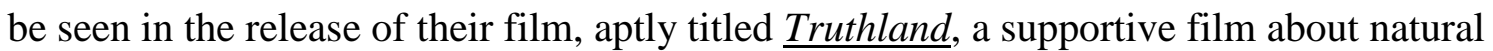
gas development in Pennsylvania, which is given out to residents, landowners, and law makers throughout the Marcellus shale region (and can be watched for free online) (July 16, 2012, June 24, 2012).

\section{Science and Modern Technology}

According to Energy in Depth, the modern technologies associated with natural gas and oil development negate any sort of human health or environmental concern that may arise surrounding the processes of development. Furthermore, there is an "overwhelming body of scientific evidence" that proves the technology is safe (October 12, 2012). Energy in Depth contends that the "truth" about the matter is that people simply "haven't experienced the problems speculated by the opposition" (October 16, 2012). The

problems speculated by the opposition have been negated by the fact that, "the hydraulic fracturing process at this point is definable as conventional for shale gas extraction and is proven safe on a daily basis” (April 18, 2012). Modern technology has conventionalized natural gas development to the point where horizontal hydraulic fracture drilling should not be considered abnormal or dangerous; it is simply the safest way to go about retrieving natural gas. This aspect of the frame reiterates that "science" is on the side of natural gas development. A quote from an Energy in Depth blog post exemplifies this frame, 
"Hydraulic fracturing began in the 1950's and the combination of high volume hydraulic fracturing and horizontal boring of wells has been used safely for many years to develop thousands of gas wells. Problems are few and becoming fewer all the time. And, unlike all those other innovations hydraulic fracturing has never seriously harmed anyone. Science.” (September 18, 2012).

Scientific rigor and modern technology both support the development of natural gas as a safe and clean. Decades of technological development have rendered problems "fewer and fewer all the time," so few that "hydraulic fracturing has never harmed anyone.” How has natural gas development via horizontal hydraulic fracture drilling become such a safe and trouble-free process? Energy in Depth reveals the reason in a one-word sentence, “Science.” (September 18, 2012). Technology has rescued residents of the Marcellus shale region from the negative aspects associated with natural resource extraction, like environmental and human health impacts. EID writes,

“...Modern drilling techniques has dramatically reduced [natural gas extraction’s] environmental footprint to the point it is now far less than any other form of economic development we can imagine. Every year, more wells are being drilled on single well pads, thereby further reducing land disturbance and the number of vehicle trips to drilling sites as companies have implemented closed loop drilling systems and now are close to recycling 100\% of brine/flow back water" (June 23, 2011).

Energy in Depth argues that the environmental footprint of the natural gas extraction process is now less than that of "any other form of economic development we can imagine," due to the use of "modern drilling techniques" (June 23, 2011). Not only 
that, but it becomes safer and safer every single year as technology progresses. Water is safe and contained in a “closed loop drilling system” that negates any oppositional concern over water quality or quantity. They write of the ability of modern technology to negate environmental and human health concerns associated with water,

"How to deal with the "produced water" that comes back up the well with natural gas is a frequently expressed concern of those opposing natural gas exploration in our area. Norse [Energy Corporation], in cooperation with Texas A\&M engineers, has addressed this issue by creating a filtration system that operates within the compressor stations serving each drilling unit or group of units. Once again, technological innovations by the industry are rendering issues moot as fast as they can be raised" (October 10, 2011).

Technology created by Norwegian energy corporation Norse, and university engineers in Texas, have been "rendering [water] issues moot as fast as they can be raised" (October 10, 2011). Again, technology has negated the need for environmental or human health concerns surrounding natural gas and oil development. Energy in Depth continues,

"Norse has been striving to improve its production process by implementing these filtration techniques as they become available. This facility is not only well maintained, but is an example of leading edge technology. The operators are well-trained and know exactly what to do with each product extracted out of the water - one of the many steps Norse is taking steps to ensure both safety and 
efficiency. Norse Energy, like most gas companies, has a strong incentive to protect the environment using such approaches" (October 10, 2011).

This quote exemplifies the way in which Energy in Depth presents the oil and gas industry with an air of expertise. They operate well-maintained facilities and utilize only "leading edge technology". They know "exactly" what to do with contaminated produced water from oil and gas operations, ensuring both "safety and efficiency," an approach that protects the natural environment (October 10, 2011). Another blog post cites the "Best Management Practices" used to control contaminated produced fracturing water. They write,

"Understandably, concerns with endocrine disruptors among any of the chemicals utilized should not be minimized. Nevertheless, as with any other process that uses chemicals, there are protective measures in place to prevent exposure. The industry works to protect water aquifers by mitigating potential risks, through the utilization of Best Management Practices. These practices have been developed and standardized by the American Petroleum Industry...These guidelines include mitigation strategies to minimize surface impacts, well design and integrity guidelines, and water management strategies.

Moreover, just because the chemicals are present does not mean people will be affected. The chemicals (like the gasoline in your car's tank) are contained and separated from exposure routes. Should there be a situation where exposure can happen (human or mechanical failure) these already developed best practices are 
designed to minimize any impact. Many are found in regulations and others are simply a matter of industry practice” (July 27, 2012).

"Standardized" protective measures, "integrity guidelines," and “water management strategies" all serve to protect ground water, surface water, and “mitigate potential risks" according to EID (July 27, 2012). They reassure readers that the expertise and the very "Best Management Practices" of the industry ensure the safety of natural gas and oil development (July 27, 2012). Still, a level of risk exists. Though chemicals are "contained," and as normal as "gasoline in you car's tank," accidents occur, forcing industry to fall back onto "best practices" to minimize impacts (July 27, 2012). An explosion at a compressor station in Springville, Pennsylvania evoked the frame of cool, calculated, scientific expertise in a blog post that documented the incident. They write of the explosion,

"We learn natural gas development, like any industry, is not 100 percent risk free, but teams of scientists and engineers work daily to ensure those risks are minimized. As much as we would love to continue simply telling you about the remarkable safety precautions at compressor stations, we now have an excellent example of what can go right when things go wrong. It is a testament to the dedication of companies like Williams making safety their number one priority in everything they do" (April 18, 2012).

Though, now admittedly not risk-free, Energy in Depth assures readers that risks of problems such as an explosion at a compressor stations are anomalies, and that "teams of scientists and engineers work daily to ensure those risks are minimized" (April 18, 
2012). They write, quoting the NY DEC that, “'hydraulic fracturing design is an iterative process, i.e., it is continually improved and refined as development progresses and more data is collected"' (July 8, 2011). The "iterative" nature of the natural gas extraction process assures readers that each and every day the industry increases its expertise, refining and perfecting the process, minimizing human and environmental impacts. According to the NY DEC and EID, both the expertise of the industry, and "'technological considerations favor the use of horizontal drilling for shale gas development,"” (July 8, 2011).

These technological and scientific considerations come into play in a 2011 blog post entitled "A Case of Pipeline and Propane Phobia," which purports to give the facts about natural gas pipeline development in the Marcellus shale region. They use a few examples of industry expertise, best practices, and technological considerations negating the need for environmental concern. They first offer two emboldened "Facts" that offer technological solutions to environmental worry, "Fact: Pipeline construction will be specially timed to minimize any negative impact on migratory birds...Fact: High tech drilling techniques will be employed in sensitive environmental areas (original bolds)” (October 13, 2011). The "Fact" is that "High tech" processes and "specially timed" development will reduce the risk to wildlife and "sensitive environmental areas," according to EID (October 13, 2011). One such type of "environmentally sensitive area" includes wetlands. Specifically designed technologies will mitigate the risk to these areas. According to EID, "The [pipeline] is being required to cross underneath rivers, streams, and wetlands using special equipment to minimize impacts" (October 13, 2011). Again, modern scientific technology has negated concern for environmental or human health 
risks associated with the process of extracting, transporting, and processing natural gas and oil. The modern technology associated with horizontal hydraulic fracture drilling for oil and natural gas is not the problem, it is the solution to the problem; rendering environmental and human health safer and safer every single day.

Energy in Depth uses scientific imagery as a major frame in the narrative surrounding oil and gas development in the Marcellus shale region. Throughout the sampled blog posts examples can be found of various subthemes including the posturing and self identification of Energy in Depth as an educational and research group; the dichotomy of industry experts, privy to objective scientific reason, and emotional objectors in denial of the facts; and the presentation of modern extractive technology as negating the need for environmental and human health concern (October 13, 2012, October 10, 2012, October 18, 2012, October 17, 2012, October 16, 2012, October 16, 2012, June 14, 2011, June 15, 2011, September 23, 2011, March 13, 2012, July 27, 2012, July 23, 2012, July 30, 2012, July 17, 2012, July 23, 2012, April 18, 2012, April 8, 2012, April 3, 2012, June 29, 2011, June 23, 2011, September 14, 2012, October 13, 2011, February 13, 2012, July 8, 2012, January 23, 2012, May 26, 2011, August 16, 2012, May 13, 2012, October 12, 2011, May 29, 2011, May 30, 2012, August 2, 2012, April 18, 2012, June 24, 2012, October 10, 2011, September 18, 2012).

According to Laufer (2003), “corporations creatively manage their reputations with the public, financial community, and regulators, so as to hide deviance, deflect attributions of fault, obscure the nature of the problem or allegation, reattribute blame, ensure an entity's reputation and, finally, seek to appear in a leadership position” (Laufer 2009, 255). Stauber and Rampton (2002) reveal the ways in which the posturing 
of expertise is widely used by public relations organizations and destructive multinational corporations in strategic perception management (Rampton and Stauber 2002). The framing of the natural gas and oil industry boom in the Marcellus shale region as backed by a sound and objective scientific truth works to do just that. It reinforces the expertise of the oil and gas industry, places them in a leadership position, and ensures a positive reputation for the energy conglomerates taking part in the boom. Environmental or human health deviance is hidden by a veil of safety and responsibility based in modern technology and the scientific method that negates the concern for such deviance. 


\section{Discrediting “The Natural Gas Resistance Cult”}

(i.e. the Anti's, the Greenies, the Anti-Gassers, the Natural Gas Opposition, the Green Elite, Anti-Gas Forces, the Anti-Gas Crowd, the Anti-Gas Bullies, Opponents of Responsible Energy Development, Anti-Gas Zealots, Anti-Gas Obstructionists, American Production Opponents, or Natural Gas Detractors)

A major role of public relations organizations, 'research centers', and 'think tanks' operating in support of energy and chemical industries in what Faber (2008) calls the 'polluter industrial complex' is to discredit opponents of certain extraction processes and the environmental movement in general (Faber 2008, Stauber and Rampton 1995, and Jacques et al. 2009). Lockard (2010) points out that extremely profitable, but environmentally destructive extraction industry practices often lead to an industry need to discredit those vocally opposed (Lockard 1998). This is a stated goal of Energy in Depth which seeks to "respond to the attacks" of those they see as "American production opponents” (Russell 2009). They write in a passage that not only sums up the need to address their opponents, but also draws on other themes of scientific expertise and nationalism,

"Given the truth of what's behind the natural gas resistance cult, one might ask why we should bother to address them? Well, unfortunately, we have to do so, for the simple fact they contaminate the innocent minds not familiar with the facts and they are simply harmful to our economy, our property rights, our personal opportunities, our nation's security and well-being. They are just another 'occupy' movement. This group may not be spreading stuff on the streets, but they are full of it and they are filling our newspapers and board meetings with it” (EID October 13, 2012). 
This clear goal of discrediting the opposition to 'fracking' for natural gas and oil is pervasive in the blog posts sampled in this thesis. Individuals and groups that call into question the safety or legitimacy of any aspect of natural gas and oil extraction are framed as irrational, elitist, and radical outsiders who rely on misinformation and wish to stop natural gas development by any means necessary. They also are placed in stark opposition to the ideals of liberty, patriotism, environmental commitment, and scientific truth espoused by Energy in Depth. The group is consistently generalized as a cohesive group of scientists, academics, environmentalists, film makers, and protestors, routinely labeled anything from 'the natural gas resistance cult', 'anti-gassers', to “anti’s”, to simply “they” by Energy in Depth (October 13, 2012, April 22, 2011).

\section{Militant Extremists and the Natural Gas Wars}

Energy in Depth paints a picture of the debate surrounding natural gas as a "battle" between good and evil, between pro-gas and anti-gas. Militarized language is consistently used to describe the discourse between industry and those who may question the legitimacy of certain oil and gas extraction activities. IPAA frames the Energy in Depth initiative as a tool in the "battle" against regulations, taxes, and criticism of the industry (Russell 2009). It is a response to the idea that "American oil and natural gas producers are under attack on many fronts” (Russell 2009). Questions or disparities about society's production of energy and its potential social or environmental impacts are framed as "attacks" by "anti-gas forces" or "anti-gas zealots" who are engaged in a "war on natural gas development” and “dedicated to fighting fossil fuels of all kinds” (Sept 23 2011, April 30 2012, July 30 2011, April 8, 2012 July 30 2011). Indeed, anti’s are claimed to routinely attempt to 'attack' and' intimidate' town councils, "besiege 
townships”, “torpedo” natural gas development, and assault local residents, landowners, individual oil and gas companies, and the industry as a whole (June 7, 2011, May 26, 2011, July 17, 2011, October 2, 2011, May 16, 2012, October 15, 2012)

Hyperbolically, individuals seen as the oppositional "force" against the oil and gas industry are said to be attempting to "kill the drill” with regulatory challenges or attempts for natural gas moratoriums and bans (October 13, 2012). Language used by Energy in Depth to describe their behavior and stance is arguably symbolic and metaphorical, though it is in no doubt militarized. However, Energy in Depth makes very literal claims about tendencies towards violence held by the 'anti's'. In a 2011 blog post, Energy in Depth cites comments made on a Youtube video as telling of violent tactics employed by opponents of fracking. The video itself presents alleged water pollution from a natural gas production site. However, these claims are of secondary concern to Energy in Depth, who is focused on the comments made by other users. EID cites a comment made by Youtube user that suggests "burning their trucks at night" in response to contamination. This Youtube comment became the subject of a blog post entitled, “Anti-Marcellus Extremist Recommends Arson” where EID suggests that the comment is telling of a larger tendency towards violence,

“...We're seeing more and more [violent tactics] as a small but aggressive group of opposition folks deface signs with slurs and try to intimidate pro-gas landowners and businesses with personal insults and threats. A Cabot Oil \& Gas building was recently torched, which may be still another case. [Youtube User's] approach has been adopted by far too many on his side” (April 22, 2011) 
Violence, in the EID narrative, becomes something that oppositional groups and individuals are willing to resort to. In another example, EID contends, "if [our opponents] cannot win honestly through the normal courses of action, they are quite willing to go to 'direct action,' code for violence and other forms of not so civil disobedience” (July 17, 2011).

Words like "forces", "battle”, and other militarized language becomes very real as EID frames the opposition as a mobilized "force" willing to resort to violence. It paints a very extreme picture of the natural gas debate in places like West Virginia, Pennsylvania, or New York. It presents a dichotomous view of a complex situation involving multiple stakeholder groups with diverse standings on the issue of hydraulic fracture drilling for natural gas and oil. It simplifies the situation into a war between opposing factions, and creates a generalized "other" to rally against. This becomes a reoccurring theme throughout blogs that cover activity of oppositional groups and individuals who "are easy to recognize when they are in uniform" (June 9 2011). Consistent generalizations of individuals and groups who question the legitimacy of oil and gas operations creates a singular entity out of a myriad of stakeholders for the industry to oppose and discredit.

According to CNBC, public representatives from the oil and gas industry have recommended using U.S Military psychological operations (PSYOPS) techniques to influence communities in the Marcellus shale region (DeMelle 2011). According to an External Affairs Manager at Andarko Petroleum, a corporation that supplies funding to Energy in Depth, PSYOPS strategies can be useful in dealing with local opposition to oil and gas development (Russell 2009, DeMelle 2011). At a conference entitled, "Media \& 
Stakeholder Relations: Hydraulic Fracturing Initiative 2011” a representative from Andarko stated,

"If you are a PR representative in this industry in this room today, I recommend you do three things... Download the U.S Army/Marine Corps Counterinsurgency Manual, because we are dealing with an insurgency. There's a lot of good lessons in there, and coming from a military background, I found the insight in that extremely remarkable. With that said, there's a course provided by Harvard and MIT twice a year, and it's called 'Dealing With an Angry Public.' Take that course... It gives you the tools, it gives you the media tools on how to deal with a lot of the controversy that we as an industry are dealing with” (DeMelle 2011).

It is clear that at least some public relations representatives working for the energy industry view stakeholders with differing views about the fate of energy production to be hostile detractors, in some cases warranting the title of "insurgent". Both the language used by Energy in Depth and those in public relations support this argument. According to oil and gas company Range Resources,

“We have several former PSYOPS folks that work for us at Range because they're very comfortable in dealing with localized issues and local governments... having that understanding of PSYOPS in the Army and in the Middle East has applied very helpfully here for us in Pennsylvania” (DeMelle 2011).

Energy in Depth not only portrays the opposition as militant and potentially violent in their tactics, but their views are also portrayed as extremist. These views might range from the unwavering opposition to hydraulic fracture drilling to a full-on anti- 
capitalist sentiment (April 30, 2012, October 10, 2012). The strategy here may be to question the origin of the opposition's claims. These claims are suggested not to be from experience, facts, or knowledge, but rather from some sort of "radical” ideology. It is this ideology that oppositional groups rely on in protest, in conference proceedings, in the media, and in academic publications.

This framing of groups as inherently radical is revealed in a blog post entitled, “Natural Gas Opponents’ Balloon Bursts in Bessemer” (October 10, 2012). EID routinely reports on groups engaged in protest activity or meetings critical of the oil and natural gas industry's operations in the Marcellus shale region. Representatives were “tipped off,” and followed a group known as the Shadfish Environmental Justice Collective to a protest in front of Royal Dutch Shell operations in Bessemer, Pennsylvania (October 10, 2012). The blog post that followed this event, besides critical of the organization's viewpoint, size, knowledge of oil and gas operations, and character, also questioned the ideology of the group,

\footnotetext{
"What the collective is, and so many are, is an anti-capitalist extremist group masquerading as an environmental organization and using natural gas development as a target of opportunity. Their rhetoric makes it explicitly clear. They couldn't care less about what Shell is doing in Bessemer. Rather they oppose Shell for what it is... No corporation can do anything right in the collective's eyes." (October 10, 2012).
}

The industry portrays this group as an anti-capitalist front using a Shell oil and gas production site as a target to rally against capital. Portrayed as radical, the group’s 
questions or concerns are irrelevant; it is their character and potential ideological leanings that warrant a blog post by EID’s Northeast Marcellus Initiative. This portrayal is not limited to small groups of demonstrators, but academics as well. In one blog post, an academic study from Cornell University, concerning economic impacts resulting from hydraulic fracture drilling for oil and gas, was subject to this criticism. The "true" intentions and underlying ideology of the study's funders were called into question. EID refers to the funding groups as "socialist outfits dedicated to using the fruits of capitalism to stop natural gas development” (July 30, 2011). These groups were the Park Foundation, and the Heinz Endowments. In another post, anti-fracking groups are generalized to be associated with the Occupy Wall Street protests, as well as Hugo Chavez, further questioning their ideological commitment to capitalism (October 13, 2012). These embellished claims hark back to the framing of anti-strip mining groups and individuals in West Virginia by $20^{\text {th }}$ Century energy conglomerates. Lockard (2010) writes,

"Some measure of the spirited self defense of [energy conglomerates] is evident in the comment of the vice-president of Consol in a 1968 speech denouncing conservationists as: 'stupid idiots, socialists, and Commies who don't know what they're talking about. I think it is our bounden duty to knock them down and subject them to the ridicule they deserve'” (Lockard 2010; 335).

While not always cited as anti-capitalists, opposition groups are also portrayed as 'anti-growth’ in their environmental ideology (May 13, 2012, October 7, 2011). Bans and moratoriums are said by EID to be driven by this environmental ideology, and are repeatedly referred to as "special interest laws" (April 18, 2012, May 16, 2012). 
Environmentalism is framed as a fixed position; one that Energy in Depth goes as far to say is “their religion” (July 18, 2012). It is an unwavering creed by which the anti's will adhere to no matter what the consequences may be. This is a radical "worldview that contends that anybody who doesn't agree is conspiring against them," which is revealed in the hard line resistance to natural gas development (July 30, 2012). Tied to socialist tendencies, environmentalism is also portrayed as dichotomous to the tenets of personal property, liberty, and the constitution (May 16, 2012, May 30, 2012). These claims and depictions of environmentalism in general as a relentless ideology negate the need to investigate positions of the various stakeholder groups who may question or oppose natural gas development; it works to delegitimize their position as simply a matter of false conviction.

Irrational, Hysterical, and Plain Wrong

As the label "natural gas resistance cult” implies, individuals and groups opposed to natural gas development through hydraulic fracture drilling are portrayed as emotional, irrational, hysterical, immature, and even "brainwashed"; deepening their inexplicable commitment to environmentalism as cultist (June 15, 2011, September 23, 2011, March 9, 2012, March 15, 2012, October 13, 2011, November 10, 2011, July 17, 2011, May 26, 2011, May 13, 2012, May 29, 2011, May 16, 2012, October 10, 2012, October 17, 2012, October 16, 2012, June 14, 2011, April 3, 2012, October 13, 2011). Their claims are characterized as “...'balderdash,' 'claptrap,' 'hokum,' 'drivel,' and 'quackery,"” and according to EID, "We are reminded of all these terms when we try to analyze what the anti-natural gas activists are up to when we listen to most of their statements” (July 18, 2012). 
The expertise of individuals who speak publicly or produce articles that call into question the development of natural gas through hydraulic fracture drilling is routinely called into question by Energy in Depth (Februrary 2, 2012, June 24, 2012, May 16, 2012, May 29, 2011, September 1, 2011, March 12, 2012, October 13, 2011, June 23, 2011, March 9, 2012, April 3, 2012) EID contends in a blog post entitled, "Together We Have It All With Natural Gas!” that “the most opinionated people haven't taken the time to do any research on what they're protesting" and are "more wedded to ideologies than facts" (June 24, 2012). This claim is exemplified by numerous anti-fracking speakers at a pipeline conference in August 2011 where EID calls into question the speakers' knowledge of various aspects of pipeline development, they write,

"Is it just me? Or is it that [speaker's name] has no clue what he was talking about? So far as I can tell, he is neither an engineer nor a geologist and he has no zoning expertise but he pontificates on all these subjects... I did expect he might know something about tax structures, but I was disappointed" (August 13, 2011).

Another speaker at this event was said to "venture into areas outside his expertise," and EID generalized this characteristic as telling of the movement against natural gas, stating, "If this is the best expertise the anti-gas obstructionists can muster... well, you get the idea" (August 13, 2011).

A blog written less than a month later questions the expertise of a Utica, NY newspaper journalist who wrote an article about the potential detrimental aspects of oil and gas development through "fracking”. The article is characterized as "appalling," "biased," and "infactual," "shoddy journalism" relying on "unsubstantiated accusations, 
assertions and assumptions” (September 1, 2011). The author's expertise and his career as owner of a farm and garden store are questioned, "Interesting that an owner of a Farm Garden Center is an expert on the composition of hydraulic fracturing fluids but I digress” (September 1, 2011). This ‘digression’, however, did not last long. EID goes on to say, “Of course we wouldn't expect someone who manages a garden center to have a detailed understanding of toxicity, how it is reached and levels at which certain chemicals can be harmful” (September 1, 2011). In conclusion, EID says of the article, "At best this is an individual speaking on a topic of which he has no knowledge, at worst its an outright lie” (September 1, 2011).

Other individuals were called into question because of their careers outside of the oil and natural gas industry and subsequent lack of expertise. Sometimes the same individual is targeted in multiple blog posts (March 9, 2012, April 3, 2012, August 13, 2011, June 29, 2011). One such individual's expertise was questioned in two blog posts within a month,

“We notice an individual named [individual's name] seems to be the latest cause célèbre for the anti-natural gas crowd. Put forth as a member of the Dallas Federal Reserve Bank Advisory Committee, she seems to be everywhere at once in upstate New York as of late. Her routine involves an attack on the natural gas industry as being a supposed Ponzi scheme. Of course, nothing could be further from the truth. Who is she in real life? She's a goat farmer, cheese maker, former model, and committed anti-natural gas activist who chooses to present herself as an independent economic expert. Her message simply sells better that way. 
Now before all you anti's scream ad hominem, let me say I am a fan of goat farmers, cheese makers and models... It's just this - I don't go to these folks for advice on oil and natural gas development” (March 10, 2012).

Calling on this individual's previous and current employment is done in efforts to discredit her as a credible source for information regarding the economic impacts of oil and gas development via hydraulic fracture drilling. The fact that employment as a model or a cheese maker seem so far from the energy sector serve Energy in Depth's narrative well. EID later refers to the same individual as the "Mother of All Spin" who goes "into the weeds" in her vague presentations with absurdity, spin, and bogus, overstated theories. Her presentations are characterized as, "taking something somebody told her, that she either never understood, or never wanted to understand, and spinning a tale to fit her needs." This is in stark dichotomy with industry expertise, "Petroleum engineers are well educated, seasoned professionals who use their best judgment" (April 3, 2012). Rather than expertise, as exemplified by these detractors employment, those opposed to oil and gas rely simply on spin, emotion, and fear to argue against fracking.

Framed as based in an irrational fear, oppositional claims run counter to the narrative that horizontal hydraulic fracture drilling for oil and natural gas is proven safe by science. Energy in Depth discredits questioning stakeholders' viewpoints as subjective and based in non-empirical sources of evidence with no basis in reality. Indeed, emotion and misinformation drives the viewpoints of those against fracking (May 29, 2011). Name-calling used by Energy in Depth ranges from "whacko" to "true-believers" in attempts to directly question the mental state of individuals and groups opposed to fracking (October 13, 2012, July 30, 2011). One blog equates the opposition to hydraulic 
fracture drilling in the Marcellus shale to a "witch hunt," citing moral panic, mass hysteria, ignorance, superstition and alarmism from those "desperate to believe the industry is evil" (October 16, 2012). In another blog entry, the author questions the character of organizations like "Food and Water Watch,” "Environmental Working Group," "EarthJustice,” and the creators of the documentary "Gasland,” stating bluntly, “These aren’t nice people” (July 14, 2011). Josh Fox, director of Gasland, and often his supporters, are routinely dismissed by Energy in Depth. In one blog post, EID criticizes the dress and questions the mental state of Fox and his supporters,

"Fox has a regular cult following. He and his little 'band of the brain-washed' looked like they just crawled out of a coal mine... unkempt and filthy. What is with that? There was one straggly man who held up \$5 every time a pro-driller spoke. I wished later that I had told him he should spend it on a bath and a haircut. I wonder if Fox is hiring people who live on the street to act as his adoring little followers. I kid you not... they were grimy” (June 15, 2011).

A particular brand of behavior underlines the emotional, hysterical, and desperate character of anti-fracking groups, according to Energy in Depth. Energy in Depth describes what basically amounts to routine unruly, exaggerated, and melodramatic conduct on the part of the 'anti's'. Journal articles, conference presentations, letters to the editor, and town hall proceedings that anti-fracking individuals are involved in are awash with juvenile "scare mongering", "screams and wails", outbursts, uproar, intimidation, disruption, temper tantrums, madness, and apocalyptic sensationalism according to Energy in Depth (October 16, 2012, August 13, 2011, July 17, 2012, February 9, 2012, Feb. 13, 2012, March 15 2012). Language like this works to draw a clear line between the 
objective and rational scientific truth upheld by the industry and the irrational, hysterical, fiction employed by the 'anti's'. Pictures portraying the opposition as hysterical and misinformed range from political cartoons with people running frantically, arms aloft, shouting, "The sky is falling! The sky is falling!” to a picture of blindfolded individuals walking in a line with the caption, "Blind leading the blind" (July 17, 2012, July 17, 2012).

Since the truth is not on the side of the 'anti's,' they must rely on melodramatic behavior to get their points across. According to EID, oppositional groups try to prove their case through the use of "theatrics", stage props, "magic tricks", "smoke and mirrors", and other trickery akin to a "carnival house of horrors" (May 16, 2012, Oct. 2 2011, November 10. 2011, June 23, 2011, January 23, 2012). For example the case of potential water contamination caused by natural gas production in Dimock, Pennsylvania was described by EID as inundated with, "stage props, backdrops and inflatable scenery deployed as part of the continuing saga known as Dimock," as well as "pomp, circumstance, and fanfare," discrediting the potential drinking water contamination in the community as erroneous (January 23, 2012). Individuals and groups that travel around the Marcellus Shale region speaking at various events about the potential environmental or social impacts of large-scale natural gas development are characterized as being engaged in "road shows", "carnivals", "magical mystery tours”, "dog and pony shows" and “circus-like parades" (October 2, 2011, November 10. 2011, June 15, 2011, June 23, 2011, April 8, 2012, April 30, 2012, July 27, 2012, Spetember 23, 2011). This language and these claims call into question both the reliability of these activists (as compared to traveling circus performers), as well as the validity of their claims (based in 
an irrational magic). As framed by EID, activists must rely on theatrics and carnival spectacles because their evidence of public health or environmental disruption does not speak for itself.

Since, according to Energy in Depth, anti-fracking groups do not have the facts of science on their side, their numbers are small, and they must rely on exaggeration. Not only do they exaggerate their claims, but, "they need to be loud to make their numbers seem closer to those projected” (June 14, 2011, May 26, 2011). Misrepresentation of numbers is routine in demonstration against natural gas development via horizontal hydraulic fracture drilling according to Energy in Depth (July 30, 2012, June 14, 2011, March 15, 2012, June 29, 2011). The group is portrayed as a "vocal minority,” loud, but of an unpopular position. This is dichotomous with the "silent majority," that EID claims to represent (October 16, 2012). According to EID, “Most Americans enjoy affordable energy and want to produce more," leaving the vocal minority wondering, "how to advance a political agenda in a democratic society where the majority is not on their side” (September 14, 2011). To make their claims seem relevant they must rely on the "liberal use of exaggeration" (Sept 14, 2011). Energy in Depth contends that this exaggerative tendency is the "one thing that ties together opponents of responsible energy production,” and that the misstatement of fact is routine (September 14, 2011). Disruption of events on the part of the anti's is also common throughout Energy in Depth's narrative of the natural gas debate. The lack of objective truth on the side of those opposed to fracking calls for a need to be loud and disruptive in their behavior. Disruptions at one such event "demonstrated the immature and desperate nature of the 
anti-natural gas movement" and left EID asking, "Should we call the police or their parents?” (March 15, 2012). EID characterizes this behavior with a quote,

"'Disruption is a tool of a desperate person whose narrative has failed to gain traction, 'disruption' being what we call it when adults do it, 'temper tantrum' when it's a child.'...Well... there were eight people in Harrisburg today that left me wondering whether I was in a hearing room in out state capitol or in my grandmother's daycare center" (March 15, 2012).

As the preceding quotes reveal, the very character of the fracking opposition is often called into question by Energy in Depth. They are framed as illogical, juvenile, desperate, and deviant in their opposition. Energy in Depth goes as far to say that,

"Their character is akin to a substance addict who simply refuses to see the harm in their behavior, refuses to change their dysfunctional thinking, and refuses to look through the lens of reality" (October 13, 2012).

Not only are anti-gas individuals and groups irrational with viewpoints based in emotion, rather than science, they are also portrayed as hypocritical in their own reliance on fossil fuels, deepening the absurdity of their claims. It is the stance that contends if an individual uses or relies on fossil fuels to navigate through society, then it would be hypocritical for them to protest or question the production or consumption of fossil fuels (October 13, 2012, October 10, 2012, October 15, 2012, October 17, 2012, July 27, 2012, July 30, 2012, June 7, 2012). EID contends in a passage with undertones of nationalism and the subsequent rejection of it by anti-fracking groups that, "many anti-gas protestors consider themselves 'environmentalists' yet they have no problem using the imported 
fossil fuels from countries with less regulation than we enjoy" (June 7, 2012). A group of musicians, visual artists, and actors known as “Artist Against Fracking,” that hold concerts and demonstrations, and produce web content that questions large scale development through horizontal hydraulic fracture drilling, was decried by EID in one blog post as, "continuous and profligate users of energy produced by natural gas and coal” (October 15, 2012). EID asks the audience to,

"Just consider how much energy is consumed at one of these anti-gas concerts... A massive amount of gas and coal is burnt to light a 10,000 seat arena and fill it with sound... Think of the energy involved in televising one of these travesties or to build the big screen, hi- def television sets on which they're viewed or even to coax fans into art exhibits that always take place in population centers and venues heated with natural gas” (October 15, 2012).

Individuals and protest groups are also portrayed as hypocritical due to the use of fossil fuels to simultaneously denounce them. Often their true intentions come into question, as do the methods by which they came to be at a demonstration, as "these activists relied on petroleum fueled vehicles to get them to and from Washington, D.C" (July 30, 2012). Another demonstration was held by a group that vowed to show that the reliance on fossil fuels, and the fossil fuel extraction processes is inherently harmful to the environment. This stance was targeted as hypocritical by EID, who posited,

"I guess this means the giant plastic signs the protestors held up was unsafe and unclean. The same must go for the microphone they used, the computer they used 
to upload their magnificent thoughts, the magic markers they used to make the other signs and many of the clothes they wore" (October 10, 2012).

Individuals living in the Marcellus region who oppose high speed natural gas development via hydraulic horizontal fracturing processes are also cited as hypocritical, EID writes, "These include folks like my neighbor, Bronx born and bred, who squats on a 0.74 acre parcel and proceeds to tell the rest of us what we can or can't do with our land and resources. A couple of nights past, I saw him in town and he stated it was getting chilly, so he was going home and firing up the gas heater! He never grasped the irony" (October 17, 2012).

Claims of hypocrisy are not limited to activists and demonstrators. A paper written by a Cornell $\mathrm{PhD}$ student that tested the relationship between natural gas extraction processes and infant health became the target of the hypocrisy frame. On this blog, a picture of a power plant reportedly owned by Cornell was captioned, "Some Very Rich Irony - Cornell University's New Combined Heat and Power Plant Which Employs Natural Gas and Solar Power to Meet the Needs of Researchers Such as [Author's Name] Who Attack Gas" (July 27, 2012). These claims of glaring hypocrisy and irony in the use of the tools of a post-industrial, fossil-fuel civilization to question reliance on fossil fuels (like natural gas) serves to discredit the environmental movement as complacent and disingenuous in claims of environmental advocacy.

\section{NIMBY Elites}


Lastly, Energy in Depth frames individuals and groups opposed to natural gas development via horizontal hydraulic fracture drilling as elitist outsiders, often from urban areas, who don't understand the benefits of natural gas production in rural areas. Those opposed to natural gas are consistently portrayed as people who do not reside in rural communities affected by development, and very often are from urban regions completely separate from issues of energy development (April 18, 2012, April 16, 2012, August 13, 2011, July 17, 2011, July 30, 2012, March 13, 2012, September 23, 2011, June 5, 2011, October 15, 2012, October 16, 2012, October 17, 2012, October 18, 2012, October 13, 2012). Whether they're from New York City, Philadelphia, Pittsburgh, Washington, D.C, or Ithaca, oppositional groups are often portrayed as urban outsiders who don't understand the need for natural gas and oil development of rural residents in shale regions. According to EID, "The anti's have drawn a line in the sand and are busing in folks from urban areas to try to tell us what we can do with our water and how much economic development we can have" (May 26, 2011). This argument is used most often in reference to debate over moratoriums in New York State and the Delaware River Basin. There is a disregard for the perspective of rural residents that is said to come from New York City residents with a "Tribeca view of the world," who may now live in shale producing regions, but whose "hearts and heads... are still somewhere east of the Hudson River" (October 15, 2012, June 5, 2011). New York City is not the only source of fracking opposition; EID states that three of the most urban counties in Pennsylvania and the city of Philadelphia are "hotbed[s] of anti-gas activity," and,

“...the homes of so many self-serving anti-natural gas activists who have the means and time to travel a significant distance to deprive others of their property 
rights and the ensuing bounty they themselves reap. Attend any Marcellus shale meeting or Delaware River Basin Commission hearing in our region and you'll find busloads of them there to protest local landowners developing their own natural resources. They'll taunt, spread misinformation, attempt to gin up hysteria, fear monger, call us greedy hicks, wave $\$ 20$ bills in our faces and tell us how they've come on their white horse to save us ignorant Wayne County residents from the errors of our ways" (October 17, 2012).

This leads to the common claim that people who question natural gas development do not understand the effect their opposition might have on rural residents in the Marcellus shale region (April 18, 2012, October 3, 2011, February 9, 2012, May 13, 2012, April 17, 2012, March 9, 2012, June 29, 2011, March 13, 2012, June 5, 2011, October 15, 2012, October 17, 2012, October 18, 2012). It is a "self-serving” position that focuses merely on their own viewpoints while disregarding the needs of "local landowners developing their own natural resources" (October 17, 2012). This furthers the dichotomy between locals and outsiders, needy landowners and greedy environmentalists. According to Energy in Depth, “...The rich, unconcerned 'green' elite will fight [natural gas development] without any regard to the socio-economic realities of what presently exists in the many depressed counties in our region” (June 5, 2011).

Common throughout EID’s narrative, is the portrayal of anti-fracking individuals or groups as wealthy elitists with financial connections to elitist "special interest" groups such as the Park Foundation (May 28, 2011, May 16, 2012, April 16, 2011, October 12, 2011, May 13, 2012, May 26, 2011, July 17, 2011, June 7, 2011, November 10, 2011, October 13, 2011, March 9, 2012, March 9, 2012, April 30, 2012, July 30, 2011, July 4, 
2011, June 5, 2011, October 18, 2012). The Park Foundation, an organization that claims to award grants for environmental issues and underwrite academic scholarships, are said to be the "main funders of anti-natural gas activities and rhetoric in the nation," (October 13, 2011, Parkfoundation.org/AboutUs.html 2013). As “main funder,” EID claims that the Park Foundation has ties to documentary filmmaker Josh Fox, organizations like the Natural Resource Defense Council, and "virtually every other group opposing natural gas development”(October 13, 2011). Some organizations that criticize natural gas development have received grant money from the Park Foundation, and Energy in Depth does not fail to make this point known, effectively attributing all criticism to a network of wealthy "special interests" with questionable credibility. They write of one such organization,

“... Just another part of the Park Foundation funded anti-gas broadside, another example of manufactured phobia to stop development of an energy source they don't agree with regardless of what the facts, science, data, experience, and a majority of the federal and state regulators have to say. Is the Park Foundation trying to distort the record, change the narrative, and manipulate data and impressions to fit their agenda and keep natural gas development out of their backyard? You decide”(October 13, 2011).

Anti-gas organizations and individuals are said to be more concerned with environmental aesthetics than progress, economic opportunity, or personal property rights, and are often characterized as “NIMBY's" (not in my backyard) - people who will benefit from industrialization, but do not want to be burdened by its processes (October 3, 2011, May 16, 2012, May 30, 2012, May 13, 2012, May 26, 2011, March 9, 2012, March 
9, 2012, July 17, 2012, July 4, 2011, June 5, 2011, October 15, 2012, October 17, 2012). According to EID, "We are fighting a lot of very ideological folks, rich preservationists and plain old NIMBY types who would like to stop natural gas development in our area" (May 26, 2011). NIMBY's are also portrayed as individuals that feel entitled to tell others what they can and can't do on their private land (i.e. whether to allow natural gas and oil operations). This is exemplified in a 2011 blog post entitled, "Pastoral Prosperity Supporting Milk House Views,” which states,

"There is also an inherent idea expressed in [author's] article. The idea being that the action of this landowner [allowing for oil and gas operations] is detrimental to the public good. Inherent in the writer's tone is displeasure, agitation and condescension for the loss of a memory to which he was attached but had no stake in supporting. The idea of public entitlement on private land espoused here is a questionable one and it has been an undercurrent throughout the debate encompassing the Marcellus shale" (October 3, 2011).

EID, argues that not only do NIMBY individuals wish to impose their will on other private landowners, but they also are engaged in a conspiracy to depopulate rural areas through natural gas moratoriums and bans in hopes of lowering property values and forcing residents to move away. As residents move away, rich NIMBY's will acquire land without the worry of noisy, high traffic natural gas development (May 13, 2012). NIMBY's are characterized as residents of rural NY and PA with second vacation homes, a disregard for impoverished residents, who "want Upstate NY for a playground and the residents of our region for their serfs" (May 28, 2011). These outsiders in the region 
wish to "support such ban[s] to 'protect' their vacation areas from imagined threats" and,

“...Have nothing to lose if the town bans development. Long-time local residents however often end up losing their homes and leaving the area in search of economic opportunity elsewhere, forfeiting land to wealthy individuals... It is a distinctly modern and rural form of gentrification” (March 19, 2012).

EID documents this "gentrification" process in stark terms in a 2012 blog post, "There's a move afoot to ruin the hopes, dreams, and economic futures of some of the poorest residents of the Delaware River Basin. It's being led by some of the wealthiest residents who happen to live downstate or out-of-state, even out-ofbasin, who would like nothing more than to depopulate the Upper Basin and save it as a playground for themselves, with total disregard for the aspirations and needs of those of us who actually have to make a living here" (May 13, 2012).

In conclusion, Energy in Depth works to discredit those seen as 'the opposition' by generalizing various stakeholders with questions and concerns about the environmental, social, or economic implications of high speed oil and gas development as outsider ideologues, driven by theatrics, with evidence based in irrational emotion and elitism as opposed to scientific fact. Discrediting individuals and groups opposed to fracking works to underline the depiction of the oil and gas industry as the polar opposite, drawing clear dichotomies. Rather than emotion and hysteria, the oil and gas industry has facts and science on its side; rather than being driven by ideology, the industry is driven by realistic pragmatism; rather than elitist outsiders, the industry stands as pillars of 
community in the Marcellus shale region; rather than being militant, the industry is compliant with the law; rather than a lack of understanding, the industry possesses expertise; rather than opposition to industrialization, the industry supports responsible progress; rather than being leftist or anti-capitalist, the industry supports the free market system and the American dream; rather than being juvenile, the industry is adult; and rather than road shows and theatrics, the industry uses objective fact to prove the promise of natural gas development. 


\section{Conclusion}

Neoliberalism can be characterized as a sociopolitical movement of economic elites that seeks out areas of low environmental and human safety regulations in an effort to maximize profitability of a given economic activity (Harvey 2005, Renfrew 2011). The tenets of neoliberalism hold that individual freedom, property rights, and a dedication to the principles of a 'free market' are in the best interests of all members of society (Harvey 2005). In practice, neoliberalism is most concerned with the expansion and consolidation of capital, the intercession and control of government in its dealings with the private sector, including the placement of limits on taxation and regulation of multinational corporations and the financial sector. In general, the neoliberal movement opposes any sort of regulation impinging on profitability, whether they be environmental, safety, or otherwise, and involves the weakening and dismantling of unions, the rolling back of municipal governments and state social-spending, privatization of public services, and reduction of taxes for business interests (Faber 2008).

Neoliberalism favors corporate investment in what Hedges and Saco (2012) call extractive ‘sacrifice zones' like Appalachia and the 'global south', where government regulation is more lax or non-existent, providing a greater return on investment, as worker safety cost, environmental stewardship, and high tax rates can be avoided or minimized (Hedges, Sacco 2012). These ‘sacrifice zones’ have traditionally become areas of natural resource extraction for the energy industry. For example, Appalachia has primarily been seen as a national extractive region for coal, oil, and natural gas (Hedges and Saco 2012, Faber 2008, Lockard 2010). 
Modernity is met with a crisis of global energy capitalism. Traditional oil, gas, and coal supplies are dwindling, and the processes of extraction are becoming unconventional, risky, and environmentally destructive (Klare 2010). The industry response to this crisis has been to increase production and push for deregulation, at the cost of increasing environmental and human health deterioration worldwide (Mitchell 2012). Standards in safety and health are routinely and systematically avoided and lobbied against by multinational energy conglomerates seeking maximum profitability (Harvey 2005). For this reason, the cost of harm to air, water, and soil are externalized onto society, and the cost of increased production and decreased regulation (medical care, environmental reclamation, etc.) is paid for not by the energy industry, but by residents of extraction zones worldwide (Faber 2008, Lockard 2010).

In the face of growing externalities, and a growing public awareness and concern for degrading environmental and human health standards in the U.S and worldwide, the energy industry has engaged in a massive public relations initiatives (Faber 2008, Jacques et al. 2008, Wilson and Ogden 2006, Stauber and Rampton 1995). This thesis provides an examination of one of these public relations initiative, Energy in Depth, existing in what Faber (2008) calls the 'polluter industrial complex' - a network of connected think-tanks, research foundations, policy institutes, public-opinion shaping organizations, public relations campaigns, non profits, and political strategy groups affiliated with polluting industries such as chemical and energy sectors. This interconnected network attempts to discredit the environmental and labor movements, as well as state programs, policies, and regulations concerning environmental and human health safety (Faber 2008, Stauber and Rampton 1995). 
Energy in Depth exists within this conceptual neoliberal network of think tanks, 'research institutes,' educational initiatives, and public relation campaigns. As an initiative of the Independent Petroleum Association of America, Energy in Depth represents $95 \%$ of the oil and gas industry in the United States of America, which is now engaged in a high-speed oil and gas boom in the Marcellus shale region (Lomax 2012). As representative of an industry engaged in a potentially environmentally destructive natural gas boom, Energy in Depth must work to frame the boom in the Marcellus shale region in a way that presents the industry and its extractive processes in a positive light.

This framing process was described by Goffman as the methodology of 'facework,' or 'impression management' - the concentrated effort to frame one's identity in a positive manner (Goffman 1967, Lakoff 2004). Framing processes work to narrate or 'make sense' of reality, and involve the act of creating the meaning attached to an event, phenomena, persons, or movements. All social actors attempt to engage in 'reality construction,' in order to organize events, occurrences, meanings, and to create a narrative of a situation that best represents their interests (Benford and Snow 2000). This organization is done primarily to prevent the individual or group in a positive manner to others. A 'frame' works to control the 'boundaries' of a discussion or debate. It serves to allow for certain facts, events, and occurrences to be within the frame, while others are not, and allows the user to define the terms of a conversation (Gamson and Ryan 2006).

Powerful economic elite will often invoke ideological frames to manage and manipulate support for a given process (Mills 1959, Gaventa 1982, Achbar and Wintonick 1992, Chomsky 1999; 2002). This is often in the form of propaganda (Chomsky 2002). This thesis explores the way in which powerful energy conglomerates 
frame the shale gas boom in the Marcellus region in a positive light through the use of public relations materials or propaganda. This thesis offers some description of the way in which the oil and gas industry legitimize their actions and presences in the Marcellus shale region to widely held moral values, ideological frames, sacred themes, or what Mills (1959) calls ‘symbols of justification'. The goal is to shape wants, keep certain issues out of the discourse, and affect common conceptions of the issue through the use of certain themes, symbols, and frames (Gaventa 1982, Bell and York 2010).

As revealed throughout the discussion section of this thesis, Energy in Depth uses four key frames to legitimize the shale gas boom in the Marcellus shale region; environmental imagery and the framing of natural gas and oil development via hydraulic fracture drilling as environmentally friendly; nationalism and the framing of the American shale gas boom as patriotic and in the best interest of national security; scientific imagery and the framing of natural gas and oil extraction processes as being backed by scientific reason; and the characterization of individuals who call into question the processes of oil and gas extraction as irrational obstructionists.

Energy in Depth narrates the debate surrounding natural gas and oil extraction as one of clear dichotomies that draw on the four most common frames found in the narration of the shale gas boom in the Marcellus shale region. It is a story of the ideals of liberty and personal property rights confronting tyrannical town boards and elitist oppositional forces determined to stop natural gas development; it is a story of an industry dedicated to environmental conservation alongside economic progress, versus the ideological environmental movement dedicated to a "no-growth" vision of a cold future; a tale of an industry dedicated to the betterment of the Marcellus shale region 
confronting an outsider environmental movement dedicated to halting an economic boom for the region; an industry in possession of objective truth and expertise that drive its processes, and an irrational oppositional force, driven by hysterics and emotion rather than science. In all, it simplifies a complex debate revolving around a myriad of motivations and stakeholder positions into a simple dichotomy of good versus evil, of the oil and gas industry versus the "anti's."

The oil and gas industry presents itself via Energy in Depth as a patriotic and environmentally conscious economic actor, driven by a dedication to the scientific method, and a dedication to the Marcellus shale communities it seeks to operate within. These frames serve to outweigh and gloss over the environmental and human health consequences of high-speed oil and gas extraction processes throughout the Marcellus shale region, and confront opposition toward the industry. They serve to 'mobilize bias' in individuals exposed to the narrative, who are asked to be supportive of the natural gas boom in the Marcellus shale region for the good of their community, their country, and their planet (Gaventa 1982). They align the industry with environmental conservation, the rationale of science, and the tenets of patriotism. They serve to frame the oil and gas industry as a positive, socially conscious economic actor that will greatly benefit the region, all the while discrediting those who call into question the processes of natural gas extraction.

Access to multimillion dollar public relations campaigns allows extractive industries to amplify their narrative in a way that other social actors cannot, and serves to offset claims of less connected (financially and politically) social actors who question the processes of such industries (Bell and York 2010). During the height of the shale gas 
boom, the oil and gas industry spent (Scanlan 2013). The 'polluter industrial complex’ utilizes these massive lobbying campaigns alongside multifaceted public relations initiatives to amplify and project positive identity through the use of framing (Scanlan 2013, Bell and York 2010, Faber 2008, Stauber and Rampton 1995, Gavenya 1982). These framing devices serve to "hide deviance, deflect attributions of fault, obscure the nature of the problem or allegation, reattribute blame, ensure an entity's reputation and, finally, seek to appear in a leadership position” (Laufer 2003, 255).

Concepts of power retention, such as 'impression management', 'ideological manipulation', the 'mobilization of bias', and the use of 'propaganda' by powerful extractive energy industries have long been documented by social scientists (Gaventa 1982, Bell and York 2010, Miller 2010, Stauber and Rampton 1995, Reynolds 2004, Pearson 2012, Laufer 2003, Jacques et al 2008, Holcomb 2008, Faber 2008). This qualitative content analysis of one situation in which an extractive industry frames its narrative is important not only to reveal the posturing of the most powerful economic actor engaged in the issue of natural gas development in the Marcellus shale, but also to discover frames that reoccur within the polluter industrial complex, and echo throughout other debates about energy extraction. As energy extraction becomes more intensive, with traditional reserves depleted, and the development of processes like horizontal hydraulic fracturing, mountaintop removal, and the harvest of oil trapped in 'tar sands,' environmental disruption is imminent (Klare 2010, Mitchell 2012). This requires the organizations that carry out these processes to engage in a public discourse in which they posture their identities, motivations, goals, and processes in a positive way. Entities like Energy in Depth exist for exactly this reason, and seek to engage in the public discourse, 
broadcasting to all social actors involved, whether landowner, resident, town council member, or state legislature.

As with any social science research study, this thesis comes with a number of limitations that call for further research and scrutiny. The first limitation comes from the overall population of blog posts that this thesis sampled. The blogs chronicle the industry's presence in the Marcellus shale region only in the months between April 2011 and October 2012. This relatively small window of time does not include the build up of the natural gas boom in the Marcellus shale region in the years leading up to 2011. There is no telling how frames could have shifted by 2011. Also, though the Energy in Depth Marcellus initiative began posting blog entries in April 2011, most of the blog entries in the population came from 2012, with almost 389 of 700 being posted from January 2012 to October 2012. This fact reveals itself in the sampled blog entries, most of which represent 2012, rather than 2011.

It is important to note that the perspectives presented by Energy in Depth, while representative of the stance of the IPAA (Independent Petroleum Association of America), do not necessarily reflect the multitude of diverse perspectives held by those within the oil and gas industry. This thesis does not intend to homogenize the industry as a singular actor, but rather uses Energy in Depth as a representative collection of public relations material presented by the oil and gas industry through the IPAA. The focus of this thesis is to describe and critically analyze the framing strategies used by such public relations initiatives. 
While qualitatively describing frames employed by the natural gas industry in the Marcellus shale region, this paper does not necessarily take into account specific events, times, or locations while describing frames. For instance, the paper does not consider the employment of specific frames after a major event or a spike in media attention received by the shale gas boom. There is no telling how frames are employed differently and selectively based on shifts in public attention or scrutiny on specific events or aspects of the extraction process. The blog posts and framing strategies are treated as static. A frame employed in April 2011 is given the same credence as a frame employed in April 2012. This does not take into consideration the timely events that could have led to the use of these frames. Furthermore, as the blog posts encapsulate the Marcellus region, this thesis rarely delves into the differences in framing techniques from state to state. The geographical, cultural, and political difference between states in the Marcellus shale region certainly have an impact on the way in which public relations initiatives are employed, and should be further examined. Furthermore, Energy in Depth has campaigns ranging from California to Ohio. Certainly, regional differences will come into play as the oil and gas industry narrate shale gas or oil booms in these vastly different regions, this indicates a need for further research.

This thesis only describes the frames employed by a public relations initiative's online materials. Only a handful of public conference appearances and opinion editorials are mentioned here, going beyond Internet content. It is important to see how these frames and techniques are carried out beyond the Internet, in print media, television advertisements, town hall meetings, and conference proceedings. Again, this indicates a need for further research on how these frames are utilized in face-to-face industry 
interaction with the public. This could be revealed through further sociological participant observation, content analysis, and interviews with representatives from industry public relations campaigns, including Energy in Depth. Furthermore, it is important to go beyond the scope of this project and interview stakeholders to determine the success of such public relations campaigns. This can help social researchers determine whether or not these frames resonate with residents, policy makers, and other stakeholders in the Marcellus shale region. It is important to understand how and why frames delivered by the industry correspond with stakeholders' own ideologies and narratives of the Marcellus shale gas boom.

Nevertheless, this thesis offers an important contribution to an understanding of the framing devices employed by powerful multinational energy conglomerates operating within the polluter industrial complex. The frames of environmental commitment, scientific expertise, and patriotism are all used in tandem to discredit any opposition to the processes of natural gas extraction via horizontal hydraulic fracture drilling - an expanding energy extraction process of growing national concern (Saiers 2012). What does it mean for who are arguably some of the most powerful economic actors in the world to create entities that frame themselves as educational and research oriented organizations (rather than public relations campaigns) to engage with the stakeholders involved in debates over potentially environmentally destructive processes? How does the framing employed by Energy in Depth work to discredit alternatives and maintain the traditional power of extractive industries? Do these frames resonate with stakeholders in the Marcellus shale region and elsewhere? How do landowners, leasing agents, industry employees, policy makers, and residents of shale gas regions respond to these frames? Do 
they change based on audience or time? How are frames of environmentalism, scientific rigor, and patriotic duty used in other contentious economic debates as selling points or to discredit opposition groups? And what are the implications for democratic decision making of the large-scale public relations and lobbying activities of the polluter industrial complex? These are just some of many questions that can be further explored and scrutinized using the descriptive information provided by this thesis. 


\section{References}

Achbar, M., \& Wintonick, P. (Directors). (1992). Manufacturing consent: Noam Chomsky and the media. Canada: Humanist Broadcasting Foundation. (1992)

Altheide, David L. (1996). Qualitative Media Analysis. Qualitative Research Methods Vol. 38. Thousands Oak, California. Print.

Ameri, S., \& Aminian, K. (2011, October). Marcellus Shale 101. Lecture presented at WVU Department of Petroleum and Natural Gas Engineering, 113 Mineral Resources Building.

Artel, S. (2012, July 30). Thousands converge in Washington to launch national movement against fracking. Retrieved February 13, 2013, from AlterNet website: http://www.alternet.org/fracking/thousands-converge-washington-launchnational-movement-against-fracking

Bauers, S. (2011, April 15). Groups deliver boxloads of comments to commission on proposed rules for Delaware River Basin drilling. Retrieved February 13, 2013, from Philly.com website: http://articles.philly.com/2011-04-15/news/ 29421664_1_natural-gas-drilling-regulations-marcellus-shale-environmentalgroups

Beard, D. (2012, April 13). Drilling mud in Pa. stream firm cleans up at tributary of Dunkard Creek. Dominion Post.

Bell, S. E., \& York, R. (2010). Community Economic Identity: The Coal Industry and Ideology Construction in West Virginia. Rural Sociology, 75(1), 111-143. 
Benford, R. D., \& Snow, D. A. (2000). Framing processes and social movements: An overview and assessment. Annual Review of Sociology, 26, 611-639.

Bernays, E. L. (Ed.). (1955). The engineering of consent. Norman: University of Oklahoma.

Bernays, E. (2005). Propaganda. Brooklyn, NY: Ig Publishing.

Bertola, David. "Researchers: Shale holds vast supply of natural gas." Business First 11 Feb. 2008: bizjournals.com. Web. 13 Dec. 2011. http://www.bizjournals.com/buffalo/stories/2008/02/11/story2.html.

Brasier, K. J., Filteau, M. R., McLaughlin, D. K., Jacquet, J., Stedman, R. C., \& Kelsey, T. W. (2011). Resident's Perceptions of Community and Environmental Impacts from Development of Natural Gas in the Marcellus Shale: A Comparison of Pennsylvania and New York Cases. Journal of Rural Social Sciences, 26(1), 3261.

Browning, J., \& Kaplan, A. (2011, November 11). Deep Drilling, Deep Pockets In Congress (Common Cause,Ed.). Washington D.C.

Center for Energy and Sustainable Development, \& WVU College of Law. (2011, October). Drilling Down on Regulatory Challenges: Balancing Preservation and Profitability in the Development of Shale Gas Resources. Conference presented at The WVU College of Law Marlyn E. Lugar Courtroom, Morgantown, WV. Retrieved from www.energy.law.wvu.edu/events/drilling_down 
Chomsky, N. (2002). Media control: The spectacular achievements of propaganda_(2nd ed.). New York, NY: Seven Stories Press.

Chomsky, N. (1999). Profit over people: Neoliberalism and global order. New York, NY: Seven Stories Press.

Dahl, R. (2010). Greenwashing: Do you know what you're buying? Environmental Health Perspectives, 118(6), 246-252.

Dedman, B., \& Weintraub, K. (2013, April 7). Disputes over environmental impact of 'fracking' obscure its future. Retrieved April 22, 2013, from Open Channel on NBC News website: http://openchannel.nbcnews.com/_news/2013/04/05/17616990-disputes-overenvironmental-impact-of-fracking-obscure-its-future?lite

DeMelle, B. (2011, November 9). Gas fracking industry using military psychological warfare tactics and personnel in U.S. communities [Blog post]. Retrieved from Desmog Blog: http://desmogblog.com/ gas-fracking-industry-using-militarypsychological-warfare-tactics-and-personnel-u-s-communities

Energy in Depth. IPAA, Web. 11 Oct. 2012 <energyindepth.org>

Energy in Depth - Northeast Marcellus Initiative. IPAA, Web. 11 Oct. 2012. $<$ http://eidmarcellus.org/>

Faber, D. (2008). Nature's Meaning: Capitalizing on environmental injustice: The polluter-industrial complex in the age of globalization. Lanham, MD: Rowman \& Littlefield. 
Federman, A. (2011). What killed Dunkard Creek? Residents in Pennsylvania and West Virginia say fracking. Earth Island Journal.

Finkel, M. L., \& Law, A. (2011). The rush to drill for natural gas: A public health cautionary tale. American Journal of Public Health, 101(5), 784-785.

Frac Focus. "Chemical Use in Hydraulic Fracturing." Frac Focus Chemical Disclosure Registry. N.p., 2011. Web. 13 Dec. 2011. http://fracfocus.org/waterprotection/drilling-usage.

Gas Safety Incorporated (2012). Report to the Clean Air Council on 8 June 2012 Field Inspection and Methane Sampling Survey of Parts of Leroy, Granville, and Franklin Townships Bradford County, Pennsylvania . Southborough, MA. Gassafteyusa.com

Gaventa, J. (1982). Power and powerlessness: Quiescence and rebellion in an Appalachian valley. Chicago: University of Illinois Press.

Global Community Monitor. (2011, July 12). Gassed! Citizen investigation of toxic air pollution from natural gas development [Report]. Retrieved from http://gcmonitor.org/downloads/gassedreport.pdf

Goffman, E. (1967). Interaction ritual: Essays on face-to-face interaction. Oxforf, England: Aldine.

Gramsci, A. (1971). Selections from the prison notebooks (Q. Hoare, Ed., G. N. Smith, Trans.). New York, NY: International Publishers. 
Hedges, Chris. Sacco, Joe. (2012). Days of Destruction, Days of Revolt. New York: Nation Books. Print.

Hines, D. A., \& Institute for Energy and Environmental Research of Northeastern Pennsylvania. (2012, March 8). The "Halliburton loophole": Exemption of hydraulic fracturing fluids from regulation under the Federal Safe Drinking Water Act. Retrieved from http://energy.wilkes.edu/PDFFiles/Laws\%20and\%20Regulations/Halliburton\%20 Loophole\%20Essay\%20Final.pdf

Holcomb, J. (2008). Environmentalism and the internet: Corporate greenwashers and environmental groups. Contemporary Justice Review, 11(3), 203-211.

Horton, S. (2012). Disposal of hydrofracking waste fluid by injection into subsurface aquifers triggers earthquake swarm in central arkansas with potential for damaging earthquake. Seismological Research Letters, 83(2).

Horwitt, Dusty. "Cracks in the Facade 25 Years Ago, EPA Linked 'Fracking' to Water Contamination." Environmental Working Group (Aug. 2011): 1-31. Print.

Horwitt, D., J.D, \& Environmental Working Group. (2011, December). Drilling doublespeak: Gas drillers disclose risk to shareholders - but not to landowners. Retrieved from http://www.ewg.org/release/gas-drilling-doublespeak

Howarth, R. W., Ingraffea, A., \& Engelder, T. (2011). Natural gas: Should fracking stop? Nature, 477(7364), 271-275. 
Howarth, R. W., Santoro, R., \& Ingraffea, A. (2011). Methane and the greenhouse-gas footprint of natural gas from shale formations. Climatic Change.

Jackson, R. B., Pearson, B. R., Osborn, S. G., Warner, N. R., \& Vengosh, A. (2011). Research and policy recommendations for hydraulic fracturing and shale-gas extraction. Nicholas School of the Environment and Earth Sciences Duke University, 1-11.

Jacques, P. J., Dunlap, R. E., \& Freeman, M. (2008). The organisation of denial: Conservative think tanks and environmental scepticism. Environmental Politics, 17(3), 349-385.

Jacquet, J. (2009). Energy boomtowns \& natural gas: Implications for Marcellus Shale local governments \& rural communities. Northeast Regional Center for Rural Development, (43), 1-63.

Jacquet, J., \& Stedman, R. (2009). Emerging trends in the Marcellus shale. Cornell University Research \& Policy Brief Series, (30).

Javers, E. (2011, November 8). Oil executive: Military-style 'psy ops' experience applied. Retrieved from http://www.cnbc.com/id/45208498

Johnson, N., The Nature Conservancy, \& Audubon Pennsylvania. (2010, November 15). Pennsylvania energy impacts assessment.

Klare, M. T. (2010, May 19). The relentless pursuit of extreme energy: A new oil rush endangers the Gulf of Mexico and the planet. Retrieved May 1, 2013, from 
http://www.huffingtonpost.com/michael-t-klare/the-relentless-pursuitof_b_581921.html

Kosek, Jake. (2006). Understories: The Political Life of Forests in Northern New Mexico. Duke UP. Print.

Kusnetz, N. (2011, August 23). North Dakota's oil boom brings damage along with prosperity. Propublica. Retrieved from https://www.propublica.org/article/theother-fracking-north-dakotas-oil-boom-brings-damage-along-with-prosperi

Lakoff, G. (2004). Don't think of an elephant! Know your values and frame the debate. White River Junction, VT: Chelsea Green Publishing. Print.

Laufer, W. S. (2003). Social accountability and corporate greenwashing. Journal of Business Ethics, 43(3), 253-261.

Levitt, T. (2011). UK shale gas boom 'may be dirtier than coal'. Ecologist, (23), 6-9.

Lockard, D. (2010). "Introduction," "The Problem of Externalities," and "Coal and Corporate Power," Coal: A memoir and critique. In L. Nader (Ed.), The Energy Reader (pp. 323-350). Malden, MA: Blackwell.

Lomax, Simon. “Addressing Public Health Concerns.” West Virginia University Extension Service “Enhancing Public Understanding of Natural Gas Issues”. Morgantown, WV. 6 June 2012. Presentation.

Lustgarten, Abrahm, Nicholas Kusnetz, and ProPublica. "EPA: Natural Gas Fracking Linked to Water Contamination." Scientific American (Dec. 2011):. Print. 
Miller, B. M. (2010). Community stakeholders and marketplace advocacy: A model of advocacy, agenda building, and industry approval. Journal of Public Relations Research, 22(1), 85-112.

Mills, C. W. (1958). The structure of power in American society. The British Journal of Sociology, 9(1), 29-41.

Mills, C. W. (1959). The sociological imagination. New York: Oxford University Press.

Mitchell, T. (2011). Carbon Democracy: Political power in the age of oil. London: Verso.

Montz, B., Wilmer, K., Walsh-Haehle, S., Lazurus, N., Kucuker, Y., \& Herr, M. (2010). Interconnections in resource development: Controversies surrounding the Marcellus shale in New York. The Northeastern Geographer, 2, 1-20.

Mooney, C. (2011). The truth about fracking. Scientific American, 305(5), 80-85.

Osborn, S. G., Vengosh, A., Warner, N. R., \& Jackson, R. B. (2011, April 14). Methane Contamination of Drinking Water Accompanying Gas-Well Drilling and Hydraulic Fracturing. PNAS Early Edition, 1-5.

OVEC (2012). Hydraulic Fracturing and Your Health. Ohio Valley Environmental Coalition www.ohvec.org

Pearson, T. W. (2012, October 12). How to dismantle frac sand industry rhetoric: Notes on the resource exploitation framework [Blog post]. Retrieved from Contested Landscapes website: http://wisconsinfracsand.blogspot.com/2012/10/how-todismantle-frac-sand-industry.html 
Perry, S. L. (2012). Development, land use, and collective trauma: The Marcellus shale gas boom in rural Pennsylvania. Culture, Agriculture, Food and Environment, 34(1), 81-92.

"Petition to Governor Andrew Cuomo of New York Calling for public health oversight of oil and natural gas operations. (2011, October 5).

Powell, B. A. (2003, October 27). Framing the issues: UC Berkeley professor George Lakoff tells how conservatives use language to dominate politics. Retrieved April 24, 2013, from University of California Berkeley News website: http://www.berkeley.edu/news/media/releases/2003/10/27_lakoff.shtml

Renfrew, D. (2011). The curse of wealth: Political ecologies of Latin American neoliberalism. Geography Compass, 5(8), 581-594.

Reynolds, M. (2004). How does Monsanto do it? An ethnographic case study of an advertising campaign. Text, 24(3), 329-352.

Rubinkam, M. (2011, April 21). Drilling fluid gushes from northern Pa. well. Retrieved February 12, 2013, from Philly.com website: http://articles.philly.com/2011-0421/business/29459558_1_fracking-water-natural-gas-marcellus-shale

Russell, B., \& (IPAA) The Independent Petroleum Association of America. (2009, June 5). Hydraulic fracturing under attack. IPAA.

Rutherford, T. (2012, April 2). Marcellus drilling brings radiation exposures, may harm drinking water. Retrieved February 12, 2013, from Huntington News website: http://www.huntingtonnews.net/27856 
Romm, Joe. 2012, Feb. Bombshell Study: High Methane Emissions Measured Over Gas Field “May Offset Climate Benefits of Natural Gas” 13 March 2012. Think Progress http://thinkprogress.org/romm/2012/02/08/421588/high-methaneemissions

Ryan, C., \& Gamson, W. A. (2006). The art of reframing political debates. Contexts, 5(1), 13-18.

Saiers, J. (Presenter). (2012, October 10). Environmental implications of shale-gas development: Frack versus fiction. Webinar lecture presented by The Yale Center for Environmental Law and Policy presents: The Policy Workshop Webinar Series: Emerging Issues in Shale Gas Development, Yale University, New Haven, CT. http://vimeo.com/51598345

Save Colorado from fracking. (2013). What is fracking? Retrieved April 22, 2013, from Save Colorado From Fracking website: http://www.savecoloradofromfracking.org/basics/basics.html

Scanlan, S. J. (2013, April). Framing fracking: Resource extraction, economic development, and greenwashing. Paper presented at North Central Sociological Association Annual Meeting, Crown Plaza at Historic Union Station Indianapolis, IN.

Schmidt, C. W. (2011). Blind rush? Shale gas boom proceeds amid human health questions. Environmental Health Perspectives, 119(8), 348-353. 
Schwartzel, E. (2012, August 19). Fouled waters: Woodlands residents search for ways to survive without clean water. Pittsburgh Post-Gazette.

Simon, D. R. (2000, January). Corporate Environmental Crimes and Social Inequality: New directions for environmental justice research. The American Behavioral Scientist, 43, 4. 633-645.

Skirboll, A. (2012, August 15). Toxic wastewater dumped in streets and rivers at night: Gas profiteers getting away with shocking environmental crimes. Retrieved February 12, 2013, from AlterNet website: http://www.alternet.org/fracking/toxicwastewater-dumped-streets-and-rivers-night-gas-profiteers-getting-awayshocking

Stauber, J. \& Rampton, S., (2002). Trust Us - We're Experts! New York: Tarcher/Penguin.

Stauber, J., \& Rampton, S. (1995). Toxic Sludge is Good for You! Lies, damn lies, and the public relations industry. Monroe, ME: Common Courage Press.

Stover, J. (2012, March 8). Doddridge County resident says water well damaged by oil and gas industry. Retrieved February 12, 2013, from WBOY website: http://www.wboy.com/story/17114653/family-suffers-contaminated-water-wellfrom-oil-gas-industry-on-neighbors-property

Subra, Wilma (2012). Human Health Impacts Associated with Chemicals and Pathways of Exposure from the Development of Shale Gas Plays. Presentation. August 2012. EARTHWORKS Oil and Gas Accountability Project. 
Ward, K., Jr. (2012, March 2). Chesapeake faces criminal Clean Water Act probe. Retrieved February 12, 2013, from Sustained Outrage: A Gazette Watchdog Blog: http://blogs.wvgazette.com/watchdog/2012/03/02/chesapeake-faces-criminalclean-water-act-probe/

Weigle, J. L. (2011). Resilience, community, and perceptions of Marcellus Shale development in the Pennsylvania wilds: Reframing the discussion. Sociological Viewpoints, (Fall), 3-14.

Wilber, Tom (2012). Fracking in NY - Step on the gas or slam on the breaks? Health, environmental officals far apart on impacts. Shale Gas Review. Tomwilber.blogspot.com/2012/07/fracking-in-ny-step-on-gas-or-slam-on.html

Wilson, L. J., \& Ogden, J. D. (2006). Strategic communications plannning for effective public relations and marketing (Fourth ed.). Kendall/Hunt. 
Cited Energy in Depth Blog Entries (Listed in Chronological Order)

2011, April 16. (Shepstone, T.). Afton landowners help spike onerous road law [Blog post]. Retrieved from http://eidmarcellus.org/blog/afton-landowners-help-spikeonerous-road-law/23/

2011, April 22. (Shepstone, T.). Anti-Marcellus extremist recommends arson [Blog post]. Retrieved from http://eidmarcellus.org/blog/anti-marcellus-extremistrecommends-arson/74/

2011, May 26. (Shepstone, T.). Battling hysteria - the XTO hearing [Blog post]. Retrieved from http://eidmarcellus.org/blog/battling-hysteria-the-xtohearing/1180/

2011, May 28. (Shepstone, T.). New York governor says "get it done" [Blog post]. Retrieved from http://eidmarcellus.org/blog/new-york-governor-says-get-itdone/1268/

2011, May 29. (DesRosiers, B.). June 1st DRBC hearing: A call to action! [Blog post]. Retrieved from http://eidmarcellus.org/blog/june-1st-drbc-hearing-a-call-toaction/1249/

2011, June 5. (Shepstone, T.). Battling the "green elites" (with help from our city friends?) [Blog Post] Retrieved from http://eidmarcellus.org/blog/battling-thegreen-elites-with-help-from-our-city-friends/1376/

2011, June 7. (Shepstone, T.). Something rotten in Gasland [Blog post]. Retrieved from http://eidmarcellus.org/blog/something-rotten-in-gasland/1400/ 
2011, June 9. (DesRosiers, B.). Anti-drilling event fizzles like a wet firecracker [Blog Post]. Retrieved from http://eidmarcellus.org/blog/anti-drilling-event-fizzles-likea-wet-firecracker/1434/

2011, June 14. (Jacobs, N.). Being loud is NOT the same as being heard! [Blog Post] Retrieved from http://eidmarcellus.org/blog/being-loud-is-not-the-same-as-beingheard/1511/

2011, June 15. (Shepstone, T.). Fox \& friends not ready for primetime! [Blog Post] Retrieved from http://eidmarcellus.org/blog/fox-friends-not-ready-forprimetime/1595/

2011, June 23. (DesRosier, B.). A carnival of self-proclaimed experts continues magical mystery tour [Blog Post] Retrieved from http://eidmarcellus.org/blog/a-carnivalof-self-proclaimed-experts-continues-the-magical-mystery-tour/1765/

2011, June 29. (DesRosier, B.). So, that’s why they call him “Chip” Northrup [Blog Post] Retrieved from http://eidmarcellus.org/blog/a-not-so-open-forum-in-bainbridgeny/1970/

2011, July 8. (Krohn, J.). New York confirms safety and benefits of hydraulic fracturing [Blog Post] Retrieved from http://eidmarcellus.org/blog/new-york-confirmssafety-and-economic-benefits-of-hydraulic-fracturing/2155/

2011, July 14. (Shepstone, T.). UPDATED!! The mountainkeeper doth protest too much [Blog Post] Retrieved from http://eidmarcellus.org/blog/the-mountainkeeperdoth-protest-too-much/2318/ 
2011, July 17. (Shepstone, T.). UPDATED!! Unholy alliance puts the mark on the Marc 1 pipeline [Blog Post] Retrieved from http://eidmarcellus.org/blog/unholyalliance-puts-the-mark-on-marc-1-pipeline/2400/

2011, July 30. (Shepstone, T.). Heinz and Park feed the Cornell dragon [Blog Post] Retrieved from http://eidmarcellus.org/blog/heinz-and-park-feed-the-cornelldragon/2709/

2011, August 13. (DesRosiers, B.). *UPDATE* Anti-pipeline madness rises and falls in Sidney [Blog Post] Retrieved from http://eidmarcellus.org/blog/anti-pipelinemadness-rises-and-falls-in-sidney/2875/

2011, August 17. (DesRosiers, B.). Laws of unintended consequences [Blog Post] Retrieved from http://eidmarcellus.org/blog/unintended-consequences-tompkinscounty-proposed-road-laws/3089/

2011, September 1. (Colley, R.). Utica Observer-Dispatch gets it wrong, very wrong [Blog Post] Retrieved from http://eidmarcellus.org/blog/not-only-pretty-but-abeautiful-thing/3362/

2011, September 14. (Krohn, J.). Desperation through exaggerations [Blog Post] Retrieved from http://eidmarcellus.org/blog/desperation-throughexaggeration/3867/

2011, September 23. (Colley, R.). Milling over non-existent water pollution in Milford [Blog Post] Retrieved from http://eidmarcellus.org/blog/milling-over-nonexistent-water-pollution-in-milford/3881/ 
2011, October 2. (Colley, R.). The beat goes on in Newton Township [Blog Post] Retrieved from http://eidmarcellus.org/blog/the-beat-goes-on-in-newtowntownship/3919/

2011, October 3. (Jacobs, N.). Pastoral prosperity supporting milk house views [Blog Post] Retrieved from http://eidmarcellus.org/blog/pastoral-prosperity-supportingmilk-house-views/4061/

2011, October 7. (Siebold, A.). Natural gas is the track to the future [Blog Post] Retrieved from http://eidmarcellus.org/blog/natural-gas-is-the-track-to-the-future/4160/

2011, October 10. (Colley, R.). Norse Energy shows the way! [Blog Post] Retrieved from http://eidmarcellus.org/blog/norse-energy-shows-the-way/4010/

2011, October 12. (Bates, J.). Don’t believe the anti-hype: Natural gas development is safe [Blog Post] Retrieved from http://eidmarcellus.org/blog/contrary-to-thefantasy-natural-gas-is-safe/4238/

2011, October 13. (Jacobs, N.). A case of pipeline and propane phobia [Blog Post] Retrieved from http://eidmarcellus.org/blog/a-case-of-pipeline-and-propanephobia/4264/

2011, November 10. (Colley, R.). The Slottje selling spree continues [Blog Post] Retrieved from http://eidmarcellus.org/blog/the-slottje-selling-spreecontinues/4609/

2011, November 11. (Krohn, J.). Serving those who served us all [Blog Post] Retrieved from http://eidmarcellus.org/blog/serving-those-who-served-us-all/4772/ 
2012, January 13. (Price, A.). Director of Gas Odyssey sees bright future from natural gas development [Blog Post] Retrieved from http://eidmarcellus.org/blog/director-ofgas-odyssey-sees-bright-future-from-natural-gas-development/5816/

2012, January 23. (Tucker, C.). The facts behind EPA’s Dimock two-step [Blog Post] Retrieved from http://eidmarcellus.org/blog/the-facts-behind-epa\%E2\%80\%99sdimock-two-step/5951/

2012, February 2. (Colley, R.). Flint fumbles Marcellus shale ball [Blog Post] Retrieved from http://eidmarcellus.org/blog/flint-fumbles-marcellus-shale-ball/5844/

2012, February 9. (DesRosiers, B.). *UPDATE* CNN, dazed by Dimock falls short at fact checking [Blog Post] Retrieved from http://eidmarcellus.org/blog/cnn-dazedby-dimock-falls-short-at-fact-checking/6155/

2012, February 13. (Colley, R.). Sidney says yes to natural gas and no to Slottje! [Blog Post] Retrieved from http://eidmarcellus.org/blog/sidney-says-yes-to-natural-gasand-no-to-slottje/6246/

2012, March 3. (Colley, R.). Note to EPA on Dimock: Less is not always more [Blog Post] Retrieved from http://eidmarcellus.org/marcellus-shale/lesson-for-epadimock-less-is-not-always-more/6526/

2012, March 13. (DesRosiers, B.). Marcellus shale parallel universe [Blog Post] Retrieved from http://eidmarcellus.org/marcellus-shale/marcellus-shale-paralleluniverse/6917/ 
2012, March 15. (Jacobs, N.). Natural gas temper tantrums - The show goes one [Blog Post] Retrieved from http://eidmarcellus.org/marcellus-shale/natural-gas-tempertantrum/7013/

2012, March 19. (DesRosiers, B.). Serfdom, coming to a town near you [Blog Post] Retrieved from http://eidmarcellus.org/marcellus-shale/serfdom-coming-to-atown-near-you/7099/

2012, March 19. (Shepstone, T.). Deborah Rogers: Goat farmer, cheesemaker, and model [Blog Post] Retrieved from http://eidmarcellus.org/marcellus-shale/deborahrogers-goat-farmer-cheesemaker-and-mode/7089/

2012, March 19. (Jacobs, N.). Shell natural gas decisions huge win for Pennsylvania [Blog Post] Retrieved from http://eidmarcellus.org/marcellus-shale/win-win-shellnatural-gas-strategy/6909/

2012, March 21. (Colley, R.). A Slottje by any other name [Blog Post] Retrieved from http://eidmarcellus.org/marcellus-shale/slottje-sidne/7156/

2012, April 1. (Colley, R.). Natural gas education or indoctrination? [Blog Post] Retrieved from http://eidmarcellus.org/marcellus-shale/natural-gas-educationindoctrination/7380/

2012, April 3. (Cline, S.). Rogers natural gas spin cycle [Blog Post] Retrieved from http://eidmarcellus.org/marcellus-shale/natural-gas-gimmickry-rogers/7634/ 
2012, April 8. (Shepstone, T.). Natural gas, hydraulic fracturing, and our future [Blog Post] Retrieved from http://eidmarcellus.org/marcellus-shale/natural-gashydraulic-fracturing-and-our-future/7889/

2012, April 17. (DesRosiers, B.). *UPDATE* Franklin Fork facts [Blog Post] Retrieved from http://eidmarcellus.org/marcellus-shale/franklin-forks-facts/7643/

2012, April 18. (Parker, D.). Natural gas development is safe and must occur soon [Blog Post] Retrieved from http://eidmarcellus.org/marcellus-shale/natural-gasdevelopment-is-safe-and-must-occur-soon/8012/

2012, April 18. (Jacobs, N.). Lathrop compressor station incident shows safety is priority no. 1 [Blog Post] Retrieved from http://eidmarcellus.org/marcellus-shale/lathropcompressor-station-incident-shows-safety-is-priority-no-1/7767/

2012, April 30. (Shepstone, T.). Clean Air Council helps Heinz find 57 ways to oppose natural gas [Blog Post] Retrieved from http://eidmarcellus.org/marcellusshale/clean-air-council-heinz/8392/

2012, May 13. (Shepstone, T.). Riverkeeper strategy depends on obscure reclassification of streams [Blog Post] Retrieved from http://eidmarcellus.org/marcellusshale/riverkeeper-strategy-depends-on-obscure-reclassification-of-streams/8605/

2012, May 16. (Shepstone, T.). Slottje stumbles may embarrass local officials following their lead [Blog Post] Retrieved from http://eidmarcellus.org/marcellusshale/slottje-stumbles-may-embarrass-local-officials-following-their-lead/8919/ 
2012, May 26. (Marisa, T.). Activists manipulate to employ CEA as a back door natural gas ban [Blog Post] Retrieved from http://eidmarcellus.org/marcellusshale/activists-manipulate-employ-cea-back-door-natural-gas-ban/9164/

2012, May 30. (Reynolds, T.). Marcellus shale facts, falsehoods, and flaky statements [Blog Post] Retrieved from http://eidmarcellus.org/marcellus-shale/marcellusshale-facts-falsehoods/9358/

2012, May 30. (Matusky, G.). Bringing the "yinz” and “yous” together on Marcellus shale business [Blog Post\} Retrieved from http://eidmarcellus.org/marcellusshale/bringing-the-yinz-and-yous-together-on-marcellus-shale-business/9380/

2012, June 7. (Massaro, J.). Is natural gas production affecting local birds? Don’t jump to conclusions! [Blog Post] Retrieved from http://eidmarcellus.org/marcellusshale/is-natural-gas-production-affecting-local-birds-dont-jump-toconclusions/9683/

2012, June 21. (Tucker, C.). For Josh Fox the sun also rises, but not on command [Blog Post] Retrieved from http://eidmarcellus.org/blog/for-josh-fox-the-sun-alsorises/10222/

2012, June 24. (Colley, R.). Together we have it all with natural gas! [Blog Post] Retrieved from http://eidmarcellus.org/marcellus-shale/together-we-have-it-allwith-natural-gas/10061/ 
2012, July 16. (Jacobs, N., Colley, R., Massaro, J.). New York Vote4Energy rally brings out thousands [Blog Post] Retrieved from http://eidmarcellus.org/marcellusshale/new-york-vote4energy-rally-brings-out-thousands-2/11044/

2012, July 17. (Andrews, F.). ‘Truthland' helps the rational middle understand natural gas development [Blog Post] http://eidmarcellus.org/marcellus-shale/truthlandhelps-the-rational-middle-understand-natural-gas-development/11120/

2012, July 17. (Colley, R.). Hamilton hears the shale gas horror story, but few facts! [Blog Post] Retrieved from http://eidmarcellus.org/marcellus-shale/hamiltonhears-the-shale-gas-horror-story/10871/

2012, July 18. (Heller, J.). Hydraulic fracturing halftruths [Blog Post] Retrieved from http://eidmarcellus.org/marcellus-shale/hydraulic-fracturing-halftruths/11148/

2012, July 23. (Massaro, J.). Shale gas fixes schools hospitals \& roads; Oh my! [Blog Post] Retrieved from http://eidmarcellus.org/marcellus-shale/shale-gas-fixesschools-hospitals-oh-my/11159/

2012, July 23. (Colley, R., Jacobs, N., Massaro, J.). Thousands turn out to learn about natural gas at Cabot's $3^{\text {rd }}$ annual picnic [Blog Post] Retrieved from http://eidmarcellus.org/marcellus-shale/thousands-turn-out-to-learn-about-naturalgas-at-cabots-3rd-annual-picnic/11250/

2012, July 27. (Blake, U.). More natural gas opposition parading as science [Blog Post] Retrieved from http://eidmarcellus.org/marcellus-shale/more-natural-gasopposition-parading-as-science/11309/ 
2012, July 30. (Krohn, J.). Can you call it a rally if no one shows up? [Blog Post] Retrieved from http://eidmarcellus.org/marcellus-shale/can-you-call-it-a-rally-ifno-one-shows-up/11415/

2012, August 2. (Colley, R.). Truthland heads to Steuben County to discuss natural gas [Blog Post] Retrieved from http://eidmarcellus.org/marcellus-shale/truthlandheads-to-steuben-county-to-discuss-natural-gas/11423/

2012, August 16. (Jacobs, N.). We asked for it, we got it... We're still going to protest [Blog Post] Retrieved from http://eidmarcellus.org/marcellus-shale/we-asked-forit-we-got-it-were-still-going-to-protest/12052/

2012, September 14. (Colley, R.). French and Canadian officials visit northeast Marcellus for tour [Blog Post] Retrieved from http://eidmarcellus.org/marcellusshale/french-and-canadian-officials-visit-northeast-marcellus-for-tour/12919/

2012, September 18. (Tiberio, B.). All aboard: The natural gas train is moving [Blog Post] Retrieved from http://eidmarcellus.org/marcellus-shale/all-aboard-thenatural-gas-train-is-moving/13188/

2012, October 10. (Alfaro, D.). Natural gas opponents' balloon bursts in Bessemer [Blog Post] Retrieved from http://eidmarcellus.org/marcellus-shale/natural-gasopponent-balloo-bursts-in-bessemer/13912/

2012, October 11. (Krohn, J.). EPA’s Dimock distraction: Ignoring pollution while chasing “tips” [Blog Post] Retrieved from http://eidmarcellus.org/marcellusshale/epa-dimock-distraction-ignoring-pollution-while-chasing-tips/13970/ 
2012, October 13. (Pasto, C.). Truth or politics: Which will set our natural gas opportunities free? [Blog Post] Retrieved from http://eidmarcellus.org/marcellusshale/truth-or-politics-which-will-set-our-natural-gas-opportunities-free/14037/

2012, October 15. (Coccodrilli, C.). Artists Against Natural Gas have no credibility [Blog Post] Retrieved from http://eidmarcellus.org/marcellus-shale/artists-againstnatural-gas-have-no-credibility/14057/

2012, October 16. (Tiberio, B.). Natural gas witch hunt [Blog Post] Retrieved from http://eidmarcellus.org/marcellus-shale/natural-gas-witch-hunt/14125/

2012, October 16. (Colley, R., Massaro, J.). A natural gas march to the capitol [Blog Post] Retrieved from http://eidmarcellus.org/marcellus-shale/a-natural-gas-marchto-the-capitol/13993/

2012, October 17. (Colley, R., Massaro J.). Binghamton learns about natural gas benefits [Blog Post] Retrieved from http://eidmarcellus.org/marcellus-shale/binghamtonlearns-about-natural-gas-benefits/14130/

2012, October 17. (Nolan, R.). Something rotten in the land of no Marcellus [Blog Post] Retrieved from http://eidmarcellus.org/marcellus-shale/something-rotten-in-theland-of-no-marcellus/14223/

2012, October 18. (Parker, D.). Natural gas will give New York needed boost [Blog Post] Retrieved from http://eidmarcellus.org/marcellus-shale/natural-gas-will-give-newyork-needed-boost/14264/ 